RESEARCH SERIES

NUMBER 121

MAY 2021

\section{THE DYNAMICS OF CHILD POVERTY IN IRELAND}

EVIDENCE FROM THE GROWING UP IN IRELAND SURVEY

BERTRAND MAÎTRE, HELEN RUSSELL AND EMER SMYTH

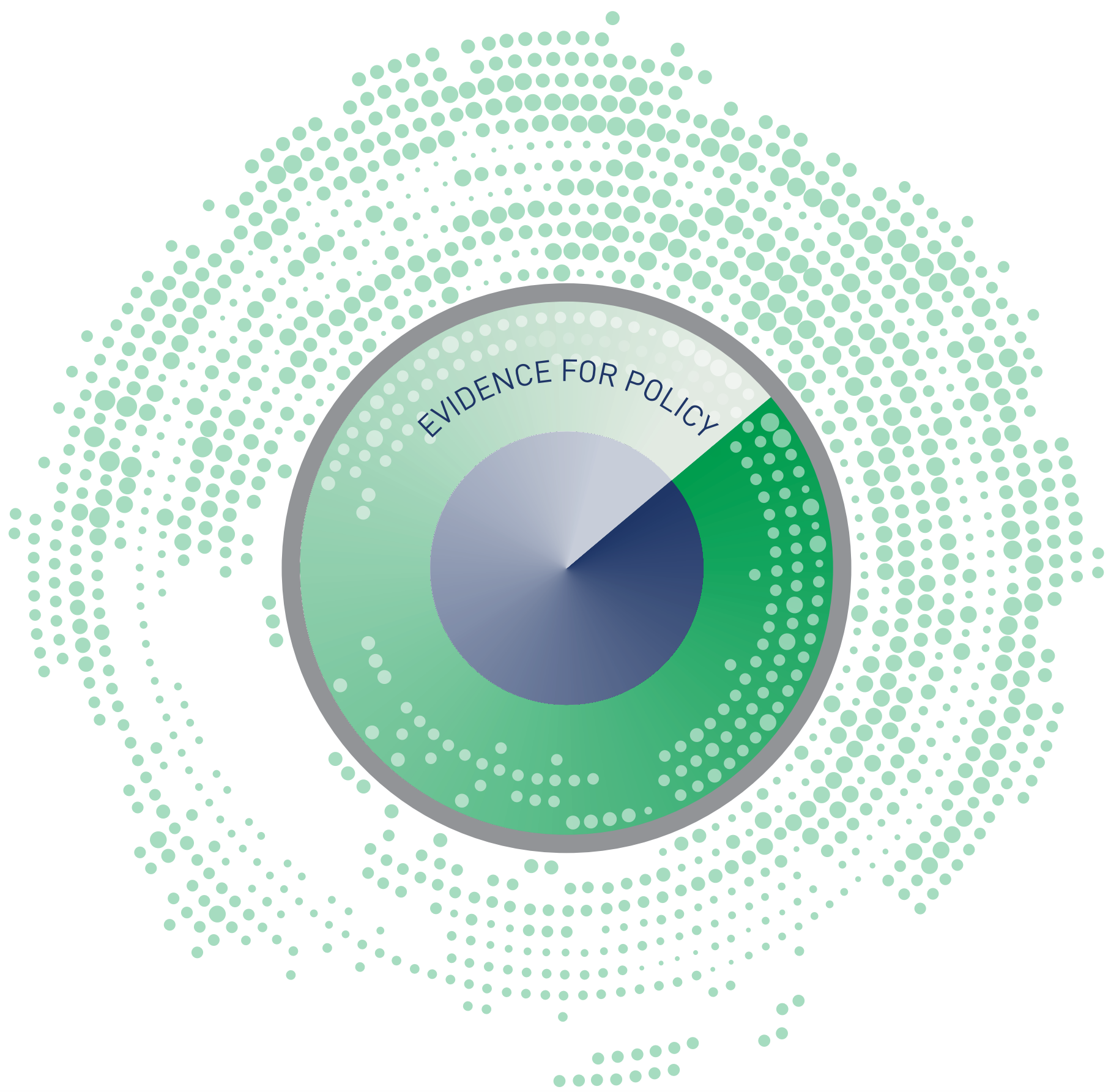




\section{THE DYNAMICS OF CHILD POVERTY IN IRELAND: EVIDENCE FROM THE GROWING UP IN IRELAND SURVEY}

Bertrand Maître

Helen Russell

Emer Smyth

May 2021

\section{RESEARCH SERIES}

\section{NUMBER 121}

Available to download from www.esri.ie

(C) The Economic and Social Research Institute

Whitaker Square, Sir John Rogerson's Quay, Dublin 2

https://doi.org/10.26504/rs121

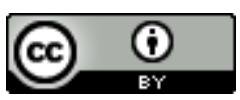

This Open Access work is licensed under a Creative Commons Attribution 4.0 International License (https://creativecommons.org/licenses/by/4.0/), which permits unrestricted use, distribution, and reproduction in any medium, provided the original work is properly credited. 



\section{ABOUT THE ESRI}

The mission of The Economic and Social Research Institute is to advance evidencebased policymaking that supports economic sustainability and social progress in Ireland. ESRI researchers apply the highest standards of academic excellence to challenges facing policymakers, focusing on 12 areas of critical importance to $21^{\text {st }}$ Century Ireland.

The Institute was founded in 1960 by a group of senior civil servants led by Dr T.K. Whitaker, who identified the need for independent and in-depth research analysis to provide a robust evidence base for policymaking in Ireland.

Since then, the Institute has remained committed to independent research and its work is free of any expressed ideology or political position. The Institute publishes all research reaching the appropriate academic standard, irrespective of its findings or who funds the research.

The quality of its research output is guaranteed by a rigorous peer review process. ESRI researchers are experts in their fields and are committed to producing work that meets the highest academic standards and practices.

The work of the Institute is disseminated widely in books, journal articles and reports. ESRI publications are available to download, free of charge, from its website. Additionally, ESRI staff communicate research findings at regular conferences and seminars.

The ESRI is a company limited by guarantee, answerable to its members and governed by a Council, comprising 14 members who represent a cross-section of ESRI members from academia, civil services, state agencies, businesses and civil society. The Institute receives an annual grant-in-aid from the Department of Public Expenditure and Reform to support the scientific and public interest elements of the Institute's activities; the grant accounted for an average of 30 per cent of the Institute's income over the lifetime of the last Research Strategy. The remaining funding comes from research programmes supported by government departments and agencies, public bodies and competitive research programmes.

Further information is available at www.esri.ie 


\section{THE AUTHORS}

Bertrand Maître is a Senior Research Officer at The Economic and Social Research Institute (ESRI) and an Adjunct Associate Professor at Trinity College Dublin (TCD). Helen Russell is a Research Professor at the ESRI and an Adjunct Professor at TCD. Emer Smyth is a Research Professor at the ESRI and an Adjunct Professor at TCD.

\section{ACKNOWLEDGEMENTS}

This publication was funded by the Department of Children, Equality, Diversity, Integration and Youth (DCEDIY) through a joint Research Partnership with the ESRI. The views, opinions, findings, conclusions and/or recommendations expressed here are strictly those of the authors. They do not necessarily reflect the views of the DCEDIY, which takes no responsibility for any errors or omissions in, or for the accuracy of, the information contained in this publication. It is presented to inform and stimulate wider debate among the policy community and among academics and practitioners in the field.

The authors thank the members of the Research Programme Steering Committee chaired by Professor Tony Fahey for helpful comments and guidance throughout the research process. The report also benefited considerably from comments received from three reviewers. We would also like to thank the Growing Up in Ireland (GUI) research and survey team at the ESRI for their invaluable work in producing the high-quality, rich data that made the research possible.

GUI is funded by the DCEDIY. It is managed by the DCEDIY, in association with the Central Statistics Office (CSO). The results in this report are based on analyses of data from Research Microdata Files provided by the CSO. Neither the CSO nor the DCEDIY take any responsibility for the views expressed or the outputs generated from these analyses.

This report has been accepted for publication by the Institute, which does not itself take institutional policy positions. All ESRI Research Series reports are peer reviewed prior to publication. The author(s) are solely responsible for the content and the views expressed. 


\section{TABLE OF CONTENTS}

EXECUTIVE SUMMARY IX

CHAPTER 1: THE DYNAMICS OF CHILD POVERTY IN IRELAND - BACKGROUND AND ISSUES 1

1.1 Poverty and time. 2

1.2 Duration and timing of child poverty .......................................................... 3

1.3 Poverty and child outcomes: pathways and mediators ....................................... 4

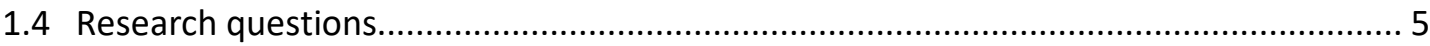

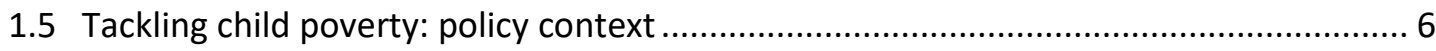

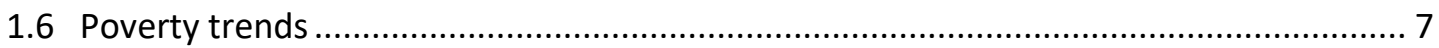

1.7 Child poverty across Europe ......................................................................... 9

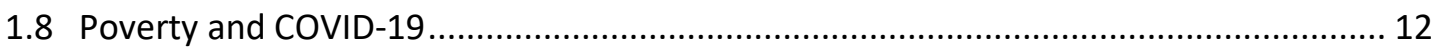

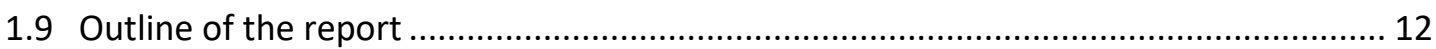

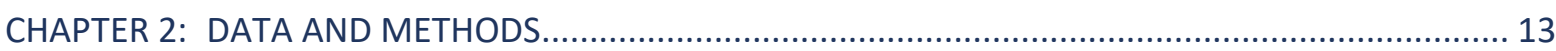

2.1 Measuring economic vulnerability and poverty dynamics .................................. 13

2.2 Measurement of economic vulnerability ...................................................... 14

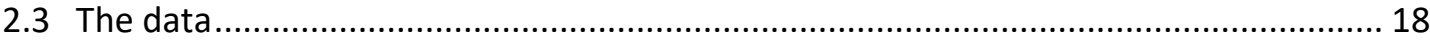

$\begin{array}{lll}2.3 .1 & \text { Attrition } & 19\end{array}$

2.3.2 Measurement of child outcome variables and family background 20

CHAPTER 3: CHILD ECONOMIC VULNERABILITY (EV) OVER TIME.......................................... 27

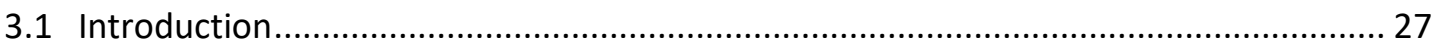

3.2 Trends in ecoconomic strain, deprivation and economic vulnerability in early,

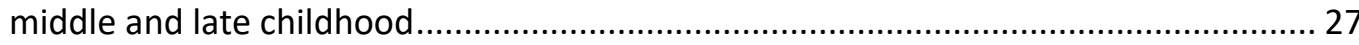

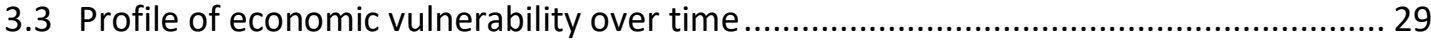

3.4 Economic vulnerability profiles by social characteristics of families of the cohort '08

3.4.1 Economic vulnerability (EV) profiles in middle to late childhood (cohort '98)

4.1 Flows into and out of economic vulnerability (EV) ....................................... 45

4.2 Factors influencing flows into and out of EV .............................................. 46

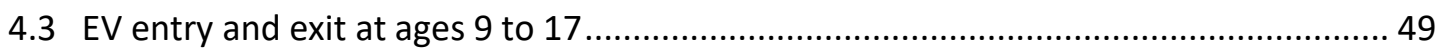

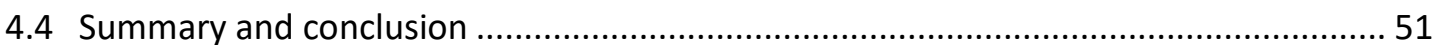


5.1 Health outcomes: obesity, subjective health having a hampering illness/disability and risky health behaviours

5.1.1 Mental health and socio-emotional wellbeing

5.1.2 Self-concept

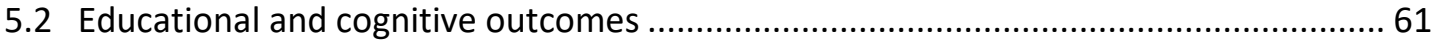

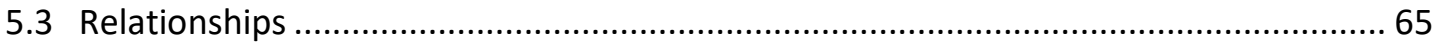

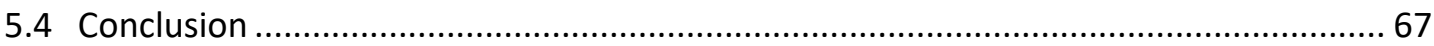

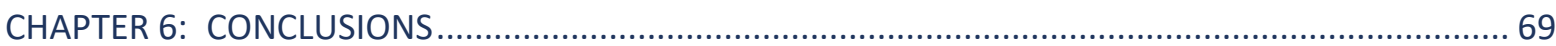

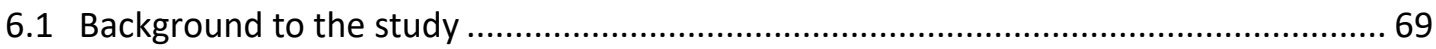

6.2 What are the factors associated with persistent poverty? ............................................ 70

6.3 The dynamics of child poverty - what influences inflow to and outflow from economic vulnerability (EV)? ..................................................................................... 71

6.4 Outcomes for children and young people .................................................................. 72

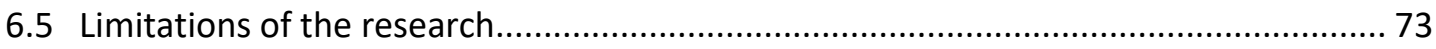

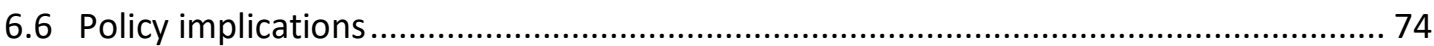

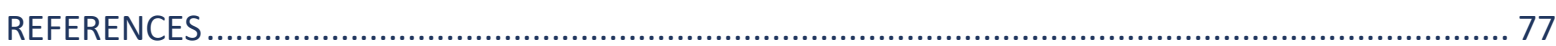

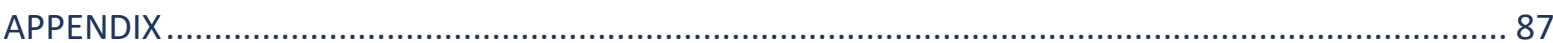

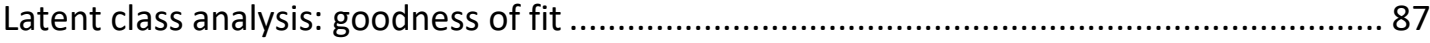




\section{LIST OF TABLES}

Table 2.1a: Latent class profile of economic vulnerability (EV) of ' 98 cohort, cross-sectional results using full sample for each year.....

Table 2.1b: Latent class profile of economic vulnerability (EV) of '98 cohort, longitudinal sample.

Table 2.2a: Latent class profile of economic vulnerability (EV) of ' 08 cohort, cross-sectional...... 17

Table 2.2b: Latent class profile of economic vulnerability (EV) of '08 cohort, longitudinal sample.

Table 2.3: Attrition '08 cohort: wave 1 to wave 5 20

Table 2.4: Attrition '98 cohort: wave 1 to wave 3 (age 9, age 12, age 17-18)............................ 20

Table 3.1: Persistence of Economic vulnerability ('08 cohort) ................................................... 30

Table 3.2: Persistence of economic vulnerability ('08 cohort) ................................................... 31

Table 3.3: Multinomial regression model of factors associated with transient and persistent economic vulnerability (ODDS Ratios) ..................................................................... 41

Table 4.1: Flows into and out of economic vulnerability, 2008-2017 ('08 cohort) ..................... 46

Table 4.2: Flows into and out of economic vulnerability, 2007-2016 ('98 cohort) ..................... 46

Table 4.3: Economic vulnerability entry and exit logistic model: pooled data ('08 Cohort) ........ 48

Table 4.4: Economic vulnerability entry and exit logistic model: pooled data ('98 cohort) ........ 50

Table 5.1: Overweight/obesity at age 9 by longitudinal EV in early/middle childhood, ('08 cohort)

Table 5.2: Overweight/obesity at 17 by longitudinal EV in middle/late childhood ('98 cohort) 55

Table 5.3: $\quad$ Chronic illness or disability that hampers daily activity at age 9 years by exposure to EV ('08 cohort)

Table 5.4: Chronic Illness or disability that hampers daily activity at age 17 years by exposure to EV ('98 cohort) 56

Table 5.5: $\quad$ Risky health behaviours (smoking and drinking) at 17 years by longitudinal EV ('98 cohort) 57

Table 5.6: SDQ scores at age 9 by longitudinal EV ('08 cohort) 58

Table 5.7: $\quad$ SDQ score at age 17 by longitudinal economic vulnerability ('98 cohort) 59

Table 5.8: Self-concept at age 9 by longitudinal economic vulnerability ('08 cohort)...... 60

Table 5.9: Anxiety and life satisfaction at age 17 by longitudinal economic vulnerability ('98 cohort)

Table 5.10: Cognitive tests at age 9 by longitudinal economic vulnerability ('08 cohort) 62

Table 5.11: Cognitive tests at age 17 years by longitudinal EV ('98 cohort) .....

Table 5.12: Junior certificate results ('98 cohort) 
Table 5.13: Number of days absent from school in the previous year, age 9 ('08 cohort)............64 64

Table 5.14: Dislike school by longitudinal economic vulnerability, age 17 ('98 cohort) ................ 65

Table 5.15: Closeness and conflict with primary and secondary caregivers at 9 years ('08 cohort) by longitudinal EV status

Table 5.16: Closeness and conflict with primary and secondary caregivers at 17 years ('98 cohort) by longitudinal EV status. 66

Table 5.17: Number of friends at Age 17 by longitudinal ev status ('98 cohort) 66

Table A2.1: Latent class model fit for infant and child cohort cross-sectional sample wave 1

Table A2.2: 'Alternative consistent poverty' rates for cohorts '08 and '98 88

Table A2.3: latent class profile of NON-EV ('98 cohort), longitudinal sample. 88

Table A2.4: latent class profile of NON-EV infant cohort ('08 cohort), longitudinal sample. 88

Table A2.5: Socio-demographic profile of economic vulnerability of '08 and ' 98 cohort at wave 1

Table A3.1: Socio-demographic characteristics of children, '08 cohort panel data 90

Table A3.2: Socio demographic characteristics of children '98 cohort panel data 91

Table A4.1: Principal and secondary care giver employment transitions by pair of waves, 2007-2016'98 cohort (\%)

Table A4.2: Principal and secondary care giver employment transitions by pair of waves, 2007-2016 ‘08 cohort (\%) 


\section{LIST OF FIGURES}

Figure 1.1: Income poverty and deprivation rates: children and adults 2004-2018 .................... 9

Figure 1.2: Child income poverty rates across Europe, EU-SILC 2018 ....................................... 10

Figure 1.3: Child material and sociaL deprivation rates across Europe, EU-SILC 2018................ 11

Figure 2.1: Timeline of data collection for ' 98 cohort and ' 08 cohort......................................... 19

Figure 3.1: Economic stress and deprivation during early childhood ('08 cohort)....................... 28

Figure 3.2: Economic stress, deprivation and economic vulnerability in mid to late childhood

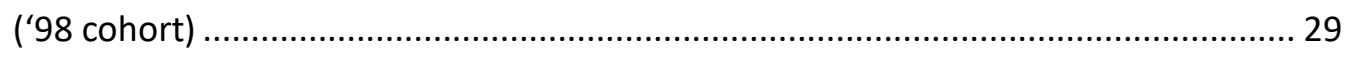

Figure 3.3: Longitudinal economic vulnerability profile by household structure ('08 cohort)...... 32

Figure 3.4: Longitudinal economic vulnerability profile by household social class W1 ('08 cohort)

Figure 3.5: Longitudinal economic vulnerability profile by mother's education W1

('08 cohort)

Figure 3.6: Longitudinal economic vulnerability profile by mother's nationality \& ethnicity W1 ('08 cohort).

Figure 3.7: Longitudinal economic vulnerability by mother's employment status W1 and HH work instensity W1 ('08 cohort)

Figure 3.8: Longitudinal economic vulnerability profile by household structure W1

('98 cohort) 36

Figure 3.9: Economic vulnerability profile by household social class W1 ('98 cohort) 37

Figure 3.10: Longitudinal economic vulnerability profile by mother's education W1 ('98 cohort) 37

Figure 3.11: Longitudinal economic vulnerability profile by mother's nationality \& ethnicity W1 ('98 cohort). 38

Figure 3.12: Longitudinal economic vulnerability profile by household work intensity and mother's employment status W1 ('98 cohort). 39

Figure 5.1: Drumcondra Reading Test logit scores for 9-year-olds who were not EV and those who were always EV 



\section{EXECUTIVE SUMMARY}

In Ireland, as in many other European countries, children are more likely to experience income poverty and material deprivation compared to other age groups of the population. Some families experience poverty as a transitory state, while others remain trapped in poverty for protracted periods (for example, Bane and Ellwood, 1986; Jenkins and Rigg, 2001). This is an important policy issue, as international research has shown that persistent poverty has negative effects (short- and long-term) on children's physical, social, emotional and psychological wellbeing and life chances (Duncan et al., 1998, 2018). The Growing up in Ireland (GUI) survey provides a unique opportunity to study children and young people's experience of poverty in Ireland from infancy to early adulthood (age 17). We adopt a multidimensional measure of poverty, which encompasses not just income but also material deprivation and economic strain. This study sets out to profile the long-term exposure to poverty during childhood, identify the families most at risk of persistent poverty, examine the factors that trigger moves into and out of poverty, and explore the consequences of poverty for children across a wide range of domains.

The study draws on all available waves of the GUI data for two cohorts: the '08 cohort, which covers the period from 9 months to 9 years, and the '98 cohort, which covers the period from 9 years to $17-18$ years. ${ }^{1}$ Our analysis is based on 6,039 families that participated in all three waves of the '98 cohort and 7,507 families that completed all four waves of the ' 08 cohort. The interviews took place between 2007 and 2017, a period of immense economic turmoil in Ireland. A key policy debate has centred on whether it is better to target supports and interventions towards younger rather than older children. The design of the GUI study allows us to consider whether the patterns we observe differ for younger and older children.

\section{Economic vulnerability (EV)}

Poverty is a complex phenomenon, and no single measure or indicator can fully capture its extent. We adopt a multidimensional measure of poverty and use latent class analysis (LCA) (a statistical technique to allocate people to unmeasured categories) to identify those who are economically vulnerable, or experiencing economic vulnerability (EV), on the basis of three indicators:

- living in a household with a low income (bottom 20 per cent);

- experiencing difficulty/great difficulty in making ends meet;

\footnotetext{
${ }^{1}$ One-fifth of the ' 98 cohort were actually 18 years of age at the time of the wave three interview. However, for convenience, the cohort is referred to as 17 -year-olds in this report.
} 
- experiencing material deprivation (the inability to afford basic goods and services).

The size of the EV group varied over time for both cohorts, reflecting the onset of the Great Recession and subsequent economic recovery. The proportion of families that we identify as being EV varies from 9 per cent among the older cohort at age 9 (2007-2008) to a high of 29 per cent for the younger cohort at age 3 (20112012).

\section{Profile of economic vulnerability (EV) across cohorts}

We construct a longitudinal profile of exposure EV over an eight- to nine-year period for both cohorts, which distinguishes those who are never EV, those who experience more transient vulnerability (once or never in two consecutive waves), those who are persistently vulnerable (in two or more consecutive waves) and those who are always vulnerable (in all waves).

A key finding of the research is that exposure to $\mathrm{EV}$ on at least one occasion was a common experience among families with young children (44 per cent) and older children (38 per cent) during this time period. At the extreme, five per cent of families in both cohorts were always EV. However, for many families, vulnerability is once off or transient (22 per cent for both cohorts).

\section{Economic vulnerability (EV) profile by family characteristics}

The analysis highlights a range of family characteristics that are predictors of being persistently or always vulnerable. Lone-parent families, larger families (four or more children), those in the lowest maternal education categories and ethnic minorities all have a much higher likelihood of experiencing persistent poverty. The labour market characteristics of parents in the first wave of the survey are also strongly predictive of persistent EV. This is particularly true where the primary caregiver (PCG) is unable to work due to disability or illness in wave 1; but it is also the case for PCG unemployment or full-time caring. ${ }^{2}$

Many of the same factors are associated with the risk of transient poverty, although the strength of the relationships is weaker.

The same factors are associated with the likelihood of experiencing persistent EV in early and later childhood. However, maternal education appears to be particularly strongly predictive of persistent poverty from infancy to nine years.

\footnotetext{
${ }^{2}$ For both cohorts, the PCG in wave 1 is the mother in $99 \%$ of cases.
} 


\section{Transitions into and out of economic vulnerability (EV)}

The impact of the Great Recession on the lives of children is clearly visible in the analysis of poverty transitions. The recession not only led to large inflows to EV, but also led to a slowing of exits from EV, meaning that more and more families became trapped.

We find that relationship breakdown is an important trigger for moves into EV. Controlling for other factors, in the ' 98 cohort, the odds ratios of entering EV were two and half times greater in families where a partner had left the household than in those where there was no partnership change. In the '08 cohort, the odds ratios were 3.5 times higher in the case of partner exits compared to no change. The analysis also identifies (for both cohorts) an increased risk of entering poverty where a new partner comes into the household, suggesting a risk factor that is not currently on the policy radar.

Both maternal and paternal job loss is an important trigger for entry into EV. Among the ' 08 cohort, the father's job loss doubles the odds of entry into poverty, while the mother's job loss is associated with a 1.7 increase. The odds ratios for the ' 98 cohort were 1.8 and 1.9 respectively.

Similarly, a mother's transition from non-employment into full-time work plays a significant role in moving families out of poverty, an effect which is almost identical to that of a father's entry to full-time employment. In contrast, transitions from non-employment into part-time employment are not associated with exits from $\mathrm{EV}$, suggesting that part-time work is not enough to lift families out of poverty.

Moves from part-time to full-time employment by either mother or father also have a positive effect on the odds ratio of exiting vulnerability in the ' 08 cohort, but significant effects are observed only for mothers in the ' 98 cohort. Conversely, moving from full- to part-time work is not significantly associated with entry to poverty, except in the case of fathers in the ' 08 cohort.

\section{Economic vulnerability (EV) and child outcomes}

Descriptive analysis shows that exposure to EV during childhood is associated with poorer outcomes at 9 years in the ' 08 cohort and at 17 years in the ' 98 cohort. These outcomes cover a range of key dimensions, including cognitive and educational attainment, school engagement, socio-emotional development, life satisfaction, self-concept, chronic illness/disability, obesity, health behaviours (for example, smoking, drinking for the ' 98 cohort) and quality of relationships. Only the closeness of the relationships with parents and pro-social behaviour were not significantly related to EV exposure. In the majority of cases, there appears to be a cumulative effect of exposure, in that outcomes are poorer where a family is persistently or always vulnerable. That said, even transitory spells of EV are associated with worse outcomes compared to never experiencing EV. The strength and pattern of relationships are found to be very similar for both cohorts, which 
suggests that effective policy interventions to counteract the negative effects of poverty can occur throughout childhood and adolescence.

While the analysis cannot identify causal processes, it highlights the myriad of ways in which poverty may be influencing children's lives and provides the basis for a broader research agenda that explores the temporal dimension of child poverty and outcomes at different stages of development.

\section{Implications for policy}

The research identifies several family characteristics that are particularly associated with persistent poverty, including lone parenthood, parents from ethnic minority backgrounds, low levels of maternal education, parents with a disability and larger families. These families require particular policy attention to prevent the range of negative child outcomes identified in the descriptive analyses.

In addition to identifying at-risk groups, the research highlights the importance of family and labour market events that can help inform the targeting of policy interventions.

The key role of both maternal and paternal employment in lifting families out of $\mathrm{EV}$ and preventing entry into poverty highlights the central importance of measures to prevent unemployment and to support employment. These supports include active labour market policies, access to education and training, and supports to assist (re)entry to employment. However, the results show that only full-time employment lifted families out of EV. This would require significant childcare support, especially for those with younger children. Moreover, for those raising a family alone, combining full-time work and caring may not be feasible. The value of core welfare supports for lone parents and other jobless households remains critical to reducing child poverty, as well as income supports for working families and policies to address low pay. Increases in child-dependent allowances for welfare recipients are a well-targeted way of reducing child poverty (for example, O'Malley et al., 2020). The situation of large families has become less prominent in discussions of child poverty over recent decades. However, the analysis shows that this is still a risk factor for persistent EV. In the light of these results, it is timely to assess the impact of the removal of additional child benefit payments for larger families.

The strong association between longitudinal exposure to EV and critical child outcomes at age 9 and age 17, such as physical and mental health, educational attainment, and social-emotional/behavioural difficulties, underscores the importance of tackling child poverty. Importantly, the relationship between EV and outcomes was equally strong for both cohorts, suggesting that effective policy interventions can be made throughout children and young peoples' lives and not only in early childhood. Preventing poverty in middle to late childhood, particularly 
persistent poverty, is likely to have very tangible benefits across a whole range of outcomes.

While the data used in this study were gathered before the pandemic, the results underline the likely consequences of the current pandemic for children through parental unemployment, increased poverty and financial stress (see also Darmody et al., 2020, for a broader review). ESRI research has demonstrated the importance of the emergency pandemic supports, including the Pandemic Unemployment Payment and the Employment Wage Subsidy Scheme, in preserving household income and preventing an increase in child poverty (Beirne et al., 2020; Reagan and Maître, 2020). The evolution and removal of these supports will need to be cognisant of the need to protect children and young people from the longer-term damaging impacts of even transient spells of EV. 



\section{The dynamics of child poverty in Ireland - background and issues}

Children and young people in Ireland are consistently found to be living in households that are at greater risk of (income) poverty and material deprivation compared to other age groups of the population (see, for example, Watson et al., 2012). This study examines exposure to poverty among children and young people during an eight- to nine-year period of their lives for two cohorts, from infancy to nine years of age in the case of one cohort and from age nine to seventeen years in the second cohort. The study draws on the literature, which has highlighted that the duration and timing of poverty during childhood has important implications for children's long-term development and life chances (see section 1.1). Research has shown that some families experience poverty as a transitory state, while others remain trapped in poverty for protracted periods ( for example, Bane and Ellwood, 1986; Jenkins and Rigg, 2001). A large body of research has also demonstrated the importance of considering poverty as a multidimensional concept rather than something that can be captured by income alone (Tomlinson and Walker, 2009; Nolan and Whelan, 2007).

We set out to examine the factors that lead to the persistence of childhood poverty and, importantly, to identify the factors that trigger moves into and out of poverty. The analysis of transitions can help inform policy interventions by identifying life events that precipitate entry into poverty and therefore inform preventative measures or supports. Similarly, this research can also inform policy efforts to reduce child poverty by identifying the factors associated with exits from poverty.

We adopt a multidimensional approach to measuring poverty. Drawing on the work of Watson et al. (2014), we establish a latent measure ${ }^{3}$ of EV that can be applied to both cohorts and which allows us to investigate the factors that influence both poverty persistence and transitions into and out of poverty (see below). We extend the work of Watson et al. (2014) by exploring the dynamics of childhood poverty over a longer time period and carry out analysis of the labour market and family events that lead to poverty entry and exits. The report also looks at the association between poverty dynamics and a broad range of child outcomes, though we do not undertake a formal analysis of causation, which is beyond the scope of the study.

\footnotetext{
3 Latent class methods analyse the underlying association between different variables (in this case economic stress, low income and material deprivation) in a dataset and, based on probabilities, assign group membership to a latent variable (here EV).
} 


\subsection{POVERTY AND TIME}

It is increasingly recognised that the temporal dimension is essential for understanding the effects of poverty. Income fluctuates over time and over the life course and therefore the measurement of income at any one point is inadequate for capturing the underlying position of individuals or families and their long-term resources and opportunities. Incorporating the duration and timing of exposure to poverty improves our understanding of poverty and its impacts.

Research has drawn on longitudinal data to explore the dynamics of poverty. Early studies revealed that mobility into and out of income poverty was more common than expected on the basis of conventional views of 'the poor' (Duncan, 1984; Jarvis and Jenkins, 1995). A focus on the factors that influence who becomes trapped in poverty and the determinants of moves into and out of poverty has also been important for the development of more effective policies for tackling poverty (Atkinson et al., 2002). Fouarge and Layte (2005) developed a profile of poverty in the EU across a five-year period in the mid to late 1990s, identifying households that were never poor, transiently poor, recurrently poor and persistently poor. They also found that Ireland was among the countries with the highest levels of recurrent and persistent poverty at that time. More recently, Jenkins and van Kerm (2011) found that Ireland had the fourth highest persistent poverty rate in the 21 examined countries that applied an EU definition of persistent income poverty, that is, households currently in income poverty and households in poverty for two of the preceding three years.

This literature has placed poverty in a life-course context and has highlighted the crucial role of key life and labour market events in influencing the transition into and out of poverty (Vandecasteele, 2010, 2011). Partnership breakdown, increases in the number of children and leaving the family home have all been identified as risk factors for entering poverty, while labour market transitions such as unemployment, re-employment and retirement are important precursors to poverty transitions (Fouarge and Layte 2005). In her study of 13 countries across Europe, Vandecasteele (2011) found that job loss has the strongest effect on poverty entry followed by partnership dissolution and childbirth.

The triggers for poverty transitions do not necessarily operate in the same way for all groups. For example, the negative income effects of partnership breakdown are particularly acute for women and children (Duncan and Brooks-Gunn, 2000; DiPrete and McManus, 2000) and childbirth was only a poverty-triggering event for those in lower social and educational classes (Vandecasteele, 2011). In contrast, job loss and partnership dissolution increased the risk of poverty entry for all education and social class groups (Vandercasteele, 2011), though class and education remained strong predictors for entry into poverty. 


\subsection{DURATION AND TIMING OF CHILD POVERTY}

In the case of child poverty, the effects may be influenced by both its timing (for example, critical periods of development) and persistence (cumulative effects). The relative influence of these processes is still debated and the literature suggests that this might vary depending on the outcome being considered.

The 'critical period' theory suggests that poverty at key stages of physical and psychological development can be particularly detrimental for subsequent outcomes. This approach is especially prominent in the medical and psychological literature and suggests that poverty in early childhood will have a greater impact on later outcomes than poverty in adolescence or in later life (see Duncan et al., 2012, for further discussion).

In the US, Duncan et al. (2012) showed that income poverty experienced in the early years of childhood can be more consequential for adult employment outcomes than for income poverty experienced in later childhood. Low household income during the early childhood years was also associated with lower rates of high school completion and this may be exacerbated by high neighbourhood poverty and poor-quality schooling. In contrast, increases in family income in later childhood had no significant impact on completed years of schooling (Brooks-Gunn and Duncan, 1997). In the US, Guo (1998) found that poverty in early childhood had a greater impact on cognitive ability than poverty in early adolescence. However, poverty in adolescence had a greater impact on educational achievement, suggesting that critical periods may differ across outcomes.

Cooper and Stewart (2020) reviewed causal studies of income and child outcomes, restricting their analysis to randomised control trials, quasi-experimental studies and longitudinal studies. They found that income in the period before birth is particularly important for child health outcomes, but income effects on education and social-behavioural outcomes are found for older children and teenagers. They also found some evidence from Norwegian studies of long-lasting effects of income supports in early childhood for later educational outcomes at secondary level. ${ }^{4}$

Cumulative process explanations emphasise that it is the accumulation of disadvantage over the life course that is most damaging. ${ }^{5}$ From this perspective, persistent poverty/disadvantage is likely to be particularly problematic for children, young people and their families, not only because of the greater depletion of resources, but also because poverty begets poverty and advantage seeds further benefits. In other words, a cycle of disadvantage or advantage operates. A lack of

\footnotetext{
4 In their 2013 review, Cooper and Stewart found that 10 of 16 studies showed a timing of income effect and that 5 showed no evidence of a timing effect. However, there was no consensus on which stage (early childhood, middle childhood or adolescence) was the most important.

${ }^{5}$ The classic reference to this theory is Merton (1968). For a review of the literature on the theory and evidence, see DiPrete and Eirich (2006).
} 
resources in early childhood means that children may get poorer-quality childcare and schooling and live in worse-quality housing. These experiences compound the initial effects of poverty, so that the difference between children will widen as they get older (Benzeval et al., 2014). Evidence from longitudinal studies supports the argument that persistent childhood poverty leads to poorer child outcomes than transient poverty does, particularly for cognitive development. In the UK, analysis of the Millennium Cohort Study (MCS) by Dickerson and Popli (2016) found that children who are persistently poor from birth are ranked almost 20 percentile points lower on cognitive test scores at age 7 than those who have never experienced poverty. Schoon et al. (2012) reached similar conclusions on cognitive outcomes but found that the effect of persistent poverty on behavioural outcomes is weaker. In the US, research has shown that the effects of persistent poverty on children's cognitive development are twice as large as they are for transitory poverty (Duncan et al., 1994). However, evidence on the impact on other outcomes is more sparse. Cooper and Stewart (2013) also caution that there is an absence of strong evidence on causality in studies that compare the impact of short-term versus long-term income.

\subsection{POVERTY AND CHILD OUTCOMES: PATHWAYS AND MEDIATORS}

Poverty and social exclusion can influence children and young people's lives in a multiplicity of ways (see Cooper and Stewart, 2013 and 2020 for reviews). The family stress model suggests that exposure to poverty affects parents' mental and physical health, which, in turn, can affect parenting behaviour and lead to adverse outcomes for children, especially in social/emotional outcomes (Conger and Donnellan, 2007; Nixon et al., 2019). The family investment model highlights differences in the resources that parents have to invest in children's educational development, diet, health care and social and cultural participation (Bradley and Corwyn, 2002; Duncan and Brooks-Gunn, 1997; Evans et al., 2012; Smyth 2016a). Poor families are also exposed to physical and social environments that are unfavourable to different aspects of development. Inadequate housing and housing insecurity not only impact on children's health, but also on their sense of security and safety and their learning outcomes (DCYA, 2014). While poor families are geographically dispersed and many do not live in disadvantaged areas, they are more likely than high-income families to live in neighbourhoods with problems of crime, poor services and environmental pollution (Whelan et al., 2007). Poverty and social exclusion may also have a direct influence on children and young people's self-esteem and self-concept (Twenge and Campbell, 2002). While studies of the stigmatising effect of poverty have generally focused on adults, qualitative studies focusing on children's experience of poverty highlight feelings of shame and anxiety about not fitting in (see Ridge (2011), for a review). A lack of resources can also limit children and young people's ability to participate in shared activities and to sustain friendships (Ridge, 2011). 
The literature also suggests that different pathways and processes can be more important for specific outcomes. While there are many commonalities, we might expect, for example, cultural capital, especially parents' education, to be more important for educational attainment and social capital to be more influential in post-school transitions (Erola, et al., 2016; Erola 2009). However, environmental factors and parental health behaviours are found to be more influential on obesity (for example, Layte et al., 2013). This means that distinct models need to be developed for each outcome to investigate both risk pathways and protective factors.

The range of policy interventions considered will also vary depending on the outcome in question. This is recognised by the diversity of policy actors and actions identified in Better outcomes brighter futures (DYCA, 2014). Research on cognitive and educational outcomes may wish to measure the impact of early years' education and care (Gambaro et al., 2014; Waldfogel, 2015) or school characteristics (Smyth, 2016b), while research on child health outcomes may wish to consider the effect of access to healthcare services, local recreation and sports facilities, antenatal care or maternity policies. Such analysis is therefore better undertaken on an outcome-by-outcome basis.

Given such diversity, this child poverty report examines the association between persistent and transitory EV for a broad range of child outcomes at a descriptive level, including cognitive development/educational attainment, socioemotional/behavioural outcomes, wellbeing/self-concept, peer and family relationships, and health behaviours and outcomes (for example, obesity). This analysis will provide the basis for selecting outcomes for further in-depth evaluation. The descriptive analyses can identify outcomes where the association with EV is particularly strong and where there is evidence of differences across cohorts/ages of children.

\subsection{RESEARCH QUESTIONS}

The study sets out to address the following research questions :

1. What are the patterns of EV for each cohort of the GUI? To what extent is exposure to vulnerability transitory or persistent over early and late childhood?

2. Which families/children are most at risk of spells of EV and persistent EV? Are the risk factors the same for the two cohorts?

3. Which triggers are associated with transitions into or out of EV? In particular, what is the role of parental employment transitions (including changes in working hours) and of changes in family structure/composition?

4. How were these patterns and relationships affected by the economic environment as Ireland moved to boom, recession and recovery? 
5. How is persistent or transient EV linked to a broad range of child outcomes? Are these relationships stronger in early or later childhood?

6. Drawing on the analysis of risk factors and triggers, how might policy best respond to break the cycle of child poverty and to meet policy targets to reduce child poverty?

\subsection{TACKLING CHILD POVERTY: POLICY CONTEXT}

The national policy framework for children and young people, Better outcomes brighter futures (DYCA, 2014), commits to adopting a multifaceted approach to tackling child poverty. The framework sets a target to reduce, by 2020, the number of children aged under 18 in consistent poverty by 70,000, from the 2011 level of $107,000 .^{6}$ The framework also recognises the need to tackle persistent poverty among households with children (DYCA, 2014, p. 89). This numerical target represents a reduction of at least two-thirds of the 2011 level. Progress towards this goal is evaluated each year in the social inclusion monitor. The most recent monitor (DEASP, 2019) shows that the number of children in consistent poverty fell by 25,000 between 2016 and 2017 (the latest figures in the monitor). However, because of previous increases, the figure was only 2,000 less than the 2011 baseline and a further 68,000 children would need to be lifted from consistent poverty by 2020 to reach the target. Progress in 2018, with a further reduction of 13,000 children in consistent poverty, means that the shortfall declined to 55,000 (DEASP, 2020).

The government's Roadmap for Social Inclusion 2020-2025 (DEASP, 2020) sets a new target for those aged under 18. It aims to reduce the proportion of children who are at risk of poverty or social exclusion (AROPE), from 24 per cent to 16 per cent. ${ }^{7}$ It also aims to move Ireland into the top 5 EU countries for tackling child poverty (as measured with the AROPE indicator), from the current position of number 20.

The route to reducing child poverty outlined in Better outcomes brighter futures (DYCA, 2014) includes improving parental employment, reducing household joblessness, improving services, supporting communities and families, and providing adequate income support. The report also recognises the importance of establishing pathways to training, further education and employment for young people.

\footnotetext{
${ }^{6}$ Consistent poverty is when people are living in a household below 60 per cent of the median household income and are also experiencing material deprivation.

7 The AROPE indicator identifies people who are either living in income poverty (below 60 per cent of the median household income) or who are severely materially deprived (lacking at least 4 out of 9 EU deprivation items) or are living in a household with a very low work intensity. For further details, see Eurostat (2021).
} 
Tackling disadvantage is most effectively achieved through active inclusion strategies that combine supports for parents to access education, training and employment with adequate income support and access to essential services, such as quality, affordable and accessible childcare, quality pre-school education, after-school services, health, housing and social services. (DYCA, 2014, p. 90)

Further analysis of the GUI data can contribute to the development of policy to tackle child poverty by providing much greater information on the persistence of poverty and EV among children and families in both age cohorts.

The importance of access to services in tackling child poverty is also recognised in the EU Child Guarantee proposed by the European Parliament (Resolution of 24 November 2015), which aims to ensure that every child at risk of poverty and social exclusion has access to free healthcare, free education, free early education and childcare, adequate nutrition and decent housing. The right to education, an adequate standard of living, including adequate food, clothing and housing, and to health care are also included among economic and social rights that are covered in the International Covenant on Economic and Social and Cultural Rights (ICESCR).

Levels of child poverty and poverty persistence are influenced by the broad policy regime within a country. Comparative research has found that countries with social democratic welfare regimes are more effective at preventing both short- and longer-term persistent poverty with Southern and Liberal regimes, including Ireland, having both higher rates and longer spells of poverty (Fouarge and Layte, 2005; Andriopoulou and Tsakloglou, 2011; Vaalavuo, 2015). The social democratic regimes feature a high level of social spending on services and a high degree of decommodification (i.e. citizens' incomes are less dependent upon market income), which involves wide coverage of welfare benefits with relatively high replacement rates alongside well-developed active labour market supports.

In the case of child poverty specifically, Chzhen (2017) found that while the labour market-shock of the Great Recession had a very significant impact on child poverty, this was cushioned to a much greater extent in countries with higher levels of social protection spending. Social spending was particularly important in reducing poverty risks in large families and in those with very low work intensity. A crossnational study by Barcena-Martin et al. (2017) confirmed the significance of family benefits in reducing child poverty. Moreover, the authors found that the value of means-tested family benefits was more important in accounting for country differences in child poverty than non-means-tested family benefits.

\subsection{POVERTY TRENDS}

Official poverty monitoring in Ireland relies on both an income poverty measure and an indicator of material deprivation. The income poverty threshold is set at 60 per cent of equivalised median household income; this is also known as the At Risk 
of Poverty (AROP) measure. Deprivation is measured as the enforced absence of two or more of a set of eleven items that are considered necessary for participation in the normal life of society. ${ }^{8} \mathrm{~A}$ measure of consistent poverty combines both income poverty and deprivation. Figure 1.1 shows the evolution of income poverty and deprivation over the period 2004 to 2018 . While the level of deprivation rose sharply with the onset of recession in 2008, and only started to recover in 2014, the relative income poverty rate was higher at the start of the period during the economic boom and then remained remarkably stable. Due to the relative nature of the income measure, it did not capture the widespread, substantial fall in household income, which reduced the median income level.

Differences in the poverty rates across age groups are striking. Throughout the period, the deprivation rates experienced by children were substantially higher than those of working-age adults and older adults. Children's exposure to the economic crisis was particularly sharp: their deprivation rate rose from 16 per cent in 2007 to 38 per cent in 2014. In all years except 2004, children also faced a much higher rate of income poverty than other age groups. During the recession years, the gap between children and older adults widened, as the incomes of older households were protected through the pension system. The most recent figures for 2018 show an income poverty rate of 16 per cent for those aged under 18, 14 per cent for working-age adults and 11 per cent for older adults (Byrne and Treanor, 2020).

\footnotetext{
8 Having two pairs of strong shoes; having a warm waterproof overcoat; buying new (not second-hand) clothes; respectively eating a meal with meat, chicken, fish (or vegetarian equivalent) every second day; having a roast joint or its equivalent once a week; having to go without heating during the last year through lack of money; keeping the home adequately warm; buying presents for family or friends at least once a year; replacing any worn out furniture; having family or friends over for a drink or meal once a month; and having had a morning, afternoon or evening out in the previous fortnight for entertainment.
} 


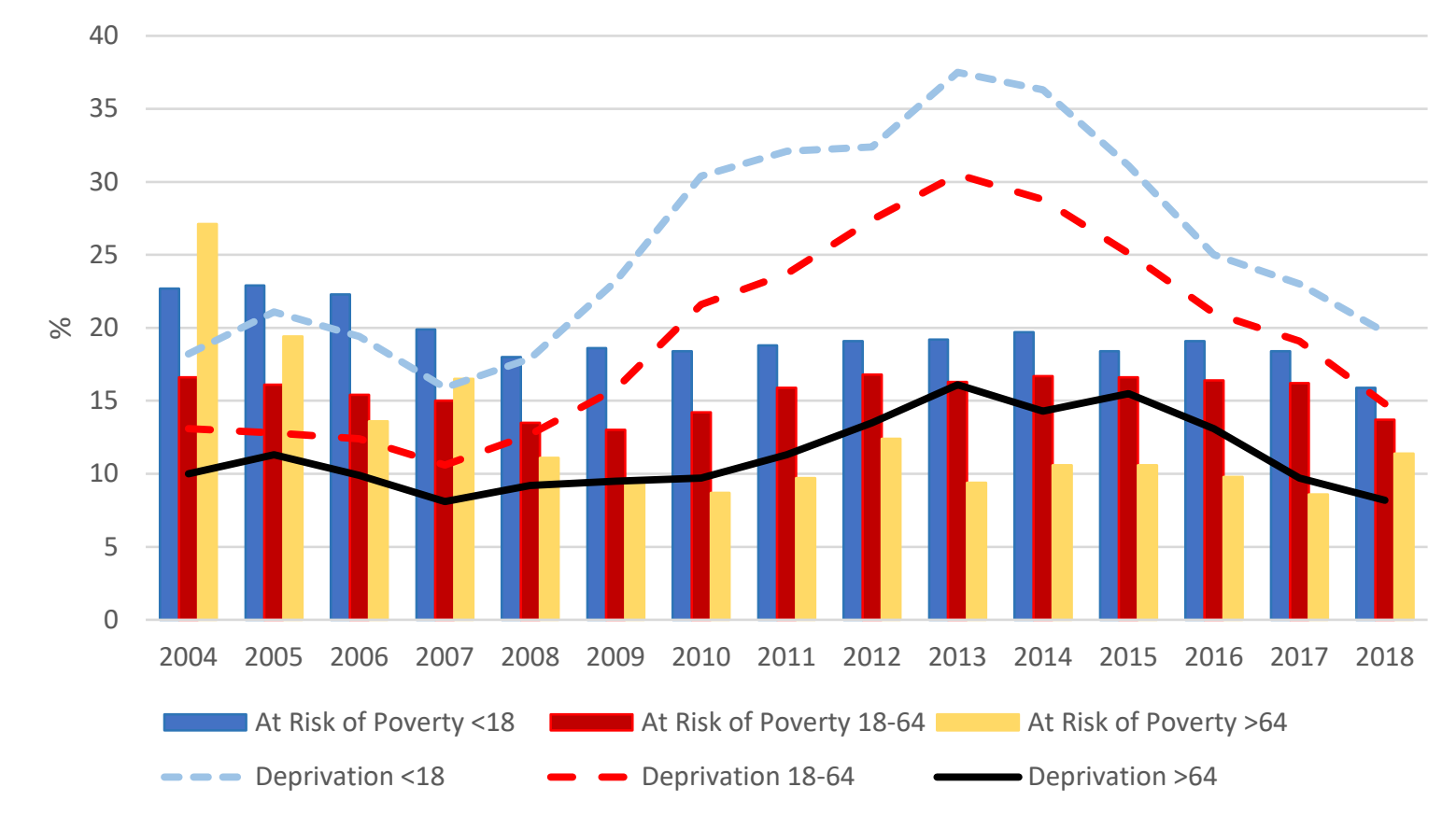

Source: $\quad$ SILC 2004-2018.

Consistent poverty among children rose from 8.8 per cent in 2010 to a peak of 12.7 per cent in 2013, before falling again to 8.8 per cent in 2017 (DEASP, 2019). As with the two component elements, consistent poverty is higher among those under 18 years compared to adults in every year (DEASP, 2019, p. 51).

The greater impact of the recession on children was also noted in other countries. Between 2008 and 2013, child poverty increased faster (or fell more slowly) than poverty among older age groups in most EU countries (Bradshaw and Chzhen, 2015). Using an anchored income poverty threshold, ${ }^{9}$ Chzhen (2017) showed that in 18 (of 30) European countries, child poverty rose between 2008 and 2013, and Ireland saw the fourth highest increase. The lowest rates of child poverty are found in the Nordic countries - Denmark, Finland and Norway - and tend to be lower or quite similar to the other age groups in these countries.

\subsection{CHILD POVERTY ACROSS EUROPE}

In Figure 1.2, we report the most recent Eurostat child income poverty rates based on the EU-SILC data for $2018 .{ }^{10}$ The countries with the lowest income poverty rates are a mix of Northern and Eastern European countries with poverty rates ranging

\footnotetext{
${ }^{9}$ The poverty threshold was anchored in 2008 and adjusted for inflation.

${ }^{10}$ While the income poverty line is based on 60 per cent of the median equivalised household income, Eurostat uses a different equivalence scale from the one used in Ireland. Eurostat uses the OECD-modified equivalence scale as designed by Hagenars and Vaidi (1994).
} 
from $11 \%$ in Denmark, Czechia and Finland to $15 \%$ in Germany and Estonia. Just above these countries, lies Ireland at $16 \%$, ranked tenth lowest of 28 countries. Around the EU28 average of 20\%, we find continental and Eastern European countries such as Latvia (18\%), Austria (19\%) and France $(20 \%)$, but also surprisingly Sweden, with a relatively high rate of $19 \%$ in comparison to other Nordic countries. Finally, between $21 \%$ in Slovakia and a high $32 \%$ in Romania, we find a few Southern European countries such as Greece (23\%), Italy (26\%) and Spain (27\%). Within this latter group, we also find two wealthy countries that are Luxembourg (23\%) and the UK (24\%).

\section{FIGURE 1.2: CHILD INCOME POVERTY RATES ACROSS EUROPE, EU-SILC 2018}

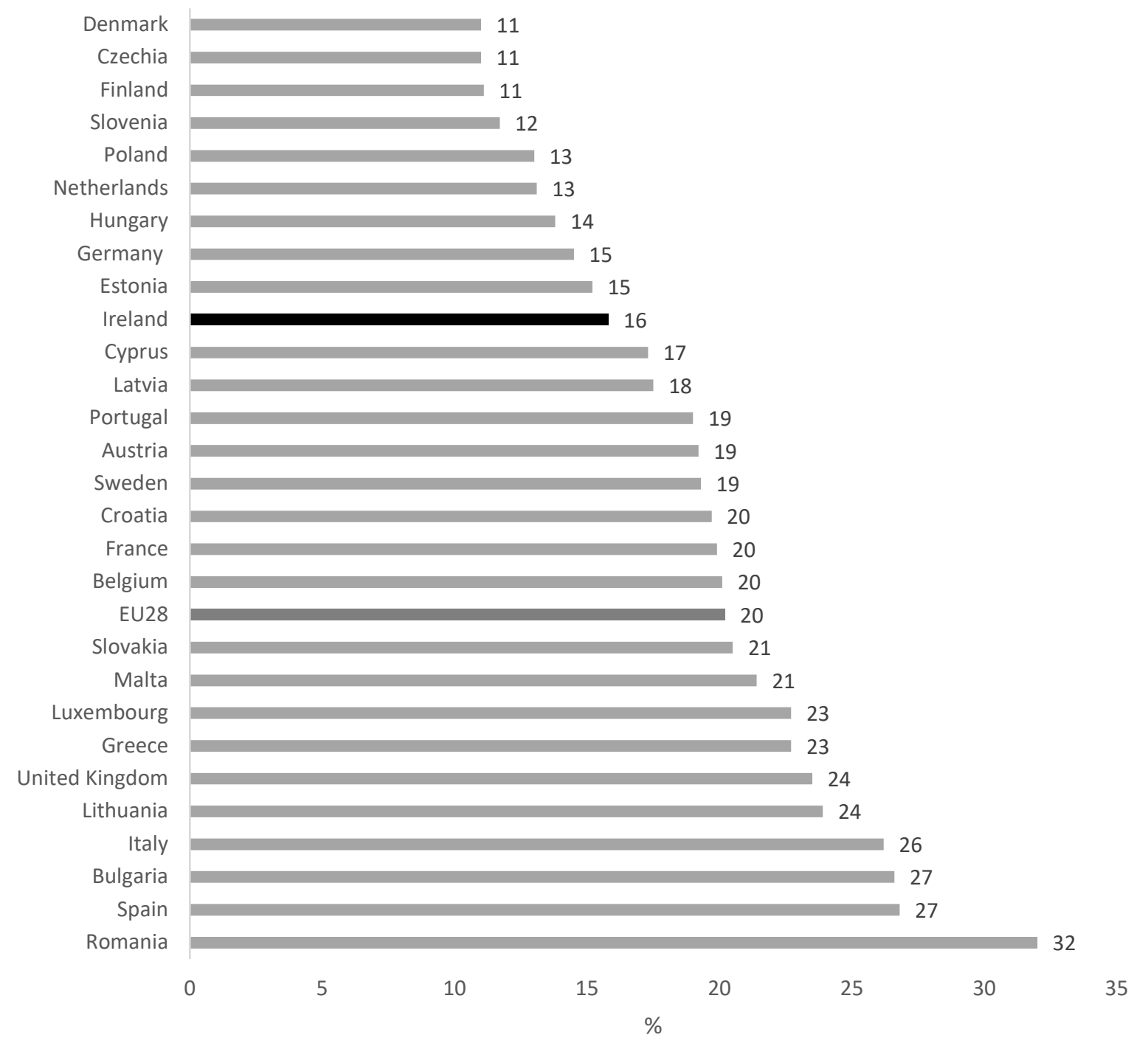

Source: Eurostat [ilc_li02].

In 2017, the EU adopted a revised material deprivation measure, the material and social deprivation indicator. While the EU indicator is different from the Irish material deprivation measure, seven deprivation items are common in both 
measures. The EU material deprivation indicator identifies households that cannot afford at least 5 items out of a list of 13 items. ${ }^{11}$ Compared to the income poverty rates shown in Figure 1.2, the range of material deprivation rates in the EU is much wider, ranging from a low of $4 \%$ in the Netherlands to $42 \%$ in Romania. Ireland is ranked 17 , with a child deprivation rate of $15 \%$, which is just above the EU average and just below the UK (Figure 1.3). There are 5 countries with very high material deprivation rates (over 20\%) and, with the exception of Greece, they are all from Eastern Europe (see also Byrne and Treanor, 2020).

\section{FIGURE 1.3: CHILD MATERIAL AND SOCIAL DEPRIVATION RATES ACROSS EUROPE, EU-SILC 2018}

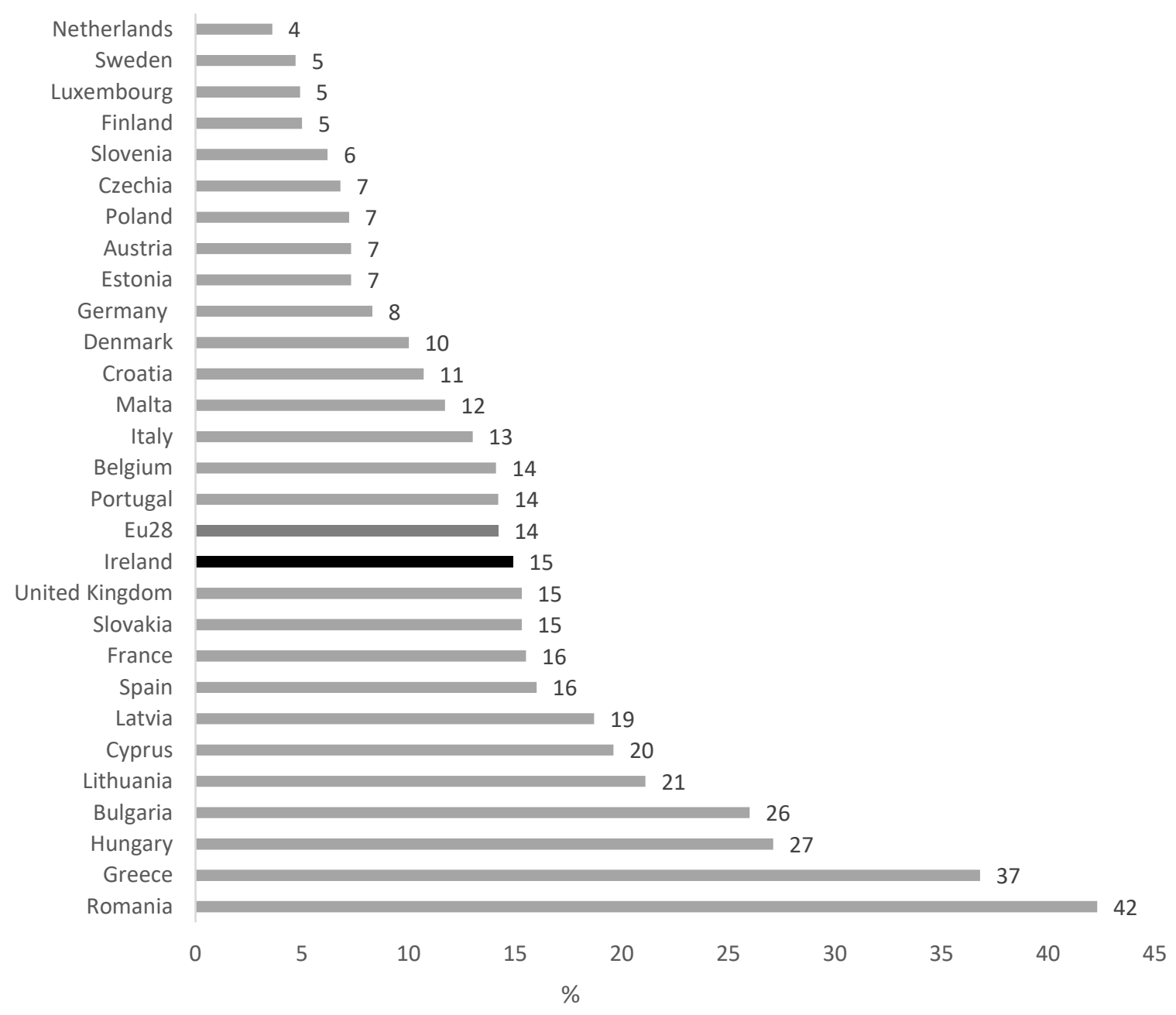

Source: $\quad$ Eurostat [ilc_mdsd07].

\footnotetext{
${ }^{11}$ Facing unexpected expenses; having one week's annual holiday away from home; avoiding arrears (in mortgage, rent, utility bills and/or hire purchase instalments); affording a meal with meat, chicken or fish (or vegetarian equivalent) every second day; keeping the home adequately warm; affording a car/van for personal use; replacing worn-out furniture; replacing worn-out clothes with some new ones; having two pairs of shoes; spending a small amount of money each week on him/herself ('pocket money'); having regular leisure activities; getting together with friends/family for a drink/meal at least once a month; and having an internet connection.
} 


\subsection{POVERTY AND COVID-19}

The trends shown in Figure 1.1 are highly relevant for our analysis of the persistence of poverty and poverty dynamics because children and young people are growing up in this context. However, it should be noted that the current analysis concerns the pre-Covid-19 period and real-time data on the effects of the pandemic on child poverty will not be available for some time. However, Reagan and Maître (2020) provide a micro-simulation of the effects on household income, using information on job losses and the emergency social welfare provisions put in place to protect households using the tax-benefit model EUROMOD. ${ }^{12}$ They estimate that, with a recovery in the fourth quarter of 2020 and the continuation of the emergency income supports, the level of child poverty will increase from a base level of 16.6 per cent to 19.5 per cent in 2020. In the absence of a recovery in the fourth quarter, the rate of child income poverty is predicted to increase to up to 23 per cent, with the mean estimate of 21 per cent.

\subsection{OUTLINE OF THE REPORT}

In the next chapter, we describe the concept and measurement of poverty adopted and outline the features of the latent class analysis (LCA) approach. The chapter also describes the data and indicators used in the report. In Chapter 3, we develop the economic vulnerability profile for the two cohorts and describe the factors associated with levels of economic vulnerability over time, that is, transient and persistent. These factors are also formally tested through logit models. In chapter 4 we turn to the analysis of poverty transitions. We investigate the life and labour market events that trigger movements into and out of vulnerability. In chapter 5 we consider the association between temporal poverty exposure and child outcomes. This analysis incorporates two temporal dimensions of poverty - first, profile of exposure across time and secondly, across two child cohorts reflecting different stages of childhood/life course (age 9 months to 9 years and 9 years to 17 years). In the final chapter we summarize the findings and draw out lessons for policy.

\footnotetext{
12 EUROMOD is a tax-benefit microsimulation model developed across several European countries. The model provides estimates from governmental changes in fiscal and social policies on personal and household income.
} 


\section{CHAPTER 2}

\section{Data and methods}

In this chapter, we outline the conceptualisation and measurement of poverty used in this study. We also describe the data and methods used in the analyses in the later chapters.

\subsection{MEASURING ECONOMIC VULNERABILITY AND POVERTY DYNAMICS}

The nature and complexity of poverty means that it is not straightforward to measure. Poverty is multidimensional and no single measure or indicator can fully capture its extent. Over the years, researchers have moved from a focus of measuring poverty with a single indicator (such as being on low income) to using other measures, including non-monetary indicators. This also involved the development of methods to combine different indicators to reflect the multidimensional aspects of poverty and social exclusion.

Measures of poverty that are confined to low income, such as the proportion falling below a relative income poverty threshold, have a number of well-known shortcomings. Whelan et al. $(2019$, p. 684) note that these limitations include the failure to take account of longer-term command over resources, unusually high expenses, accumulated debt, the distinctive circumstances of the self-employed and the role played by state services'. Relative income poverty measures are also particularly unsuitable for measuring poverty in periods of change. In a period of growth, when all household incomes rise, or in a period of recession, when all household incomes fall, the poverty line itself will rise and fall and will not capture the overall changes in living standards. Multidimensional measures better reflect a concept of poverty that incorporates both a relative inequality and an (absolute) lack of resources and capabilities (Sen, 1979). However, there are challenges in combining exposure to difficulties across multiple dimensions or domains of life (for example, income, deprivation, housing or health). If we define poverty as the intersection of multiple dimensions, we can end up with a very small proportion of individuals being identified as poor. ${ }^{13}$

In this study we adopt latent class analysis (LCA) to identify a multidimensional measure of poverty. The technique identifies those who have a high probability of experiencing a distinctive risk profile in relation to multiple dimensions of poverty,

\footnotetext{
${ }^{13}$ The official measure of consistent poverty in Ireland identifies individuals that are income poor and experience material deprivation (see Chapter 1). The overlap between these two indicators identifies 5.5 per cent of the Irish population as being in consistent poverty in 2019 (CSO, 2020). The greater the number of dimensions considered. the smaller the overlap will be.
} 
without necessarily experiencing all dimensions at a particular point in time. LCA has been used to operationalise the concept of economic vulnerability and multidimensional poverty in previous European (Breen and Moisio, 2003; Moisio, 2004a, 2004b) and Irish research (Whelan and Maître, 2005; Whelan and Maître, 2010; Watson et al. 2014).

LCA is a statistical technique that is used to allocate individuals to groups when the underlying concept is not directly measured, for example, intelligence or antisocial behaviour. The classification into these categories will depend on the relationship between different measured variables in the dataset. For example, from a survey on people's health behaviour, we could identify a latent variable of risky health behaviour where people could be classified into three categories: high, medium and low risk. People could be classified in any of these categories depending on their attitudes and behaviours on some measured variables recorded in the data, such as smoking, drinking and usage of drugs.

For the purpose of our analysis, we use a selected set of individual or household observable characteristics (or manifest variables) to identify an underlying (or latent) poverty which we label 'economic vulnerability'. The manifest variables can be categorical or continuous, but the latent class identified from the analysis is categorical. The LCA allocates a probability of belonging to each latent class to each individual in the data (the sum of these probabilities being 1 ) and we used a modal allocation for the economic vulnerability membership.

LCA has been used previously to explore the dynamics of economic vulnerability over two waves of the GUI ' 08 and ' 98 cohorts (Watson et al., 2014). The measure of economic vulnerability developed in that study was based on the household income quartile position, the experience of economic stress and being in a jobless household. ${ }^{14}$ For this analysis, we are interested in the factors contributing to economic vulnerability, and that trigger movements into and out of economic vulnerability, including employment changes among household members. For this reason, we do not want to include household employment status in the vulnerability measure itself. Therefore, we substitute the jobless variable with the measure of material deprivation. This measure has the advantage of including both dimensions of official poverty measure in Ireland, along with the measure of subjective economic stress.

\subsection{MEASUREMENT OF ECONOMIC VULNERABILITY}

The GUI data collect information on the economic circumstances of households across all cohorts and waves. In this study, we use three indicators that are

\footnotetext{
${ }^{14}$ The EU also includes a measure of household employment status (work intensity) in their measure of 'at risk of poverty and social exclusion', alongside income and deprivation.
} 
associated with the experience of poverty and social exclusion: living in a household with a low income, experiencing economic stress and material deprivation.

The measure of low income is based on the equivalised disposable household income, that is the total household net income (after deductions for tax and PRSI), adjusted for household size and composition (number of adults and children). ${ }^{15}$ Each household is then allocated an income quintile position based on the distribution of equivalised disposable household income across households. The official At Risk of Poverty (AROP) measure uses a cut-off of 60 per cent median household income to identify the proportion of the population living in income poverty (or with a low income). This is derived using the Survey of Income and Living Conditions (SILC). The GUI survey focuses only on families with children and is not designed to collect the same detailed information on all income sources as did SILC. Therefore, we use a different, widely-used measure of low income, which focuses on the bottom income quintile. ${ }^{16}$ By definition, the proportion of families in the bottom quintile remains unchanged over time: only the composition will change.

The measure of economic stress is based on one question asked to the primary caregiver (PCG) about the difficulty of making ends meet, with six possible answers ranging from 'very great difficulty' to 'very easily'. The purpose of the measure of economic stress is to capture household financial hardship and difficult living circumstances. We consider a household to experience economic stress when they have 'great difficulty' or 'difficulty' in making ends meet. This measure is collected in a large number of national and international surveys (for example, EU-SILC, European Quality of Life Surveys) and has widely been used in the national and international literature.

The measure of material deprivation is based on the Irish measure of basic deprivation that identifies households that are lacking essential goods or services out of a list of 11 items (being able to afford two pair of shoes, having protein meals, and so on). Watson et al. (2014) found that a relatively low proportion of households in the first wave of the ' 98 cohort were lacking two or more items, compared to the SILC survey, and therefore did not include the material deprivation indicator. When we expand the analysis to include more waves and the younger cohort, we find higher levels of deprivation. ${ }^{17}$ With LCA, we can test different deprivation measures, as the aim is to capture underlying vulnerability rather than the proportion below a threshold, as is the case for the consistent

\footnotetext{
${ }^{15}$ The Irish national equivalence scale is 1 for the first adult, 0.66 for every subsequent person 14 or older and 0.33 for every person less than 14 years of age.

16 For example, the bottom quintile is used in measures of income inequality, such as the $580 / \mathrm{S} 20$ ratio.

${ }^{17}$ For example, for the ' 08 cohort, basic deprivation (lacking two or more items) increased from 9 per cent at the age of 9 months to 18 per cent at the age of 5 (results available from the authors).
} 
poverty measure. ${ }^{18}$ We tested the inclusion of a measure of material deprivation as a dichotomous indicator (lacking at least one item out of eleven) or as a continuous indicator (scale from 0 to 11). The former indicator produced smaller vulnerable classes than the continuous indicator. The latter indicator has also the advantage of taking account of the severity of deprivation in determining vulnerable families, so we adopted the continuous measure for the LCA.

In order to identify the optimal number of latent classes that best fitted the data for both cohorts, we ran several statistical tests. We report on this analysis in the Appendix (see Appendix Table A2.1).

Tables 2.1 and Tables 2.2 report the LCA results for the two cohorts. ${ }^{19}$ For both cohorts we report results for the cross-sectional samples of children and families and separately for the sample of children and families present in all waves. ${ }^{20}$ The latter group is the sample that we use for the subsequent analyses from chapters 3 to 5 . The tables show that for both cohorts, the size of the economically vulnerable group, or those experiencing economic vulnerability (EV), increased over time as the Irish economy fell into recession. The size of the EV group ranges from 9 per cent in wave one of the ' 98 cohort to 30 per cent of the ' 08 cohort at wave three. Both tables also show that the LCA was able to identify a significant age of EV children with a high level of economic stress, low income and experiencing material deprivation.

An advantage of using a measure of EV based on LCA is that it identifies a group of families that may not be currently experiencing economic stress, deprivation and low household income, but which may have a high underlying risk of experiencing these outcomes and poverty defined more broadly, depending on their characteristics (low education, low social class profile); or they might face this risk if their circumstances were to change (job loss, partnership dissolution and such like). Indeed, the results from Table A2.5 in the Appendix show a high prevalence of socio-economic disadvantage characteristics among the EV. The LCA measure of $\mathrm{EV}$ is very relevant in terms of social policy for tackling and preventing poverty, as it considers a much broader at-risk group than a measure of poverty based on the intersection of several indicators (low income + deprivation + economic stress).

\footnotetext{
18 In Table A2.2 in the Appendix we present an 'alternative', consistent poverty rate based on being in the bottom income quintile and experiencing deprivation on two or more items out of eleven items. For both cohorts, the rates are very low across all waves, ranging from 2 per cent to 8 per cent, which would result in very small numbers across our categories of interest (poor once, transient poor and persistently poor).

19 In Tables A2.3 and A2.4 in the Appendix, we present the corresponding results for the non-EV group.

${ }^{20}$ We present cross-sectional and longitudinal results for general information, because the LCA is run first on each crosssectional data before being added to the panel data.
} 
TABLE 2.1A: LATENT CLASS PROFILE OF ECONOMIC VULNERABILITY (EV) OF ' 98 COHORT, CROSSSECTIONAL RESULTS USING FULL SAMPLE FOR EACH YEAR

\begin{tabular}{|c|c|c|c|}
\hline & \multicolumn{3}{|c|}{$\%$} \\
\hline & $\begin{array}{l}9 \text { years } \\
(2007)\end{array}$ & $\begin{array}{c}13 \text { years } \\
(2011)\end{array}$ & $\begin{array}{c}17 \text { years } \\
(2015)\end{array}$ \\
\hline Size EV group & 10.40 & 29.60 & 22.1 \\
\hline \multicolumn{4}{|l|}{ Characteristics EV group } \\
\hline Economic stress & 63.10 & 78.20 & 68.4 \\
\hline Bottom income quintile & 71.00 & 42.70 & 48.1 \\
\hline Material deprivation (mean deprivation on 11 items) & 1.83 & 1.74 & 2.44 \\
\hline$N$ (total) & 8,568 & 7,525 & 6,216 \\
\hline
\end{tabular}

TABLE 2.1B: LATENT CLASS PROFILE OF ECONOMIC VULNERABILITY (EV) OF '98 COHORT, LONGITUDINAL SAMPLE

\begin{tabular}{|c|c|c|c|}
\hline & $\begin{array}{c}9 \text { years } \\
(2007)\end{array}$ & $\begin{array}{c}13 \text { years } \\
(2011)\end{array}$ & $\begin{array}{c}17 \text { years } \\
(2015)\end{array}$ \\
\hline Size EV group & 9.2 & 28.5 & 21.6 \\
\hline \multicolumn{4}{|l|}{ Characteristics of EV group } \\
\hline Economic stress & 59.9 & 78.8 & 69.0 \\
\hline Bottom income quintile & 69.5 & 41.7 & 57.7 \\
\hline Material deprivation (mean deprivation on 11 items) & 1.70 & 1.71 & 2.52 \\
\hline$N$ (total) & 6,039 & 6,039 & 6,039 \\
\hline N EV unweighted & 328 & 1,377 & 978 \\
\hline
\end{tabular}

TABLE 2.2A: LATENT CLASS PROFILE OF ECONOMIC VULNERABILITY (EV) OF '08 COHORT, CROSSSECTIONAL

\begin{tabular}{|c|c|c|c|c|}
\hline & $\begin{array}{l}9 \text { months } \\
(2008)\end{array}$ & $\begin{array}{l}3 \text { years } \\
(2011)\end{array}$ & $\begin{array}{l}5 \text { years } \\
(2013)\end{array}$ & $\begin{array}{l}9 \text { years } \\
(2017)\end{array}$ \\
\hline Size economic vulnerable group & 16.4 & 24.0 & 28.2 & 18.4 \\
\hline \multicolumn{5}{|l|}{ Composition of vulnerable group } \\
\hline Economic stress & 63.1 & 70.2 & 69.9 & 59.2 \\
\hline Bottom income quintile & 64.1 & 54.3 & 47.9 & 62.4 \\
\hline $\begin{array}{l}\text { Material deprivation (mean deprivation on } 11 \\
\text { items) }\end{array}$ & 2.1 & 2.0 & 2.4 & 2.2 \\
\hline$N$ (total) & 11,134 & 9,793 & 9,001 & 8,032 \\
\hline
\end{tabular}


TABLE 2.2B: LATENT CLASS PROFILE OF ECONOMIC VULNERABILITY (EV) OF '08 COHORT, LONGITUDINAL SAMPLE

\begin{tabular}{|l|c|c|c|c|}
\hline & $\begin{array}{c}\mathbf{9} \text { months } \\
(\mathbf{2 0 0 8 )}\end{array}$ & $\begin{array}{c}\mathbf{3} \text { years } \\
\mathbf{( 2 0 1 1 )}\end{array}$ & $\begin{array}{c}\mathbf{5} \text { years } \\
\mathbf{( 2 0 1 3 )}\end{array}$ & $\begin{array}{c}\mathbf{9} \text { years } \\
\mathbf{( 2 0 1 7 )}\end{array}$ \\
\hline $\begin{array}{l}\text { Size economic vulnerable group } \\
\text { Composition of vulnerable group }\end{array}$ & $\mathbf{1 6 . 8}$ & $\mathbf{2 5 . 1}$ & $\mathbf{2 9 . 7}$ & $\mathbf{1 8 . 1}$ \\
\hline $\begin{array}{l}\text { Economic stress } \\
\text { Bottom income quintile }\end{array}$ & 62.6 & 70.4 & 70.1 & 58.8 \\
\hline $\begin{array}{l}\text { Material deprivation (mean deprivation } \\
\text { on 11 items) }\end{array}$ & 66.2 & 54.4 & 47.5 & 62.0 \\
\hline & 2.1 & 2.0 & 2.5 & 2.2 \\
\hline N (total) & & & & 7,505 \\
\hline $\mathbf{N}$ EV unweighted & 7,505 & 7,505 & 7,505 & 1,105 \\
\hline
\end{tabular}

Note: $\quad$ Results from modal allocation (weighted data). Longitudinal sample, weighted by longitudinal weight (WGT9YRb).

\subsection{THE DATA}

We draw on all currently available waves of the Growing up in Ireland (GUI) survey for both age cohorts, that is, the first four full waves of the ' 08 cohort and the first three waves of the ' 98 cohort. The timing of the waves is described in Figure 2.1. The ' 98 cohort began in the third quarter of 2007, when the study children were 9 years old and the families were revisited in 2011, when the children had turned 13 years and again in 2015, when they were aged 17-18 years. The initial fieldwork for the '08 cohort was carried out between Quarter 1, 2008 and Quarter 1, 2009, when the study child was 9 months old. The subsequent waves were carried out in 2011 (at age 3), 2013 (at age 5) and 2017 (at age 9).

The timing of the data collection is important from a child poverty perspective, as the period encompasses the Great Recession, when families faced rapidly changing economic circumstances. The economic cycle is reflected by the national unemployment rate, which rose rapidly from 2008 to a peak of 15 per cent in 2012. This deterioration in the economic environment had very real implications for the living standards of families in Ireland, as described in Figure 2.1. The GUI study design provides an opportunity to examine how exposure to this shock impacted upon children and to explore whether the effects differ depending upon the child's age at the time of the crisis. 


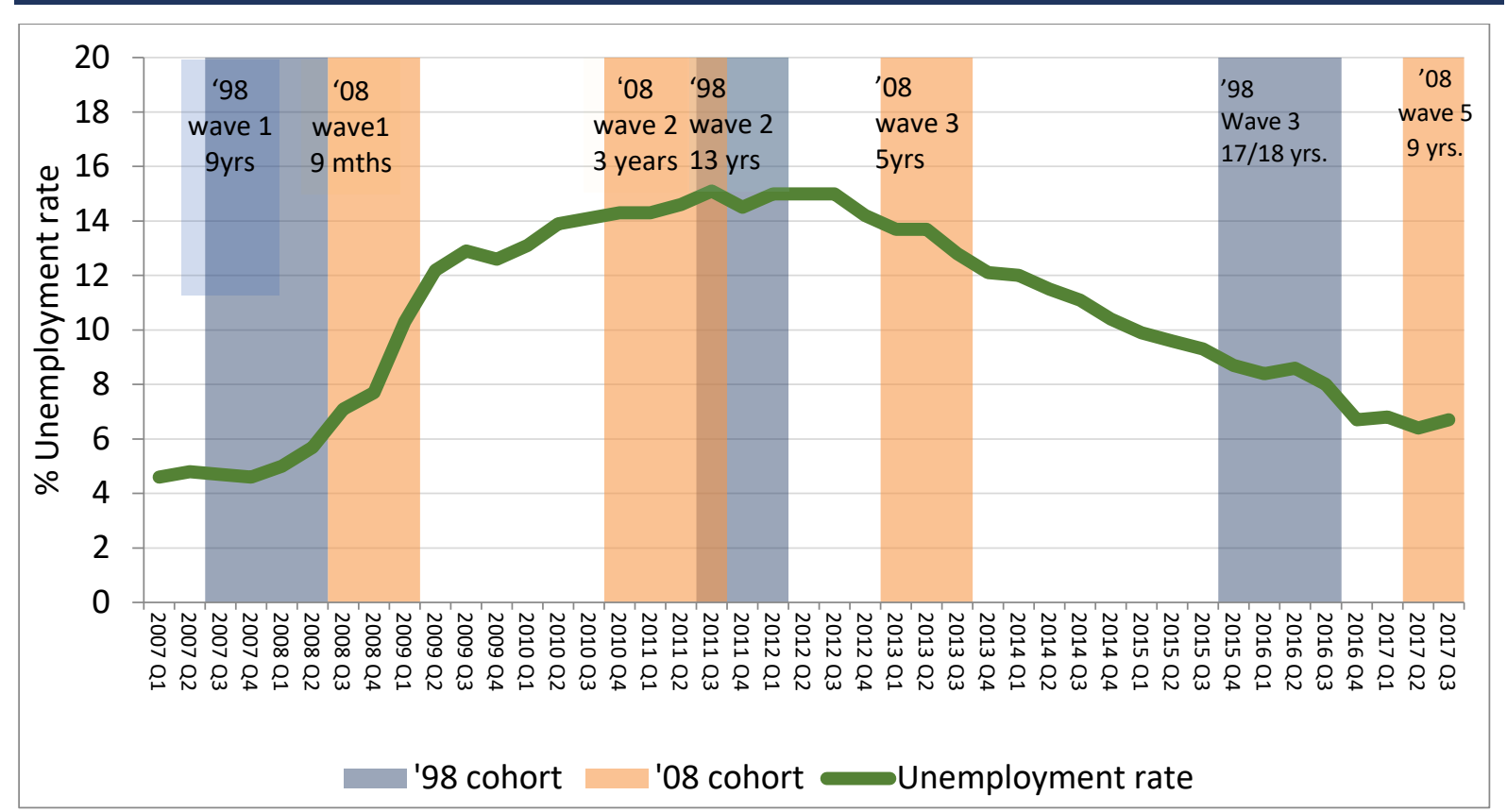

\subsubsection{Attrition}

As with all longitudinal data, analysis of the GUI requires consideration of attrition and its possible influence on research results. Attrition refers to the loss of cases due to participants who drop out of the sample over time. Table 2.3 describes the proportion of the original 2008 sample that completed the subsequent waves. We see that two-thirds of families participated in all four full waves, while 82 per cent participated in at least three of the waves. For the construction of the latent measure of $\mathrm{EV}$, we use the complete cross-sectional sample for each wave. However, for the analyses in Chapters 3 to 5 , we restrict the sample to families that participated in all four waves. In order to correct for potential bias due to nonrandom attrition, the data are re-weighted using a cross-wave longitudinal weight (see Quail et al., 2019). 


\section{TABLE 2.3: $\quad$ ATTRITION ‘08 COHORT: WAVE 1 TO WAVE 5}

\begin{tabular}{l|r|r|}
\hline & $\mathbf{N}$ & $\mathbf{\%}$ \\
\hline Completed sample at 9 months of age & 11,134 & $100.0 \%$ \\
\hline Participated in all 4 full waves (w1, w2, w3, w5) & 7,507 & $67.4 \%$ \\
\hline Participated in wave 1 only & 982 & $8.8 \%$ \\
\hline Participated in any two waves & 985 & $8.9 \%$ \\
\hline Participated in any three waves & 1,660 & $14.9 \%$ \\
\hline Source: McNamara et al. (2020a). & \\
Note: $\quad$ Wave 4 was a short postal survey and is not analysed in the current study.
\end{tabular}

Similarly, we can examine attrition in the ' 98 cohort. Overall, by wave 3 (age 1718), 70.5 per cent of the original sample remained (see Table 2.4). The analysis in the subsequent chapters is restricted to those in all three waves and is re-weighted using a longitudinal weight.

TABLE 2.4: ATTRITION ‘98 COHORT: WAVE 1 TO WAVE 3 (AGE 9, AGE 12, AGE 17-18)

\begin{tabular}{|l|r|r|}
\hline & $\mathbf{N}$ & \% \\
\hline Completed sample at $\mathbf{9}$ years of age & 8,568 & $100.0 \%$ \\
\hline Participated in all $\mathbf{3}$ waves & 6,039 & $70.5 \%$ \\
\hline Participated in wave $\mathbf{1}$ only & 866 & $10.1 \%$ \\
\hline Participated in waves $\mathbf{1}$ and $\mathbf{2}$ only & 1,486 & $17.3 \%$ \\
\hline Participated in waves $\mathbf{1}$ and $\mathbf{3}$ only & 177 & $2.1 \%$ \\
\hline
\end{tabular}

Source: McNamara et al. (2020b).

\subsubsection{Measurement of child outcome variables and family background}

In Chapter 5, we examine the association between longitudinal exposure to poverty in childhood and a range of important child outcomes. The outcomes are selected because they are important domains, as identified in the literature, including physical health, mental health, wellbeing and cognitive/educational outcomes. They also include outcomes that are relevant for policy. Where possible, we include indicators that were included in both cohorts, though appropriate measures often differ, depending on the age of respondents. The measures also include self-report, parent-report and interviewer-administered tests. These outcome variables are taken from the latest wave of data for the two cohorts: at age 9 for the ' 08 cohort and at age 17 for the ' 98 cohort. Key family background variables used in the analysis are also described below.

\section{Overweight and obesity}

The overweight and obesity variables were calculated using respondents' height and weight. All respondents had their height and weight measured by trained 
interviewers during the interview at home. The recorded height and weight measurements were then used to calculate body mass index (BMI = weight $(\mathrm{kg}) /$ height $\left(m^{2}\right)$ ). Using these figures, respondents were categorised as normal weight, overweight and obese. The categories used are based on international guidelines developed by the World Obesity Federation (Cole and Lobstein, 2012).

\section{Disability and chronic illness}

The GUI study contains measures of disability and chronic illnesses for children and caregivers for both the ' 08 and ' 98 cohorts. However, for children, these variables differ in measurement between the two cohorts. For the '08 cohort at age 9, caregivers were asked if their child had 'any longstanding illness, condition or disability'; the question clarified longstanding as 'anything that [had] troubled $\mathrm{him} /$ her over a period of time or that [was] likely to affect him/her over a period of time'. For the ' 98 cohort at age 17, the question was completed by the young person themselves, rather than a caregiver, with respondents being asked if they '[had] any ongoing chronic physical or mental health problem, illness or disability'. For both cohorts, caregivers were asked if they had 'any chronic physical or mental health problem, illness or disability'.

\section{Health behaviours}

The health behaviours of the 17-year-old cohort were measured using two questions: one concerning their smoking habits and the other on alcohol consumption. The smoking variable draws on a question from the survey, which asks respondents if they have ever smoked a cigarette. If the respondents stated that they had smoked a cigarette, they were then asked about frequency.

Alcohol consumption of the respondents was evaluated using AUDIT, which is a 10item screening tool developed by the World Health Organization to examine whether respondents' drinking habits are harmful. AUDIT consists of three items that look at consumption of alcohol, three items that look at alcohol dependence and four items used to evaluate alcohol-related problems. The first eight items are scored on a 5-point scale and the remaining two items are scored on a 3-point scale. Based on the scores which respondents receive on the 10 items, they are then recoded into three groups: low risk, problem drinking or harmful and hazardous drinking.

\section{Junior certificate results}

The GUI questionnaire measures Junior Certificate results for the '98 cohort as a self-reported measure (asked at age 17). Respondents were asked what subjects they sat for the Junior Certificate examination, as well as the level (foundation, ordinary, higher) and grade achieved in their results. 


\section{Self-concept}

The Piers-Harris self-concept scale (Piers and Herzberg, 2002) was self-completed by the child at age 9 . The scale includes six sub-scales that assess children's selfconcept across a range of domains. The behavioural adjustment scale includes items such as 'I am a good person' and 'I get into lots of fights'. The intellectual status subscale measures academic self-image and includes items such as 'I am smart' and 'I am slow in finishing my schoolwork'. Academic self-image can influence later achievement, even controlling for prior performance (Marsh and Craven, 2006). The physical appearance subscale includes items such as 'I am goodlooking' and 'my looks bother me'. The freedom from anxiety includes items such as 'I like being the way I am' and 'I am left out of things'. The popularity subscale measures the perception of the child's relationship with peers, for example, 'I am unpopular' and 'I have many friends'. Examples of the items included in the happiness and satisfaction subscale are 'I am a happy person' and 'I wish I were different'.

\section{Psychological wellbeing}

Psychological wellbeing is measured using anxiety and life satisfaction scales for the 17-year-old cohort. Anxiety was measured using the Depression, Anxiety and Stress Scale (DASS21), which contains seven items that measure autonomic arousal, skeletal muscle effects, situational anxiety and subjective experience of anxiety. ${ }^{21}$ Respondents provided answers to the items using a 4-point scale with responses of 'Did not apply to me at all', 'Applied to me to some degree', 'Applied to me a considerable degree' and 'Applied to me very much'.

Life satisfaction of respondents was measured using a 10-point scale that asked the cohort: 'If you were to describe how satisfied you are with your own life in general, how would you rate it on a scale of 0 to 10, 0 meaning you are extremely unsatisfied with your life in general, and 10 meaning that you are extremely satisfied with your life.'

\section{School engagement}

School engagement was evaluated for both the 9-year-old and 17-year-old cohorts. However, different measures are used for these groups. For the 9-year-old cohort, school engagement was measured using a question that asked caregivers the number of days the child had been absent from school in the previous school year. For the 17-year-old cohort, self-reported dislike of school was used to assess school engagement. Respondents were presented with the statement 'I dislike(d) school'

\footnotetext{
${ }^{21}$ For example, the items refer to dryness in the mouth, experiencing breathing difficulty, trembling and being worried about some situations.
} 
and were asked to indicate whether the degree to which agreed with the statement, ranging from strongly agree to strongly disagree.

\section{Number of friends}

The number-of-friends variable for the 17-year-old cohort draws on a question from the survey that asks the young person 'How many friends do you usually hang around with?' Respondents could choose from five categorical responses: none, one or two, between 3 and 5, between 6 and 10 or more than 10 .

\section{Cognitive tests}

In order to measure cognitive development in the 17-year-old cohort, three cognitive tests were completed by respondents, to capture vocabulary skills (vocabulary test), numerical skills (financial literacy test) and general knowledge (semantic fluency test).

The vocabulary test administered to the 17-year-old cohort was derived from the Millennium Cohort Study (MCS). The test consisted of 20 words which increased in difficulty throughout the task. Respondents were presented with a target word as well as five additional words and were tasked with choosing which of the five additional words was closest in meaning to the target word. The task had to be completed on paper and respondents were given a four-minute time limit.

The financial literacy test consisted of three short questions involving simple mathematical calculations. Respondents completed the task on paper and were given additional space on the page for any calculations. In contrast with the vocabulary and semantic fluency test, there was no time limit on this task.

The semantic fluency/animal naming test consisted of a minute-long task, where respondents were asked to list as many animals as they could. Respondents listed the animals out loud and responses were recorded by the interview using a Dictaphone and on paper.

\section{Drumcondra Reading Test}

Two assessments were conducted by interviewers in the home: these were the Drumcondra English reading test and a measure of selective attention (SAT) from the Test of Everyday Attention for Children $(1999,2001)$.

The Drumcondra reading test was developed for Irish schoolchildren and is linked to the national curriculum. For each 9-year-old, interviewers were instructed to administer the Drumcondra test level that corresponded to the child's last year of school. Prior to analysis, scores are adjusted according to class level and the child's age at administration, so that they are comparable across the different levels. Only the vocabulary part of the test was administered (for further details see McNamara et al., 2020a). 


\section{Test of everyday attention for children}

At nine years of age, children complete the selective attention subtest from the Test of Everyday Attention for Children (TEA-Ch: Manly et al., 1999, 2001). Selective attention is an aspect of cognitive control that enables more complex behaviours. The test requires children to search for small symbols (a knife and fork in this instance) on an A3 sized map. The child must ignore competing, distracting information on the map and circle as many of the target symbols as they can in one minute. There are 80 symbols to be found. The test is a measure of cognitive ability that is independent of accumulated knowledge, language skills or other training (for further details of the measure see McNamara et al., 2020a).

\section{Strengths and difficulties questionnaire (SDQ)}

The strengths and difficulties questionnaire (SDQ) (Goodman, 1997) provides details about the child or young person's socio-emotional and behavioural development. This instrument is designed for completion by the parents or teachers of children aged three upwards. The SDQ was completed for the 9-yearold ('08 cohort) and for the 17-year-old cohort. The SDQ consists of 25 items on five separate sub-scales, namely, emotional symptoms, conduct problems, hyperactivity/inattention, peer relationship problems and pro-social behaviour. ${ }^{22}$ Respondents indicate their level of agreement from 'Certainly true' and 'Somewhat true' to 'Not true', for all five items on these sub-scales. Scores on each subscale range between 0 and 10, and a total difficulties score, ranging from 0 to 40 , is obtained by summing scores across the four deficit-focused scales (i.e. all except the pro-social behaviour scale), so that higher scores indicate more problems. The total score can be analysed as a continuous variable or may be divided into categories that identify children most 'at risk', for example, those whose total score is in the top decile (tenth). By contrast, higher scores on the pro-social scale are indicative of more positive behaviours.

\section{Pianta Scale}

The Pianta child-parent relationship scale measures the quality of the caregiver's relationship with the child. The information was collected for the 9-year-old ('08 cohort) and for the 17-year-old cohort. The scale is a self-reported assessment completed by the child's PCG and secondary caregiver (SCG), which is used to measure perceived closeness and conflict in the child parent relationship. The conflict subscale includes questions on perceived relationship difficulties with the child, whereas the closeness subscale includes questions surrounding how well the parent or caregiver and their child get along. ${ }^{23}$ Respondents are asked to select the

\footnotetext{
22 The full set of items for different age groups, see Youthlnmind (2020).

${ }^{23}$ Example of statements 'I share an affectionate, warm relationship with my child' and 'My child and I always seem to be struggling with each other.'
} 
degree to which statements apply to their relationship with their child on a fivepoint scale: 'Definitely does not apply', 'Not really', 'Neutral', 'Not sure', 'Applies somewhat', and 'Definitely applies'.

\section{Social class}

The classification used by the GUI study to assign a social class to families was that used by the Irish Central Statistics Office (CSO). In line with standard procedures, in two-parent families in which both partners are working outside the home, the family's social class was assigned on the basis of the higher of the two occupations. The categories of this classification are as follows Professional Workers, Technical and Managerial, Non-manual, Skilled Manual, Semi-skilled, Unskilled and Other (i.e. no social class, as no current occupation or previous occupation if unemployed).

\section{Work intensity}

The measure of work intensity has been proposed by the European Commission. It is calculated from the employment hours of all working-age adults in the households. Very low work intensity means that working-age adults in the household are employed for less than one-fifth of the available hours. Workingage adults are defined as those aged 18 to 59, excluding full-time students under age 25. The percentage of available time worked is calculated as a percentage of 35 hours, which is regarded as full time for this purpose. Hours worked are available for the PCG and SCG only. For other adults of working age, we only know whether or not they are in employment. We assume that other adults are working full time for this measure and are not in education. 



\section{CHAPTER 3}

\section{Child economic vulnerability (EV) over time}

\subsection{INTRODUCTION}

In this chapter, we examine the rate of economic vulnerability, or those who are economically vulnerable (EV) found among the children and their families as they age, in the case of the younger cohort from 9 months to 9 years and in the case of the older cohort, from age 9 years to 17 years. We also examine trends in two of the component parts of being EV, namely, deprivation and economic stress. Drawing on previous research, we then develop a longitudinal profile of EV that summarises the patterns of vulnerability experienced by families over time. We then explore the characteristics that are associated with different patterns of EV, distinguishing especially between transient and more persistent exposure. ${ }^{24}$

\subsection{TRENDS IN ECOCONOMIC STRAIN, DEPRIVATION AND ECONOMIC VULNERABILITY IN EARLY, MIDDLE AND LATE CHILDHOOD}

How does the level of EV change over the two cohorts? In Figure 3.1, we present the proportion of the families in cohort ' 08 that experience economic strain at each wave and the mean levels of deprivation experienced. We do not include income quintile, as this is a relative measure, where the proportion in the lowest quintile remains constant in each wave, though the families who make up that group can change. The proportion of families experiencing difficulty or great difficulty in making ends meet rises from 10 per cent when the study child was 9 months old to 24 per cent when the child was 5 years old. The level subsequently dropped to 12 per cent when the child was aged 9 years. A similar pattern is observed for levels of material deprivation and for our latent measure of EV. Economic vulnerability increases from 18 per cent at 9 months to 25 per cent at 3 years and to a peak of 28 per cent when the study child was aged 5 years; it then drops back to 18 per cent. While the measure of EV used by Watson et al. (2014) differed slightly, they found a similar level of EV and an increased pattern from 19 per cent to 25 per cent between the age of 9 months and 3 years.

As noted in Chapter 2, the economic situation changed dramatically over this period. The unemployment rate was just under 7 per cent in wave 1 but stood at 15 and 14 per cent in waves 2 and 3, before falling back to 6.5 per cent at wave 5 . Economic vulnerability continued to grow even when unemployment had stabilised, albeit at a high level. It is likely that households had depleted any initial

\footnotetext{
${ }^{24}$ In the report, we sometimes refer to EV as poverty, as this is our preferred measure of poverty for this analysis. We also use the term 'persistent poverty' to make reference to persistent EV or always EV.
} 
resources, such as savings, in the early part of the recession. Additionally, studies on household income across all age groups show that the average household disposable income continued to fall until 2012 (Savage et al., 2015) and in 2013, it was 14 per cent lower than in 2009. For working-age families, the years 2010 to 2013 saw a number of significant increases in taxation and cuts to benefits, including child benefit (Bargain et al., 2015).

\section{FIGURE 3.1: ECONOMIC STRESS AND DEPRIVATION DURING EARLY CHILDHOOD ('08 COHORT)}

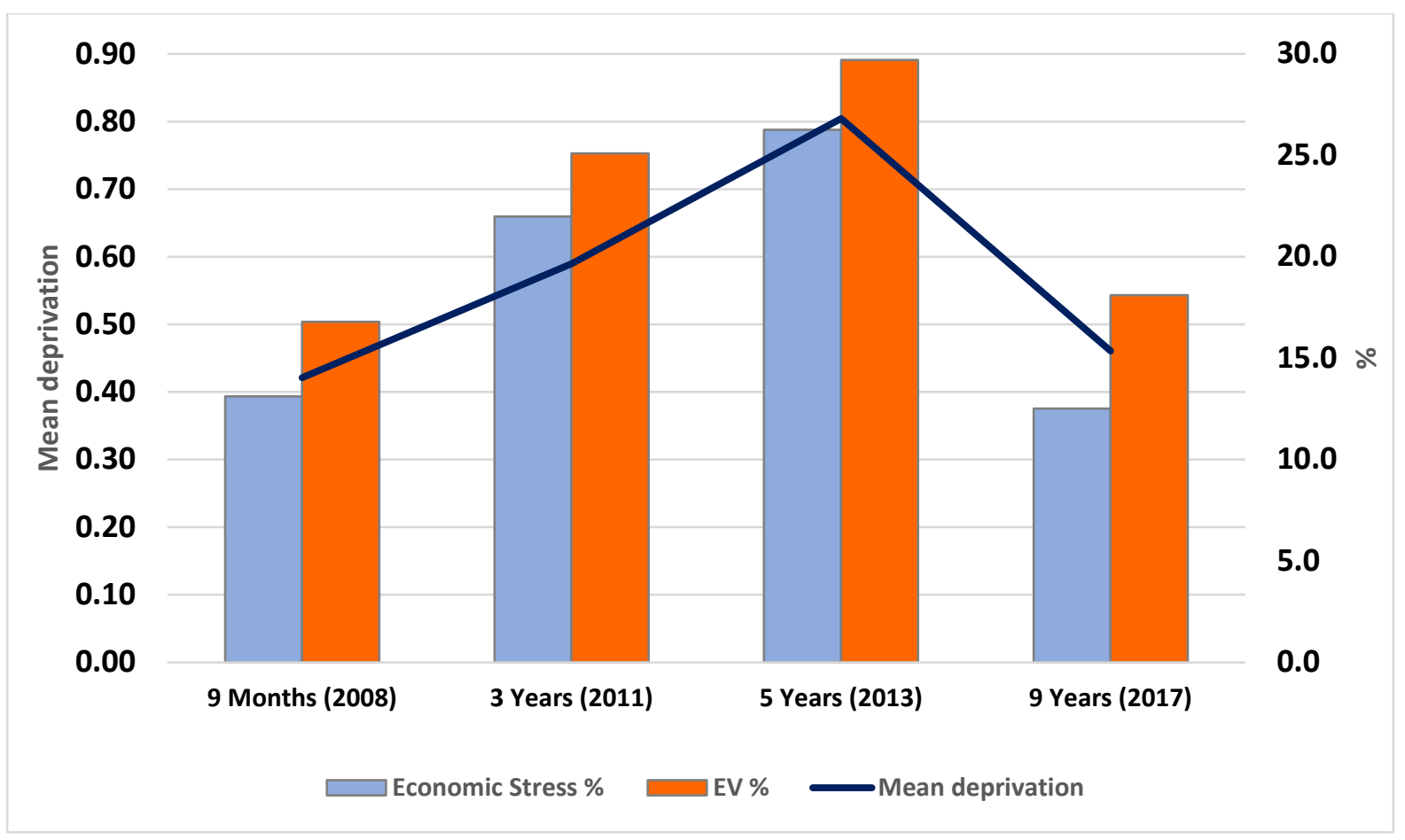

Note: $\quad$ GUI '08 cohort, w1, w2, w3, w5. Longitudinal sample N=7507, weighted by longitudinal weight.

The same trends are noticeable for the families in the older cohort. As noted in Chapter 2, the fieldwork for the first wave of data collection began in 2007, before the Great Recession; wave 2 was collected in 2011-2012, in the midst of the recession; and wave 3 was collected in 2017, when the economy was in recovery and unemployment was falling, though it had not returned to the very low levels seen in 2007. 
FIGURE 3.2: ECONOMIC STRESS, DEPRIVATION AND ECONOMIC VULNERABILITY IN MID TO LATE CHILDHOOD ('98 COHORT)

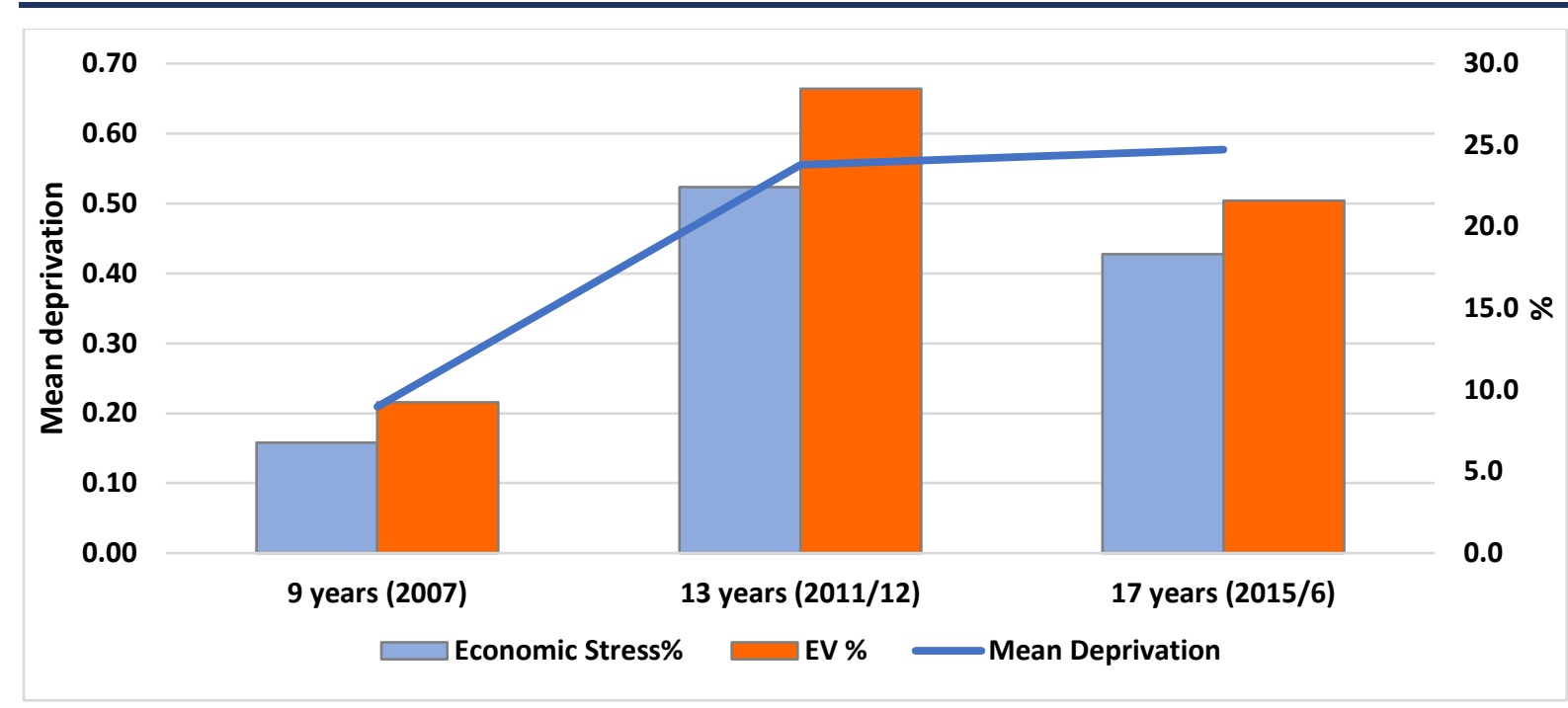

Sample: GUI '98, w1,w2, w3, longitudinal sample, weighted by longitudinal weight

\subsection{PROFILE OF ECONOMIC VULNERABILITY OVER TIME}

Following the work of Fouarge and Layte (2005) and Watson et al. (2014), we develop a profile of EV based on exposure over all available waves of the GUI data. In the absence of information between waves, it is possible that the families of both cohorts experience poverty transitions that could affect our classification. We first profile EV in early to middle childhood, 9 months to 9 years, using four waves of the ' 08 cohort. Families are divided into four categories:

1. Never EV: consists of those who were never EV across the four waves,

2. Once/Transient EV: consists of those who were EV for one of the four waves or who were EV more than once but never in two consecutive waves.

3. Persistently EV: consists of those who were EV in at least two consecutive waves.

4. Always EV: consists of those who were EV in all four waves.

The profile of families over this 9-year period show that 44 per cent experienced $\mathrm{EV}$ in at least one wave, meaning that childhood exposure to poverty is relatively common for this cohort. In half of these cases, the vulnerability is transient (22 per cent). This is mostly composed of those who are EV once over the four waves (19 per cent) rather being EV in recurrent spells ( 3 per cent). The remaining 22 per cent of families are persistently or always EV. Five per cent of children are (EV) in every 
wave. ${ }^{25}$ In order to avoid small cell sizes, we group the persistent and always categories in the following figures, though where possible, they are distinguished in chapter five when we examine child outcomes.

\section{TABLE 3.1: PERSISTENCE OF ECONOMIC VULNERABILITY ('08 COHORT)}

\begin{tabular}{|l|c|c|}
\hline & N (unweighted) & \% (weighted) \\
\hline Never EV & 4,639 & 55.5 \\
\hline Once/Transient EV & 1,483 & 21.8 \\
\hline Persistent EV & 1,105 & 17.4 \\
\hline Always EV & 280 & 5.4 \\
\hline Total & 7,507 & 100.0 \\
\hline
\end{tabular}

Sources: GUI '08 cohort, w1, w2, w3, w5.

Note: Longitudinal sample.

For the ' 98 cohort, there are currently only three waves of data available: 9 years, 13 years and 17 years. Therefore, the measure of persistence must differ somewhat. In this case we distinguish between four groups of families:

1. Never EV: those that experience no EV.

2. EV once: those $E V$ once over the three waves.

3. Persistently EV: those EV in two of the three waves.

4. Always EV: those EV in all three waves.

We find that in the older cohort, a higher proportion of families (62 per cent) avoid EV over the whole period from when the study child is aged 9 to age 17. This lower exposure to any vulnerability may arise because of the slightly shorter period and fewer data waves, or it may reflect a greater resilience to EV among families with older children. Moreover, Tables A3.1 and A3.2 in the Appendix show that there was overall a greater proportion of primary caregivers (PCG) at work and a lower proportion of families in low work intensity households among the older cohort than in the younger cohort. Both cohorts experienced the unprecedented economic shock of the Great Recession. Similar to the younger cohort, over half the spells of EV were one-off. As with cohort' 08 , just under 5 per cent of the cohort were always EV.

\footnotetext{
${ }^{25}$ By way of comparison, 8.2 per cent of the Millennium Cohort Families are always in income poverty in the first 4 waves from birth to age 7 .
} 


\begin{tabular}{l|c|c|}
\hline & N (unweighted) & \% (weighted) \\
\hline Never EV & 4,200 & 61.9 \\
\hline EV once & 1,148 & 21.5 \\
\hline Persistent EV (any 2 of 3 years) & 500 & 12.0 \\
\hline Always EV & 191 & 4.6 \\
\hline Total & 6,039 & 100.0 \\
\hline Sources: GUI ‘98 cohort, w1, w2, w3. & & \\
Note: & & \\
\hline
\end{tabular}

While using fewer waves of data for the ' 08 and ' 98 cohorts, Watson et al. (2014) found a similar pattern of EV persistence, where only a minority of children were EV all the time.

\subsection{ECONOMIC VULNERABILITY PROFILES BY SOCIAL CHARACTERISTICS OF FAMILIES OF THE COHORT ‘08}

Here we examine how the experience of EV in childhood is distributed across different social groups. The analysis addresses which families, children and young people are most exposed to persistent or permanent vulnerability and considers whether the same groups are at risk of more transient vulnerability or whether this affects different populations. In the later chapters, we explore whether these different exposures influence child outcomes.

The results presented in the following set of charts (Figure 3.3 to Figure 3.12) for both cohorts are based on bivariate analysis and therefore do not control for other individual and household characteristics. In section 3.4.2, we present results based on multivariate analysis controlling for some of these characteristics.

In Figure 3.3, we look at the EV profile by family structure. Lone-parent families are much more likely to experience long-term poverty. Among lone parents with 2 or more children, 34 per cent were persistently EV and a further 24 per cent were poor in every wave. Lone parents with one child also had high rates of persistent EV (28 per cent) but were less than half as likely as those with more children to have been always EV (11 per cent). Analysis of transitions can help us to untangle if this is because additional children and the consequent increase in economic needs for the family increase entries into $\mathrm{EV}$, or if it is because it makes transitions out of EV more difficult.

Two-parent families are much less likely to have experienced any EV over the whole period - 69 per cent of those with one child and 57 per cent of those with more than one child have no experience of EV. One spell of EV is relatively common among two-parent families, affecting 17-18 per cent of the group over the 4 waves from 9 months to 9 years. This is consistent with previous findings that one-off poverty is much more widely distributed than repeated or persistent poverty (see 
Chapter 1) and therefore snapshots of poverty at one point in time are likely to present a different view of the risk groups compared to a longitudinal approach.

The size of each household type category at each wave is outlined in Appendix Table A3.1. The proportion of one-parent families fluctuates between 15 and 17 per cent: those with one child account for 7 per cent of families on average, while lone parents with two or more children account for 9 per cent on average. ${ }^{26}$

FIGURE 3.3: LONGITUDINAL ECONOMIC VULNERABILITY PROFILE BY HOUSEHOLD STRUCTURE ('08 COHORT)

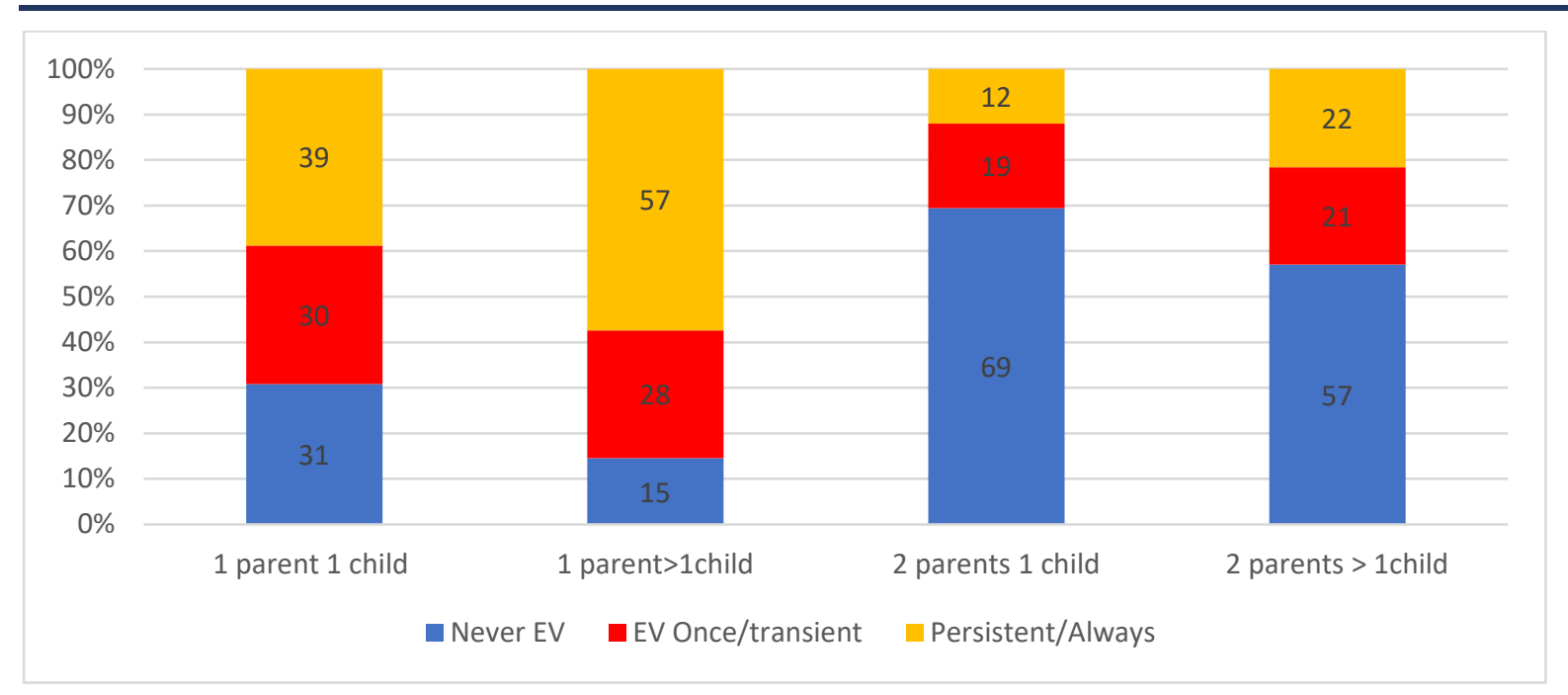

Note: $\quad$ GUI ‘08 cohort, w1, w2,w3, w5, longitudinal sample

Long term exposure to EV in early childhood is highly stratified by social class. Among those in the 'no class category' at wave 1, 60 per cent were persistently or always EV ( 35 per cent were persistently EV and 25 per cent always). This group consists predominantly of families where the parents have no current or previous employment on which to evaluate their class position. The proportion of families that are persistently or always EV falls to less than 10 per cent for the professional/managerial social class.

\footnotetext{
${ }^{26}$ Fahey et al. (2012) note that, if we consider the proportion of all children in different household types, we get a different answer. They calculate that 25 per cent of 9 -year-old children in the ' 98 cohort live in families with 4 or more children.
} 
FIGURE 3.4: LONGITUDINAL ECONOMIC VULNERABILITY PROFILE BY HOUSEHOLD SOCIAL CLASS W1 ('08 COHORT)

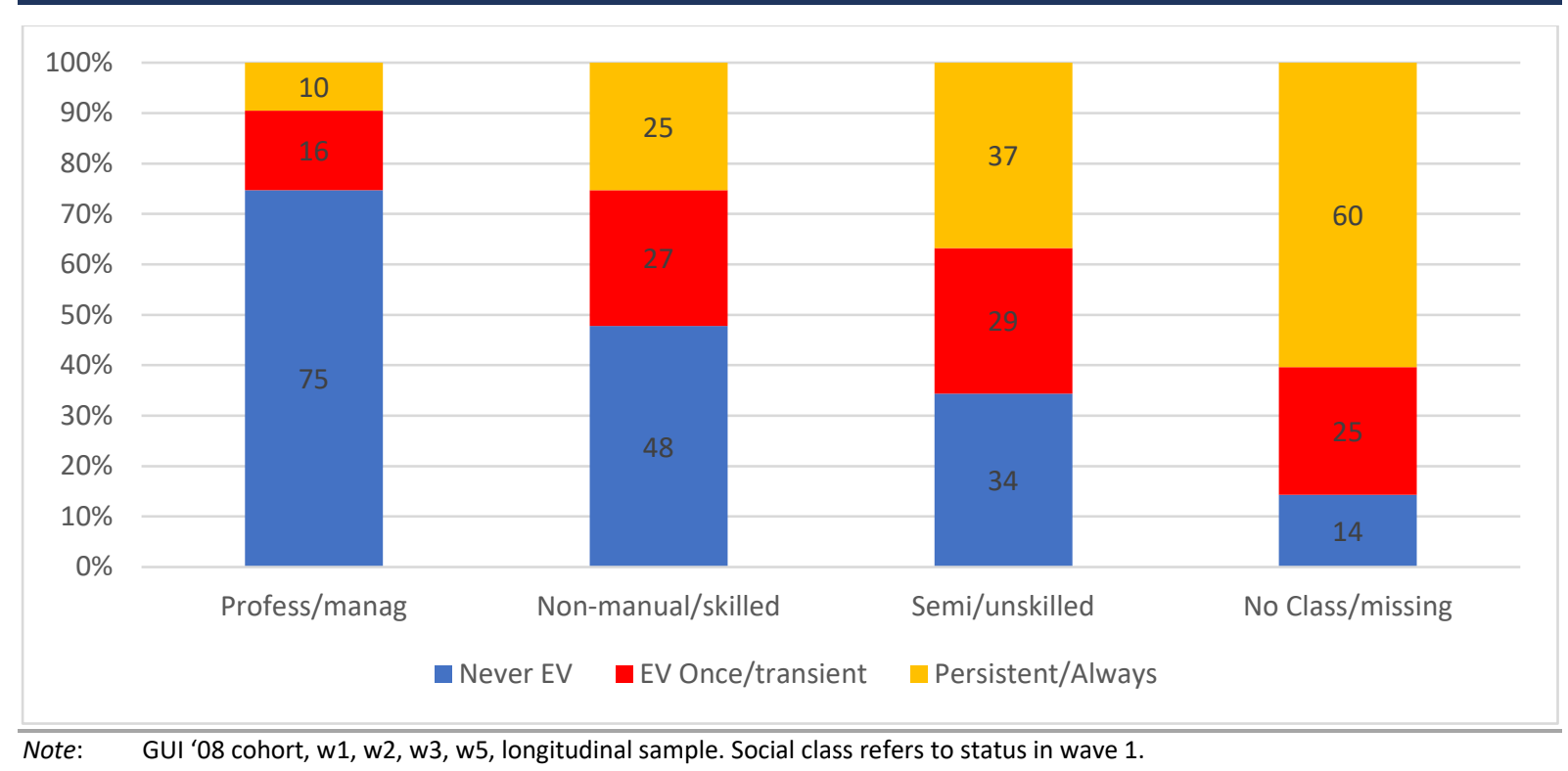

A similar gradient is observable using the mother's education as an indicator of socio-economic background (Figure 3.5). Only 27 per cent of families where the mother has lower second-level education avoided EV entirely over the 4 waves, compared to 78 per cent of families where the mother is educated to degree level. As with the other indicators, we see a significant proportion of more advantaged families experiencing a one-off spell of poverty over the period, while differences across educational groups are more pronounced for persistent/always vulnerability.

FIGURE 3.5: LONGITUDINAL ECONOMIC VULNERABILITY PROFILE BY MOTHER'S EDUCATION W1 ('08 COHORT)

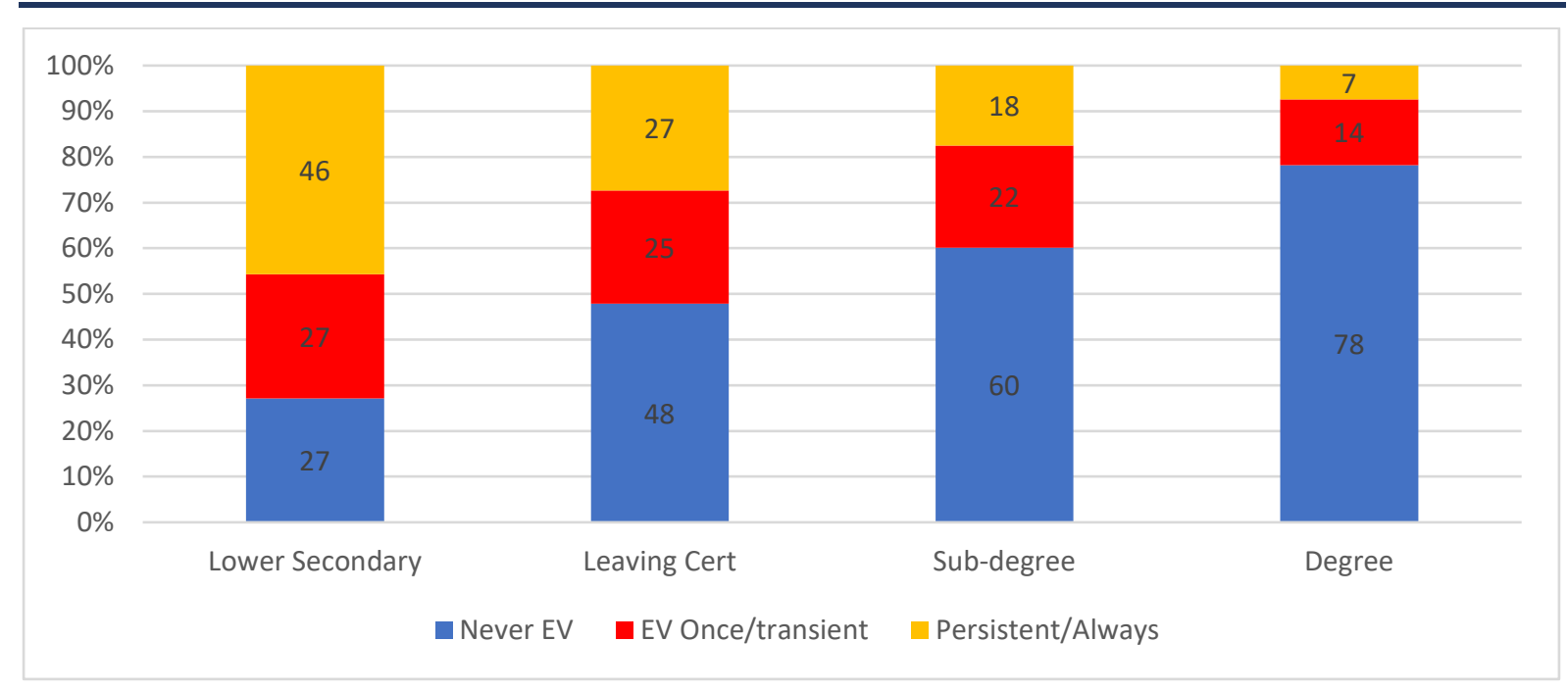

Source: GUI '08 cohort, w1,w2, w3, w5, longitudinal sample. 
Exposure to EV is also patterned by ethnicity and nationality. Those of black ethnicity are most at risk of long-term EV - 58 per cent were always or persistently $\mathrm{EV}$. This compares to 22 per cent for the white ethnic group. Travellers are included in the white ethnic group, as there are too few of them to be examined separately. However, as a group, they experience exceptionally high levels of poverty and deprivation (Watson et al. 2017). Nationality has a weaker association with EV; nevertheless, 57 per cent of Irish nationals never experienced EV compared to 46 per cent of those of other nationalities.

FIGURE 3.6: LONGITUDINAL ECONOMIC VULNERABILITY PROFILE BY MOTHER'S NATIONALITY \& ETHNICITY W1 ('08 COHORT)

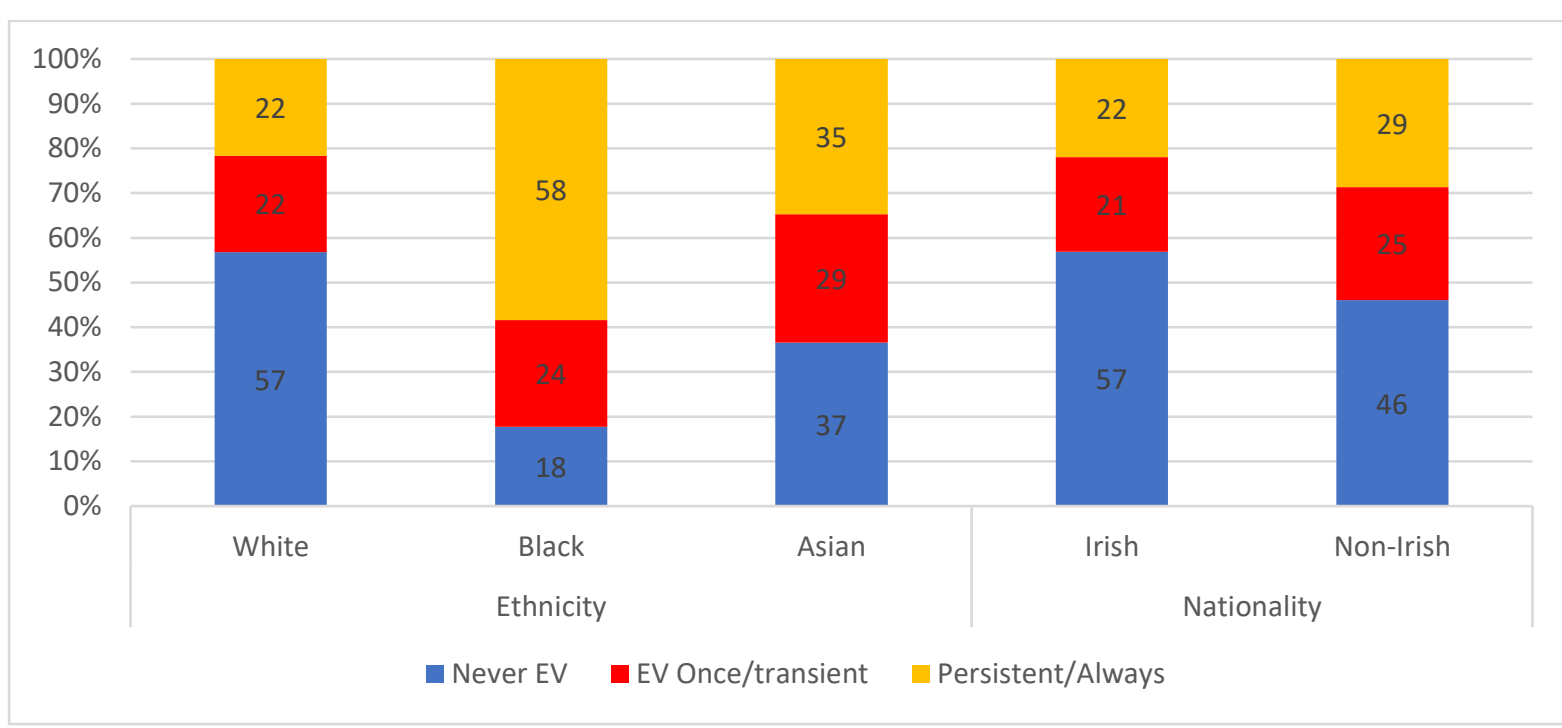

Source: $\quad$ GUI ‘08 cohort, w1, w2, w3, w5, longitudinal sample.

Finally, we look at the relationship between employment status and exposure to EV in early and middle childhood. In families where the mother was employed at the first interview, over two-thirds are never EV (Figure 3.7). In contrast, where the mother was not employed in wave 1, only 40 per cent were never EV. ${ }^{27}$ Maternal employment changes substantially in the early years of child-rearing. Previous research based on the GUI shows that the proportion of mothers employed rises from 46 per cent when the study child is 9 months to 59 per cent when the child is 5 years. Moreover, there are multiple entries and exits and changes in the paid working hours of mothers over these years (Russell et al., 2018). Therefore, the relationship between maternal employment and child EV needs to be explored using a more dynamic framework. This is done in Chapter 4.

27 Due to small numbers, we cannot present the detailed employment status categories here, so instead we group all nonemployment statuses together (family care, unemployment, unable to work due to illness or disability). More detail is included in the model. 
FIGURE 3.7: LONGITUDINAL ECONOMIC VULNERABILITY BY MOTHER'S EMPLOYMENT STATUS W1 AND HH WORK INSTENSITY W1 ('08 COHORT)

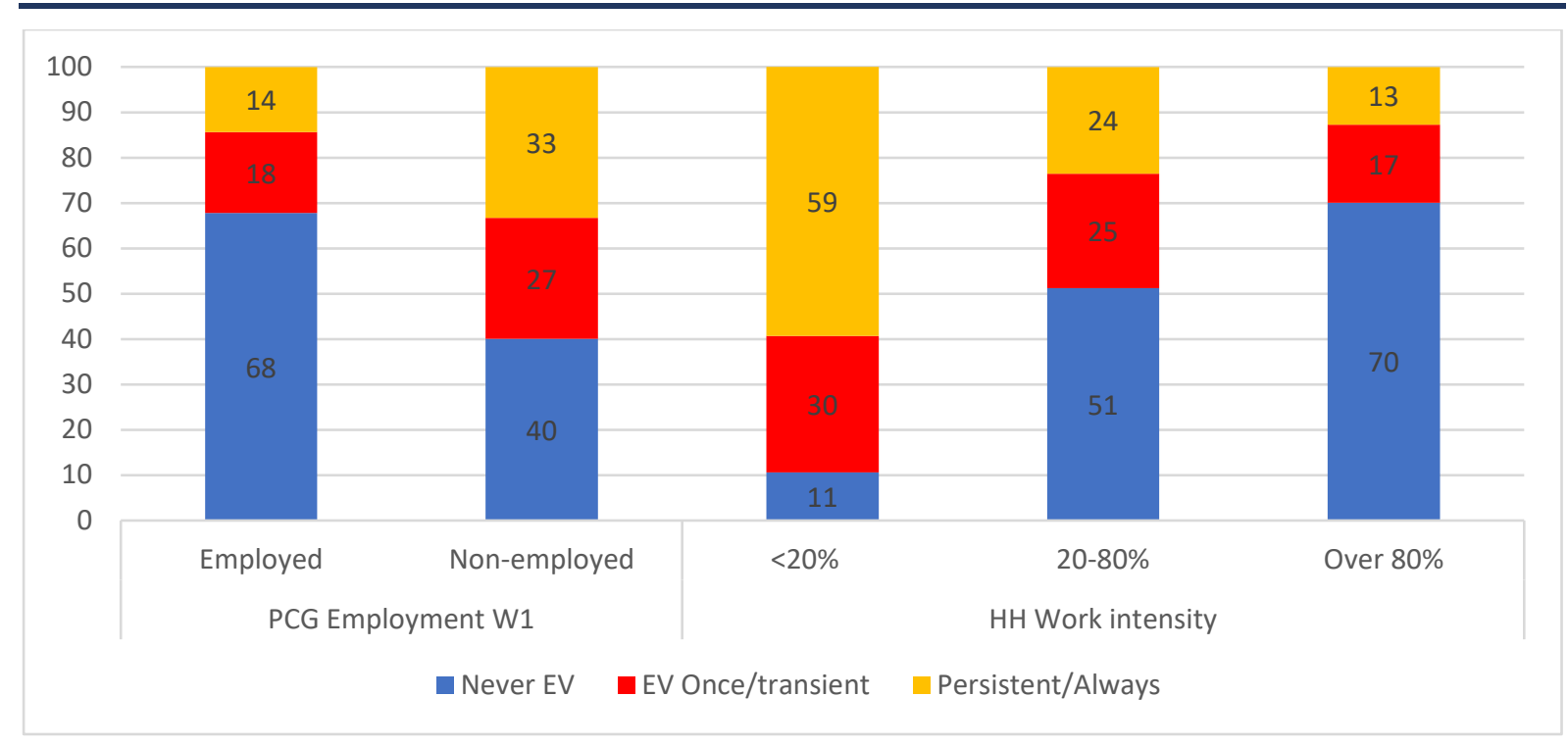

Source: GUI '08 cohort, w1, w2, w3, w5, longitudinal sample.

The economic wellbeing of children is influenced by the employment status of fathers as well as mothers, and in some cases of other household members. Therefore, in Figure 3.7 we also explore the relationship between EV and household work intensity. This measure captures the extent to which adults of working age are in paid employment as a proportion of potential working hours (a description of the measure is outlined in Chapter 2). Here, we compare those with 'very low work intensity', where this proportion is less than $20 \%$, to high work intensity, where those of working age are employed for $80 \%$ or more of the available time. For the purposes of this description, we focus on the situation at wave 1 , when the study child was 9 months. Families with very low work intensity at the first interview go on to experience persistent EV over the course of the next 9 years: 59 per cent of these families are always or persistently vulnerable.

\subsubsection{Economic vulnerability (EV) profiles in middle to late childhood (cohort ‘98)}

Are the same factors associated with persistent EV in later childhood as in early childhood? To answer this question, we repeat the analysis for the ' 98 cohort. Given the small proportion of families in the always EV group, we combine the 
persistent and always categories in the graphs, to indicate those vulnerable in at least two of the three years. ${ }^{28}$

As with the younger cohort, family structure is associated with persistence of vulnerability. Among lone parents, 31 per cent of those with one or two children and 41 per cent of those with three or more children are persistently poor. Less than 15 per cent of couple households fall into this category.

FIGURE 3.8: LONGITUDINAL ECONOMIC VULNERABILITY PROFILE BY HOUSEHOLD STRUCTURE W1 ('98 COHORT)

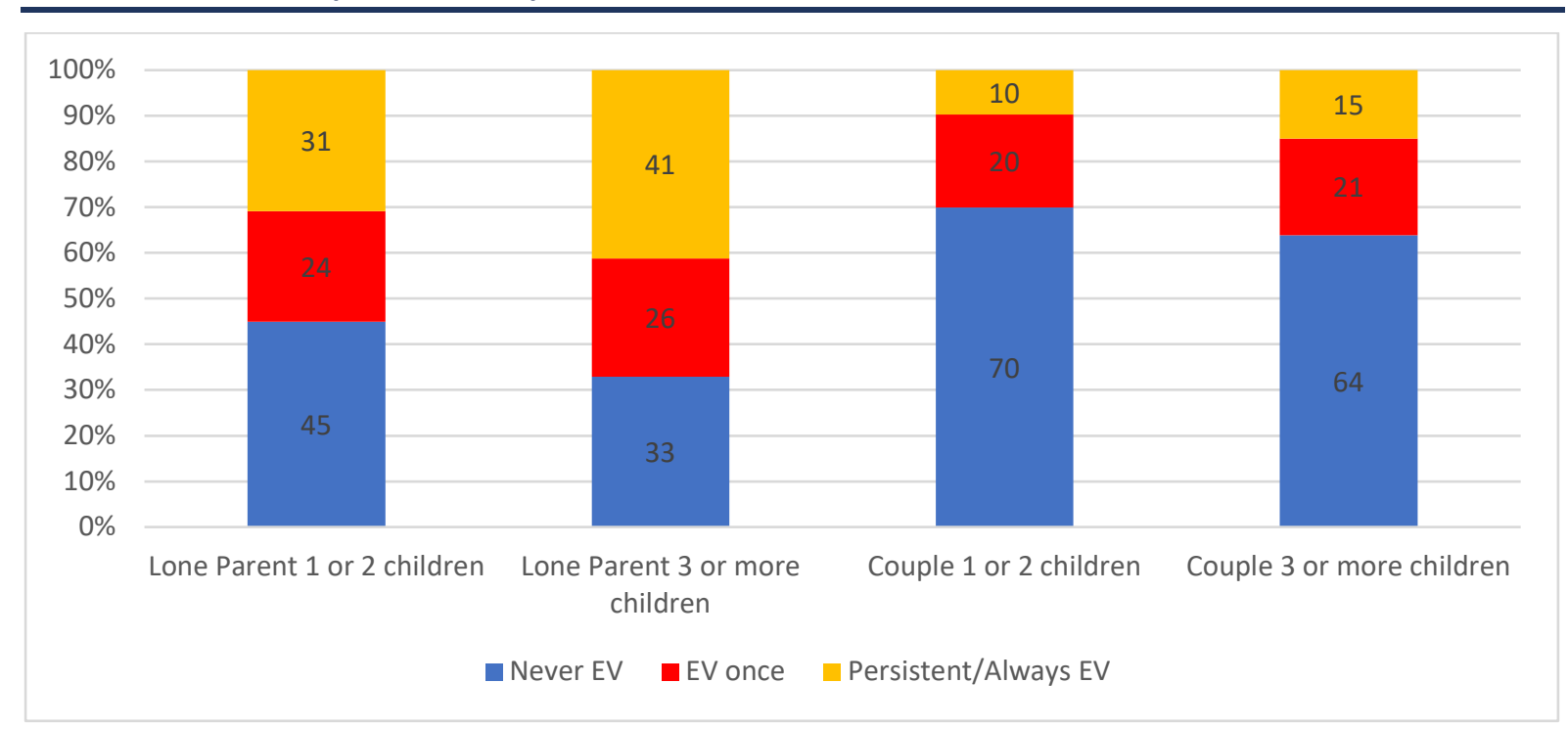

Source: $\quad$ GUI '98 cohort, w1, w2, w3 longitudinal sample.

Household social class is again a strong predictor of EV persistence (Figure 3.9). Three-quarters of those in the professional/managerial class are never EV and only 8 per cent of the group are persistently vulnerable. Persistent vulnerability affects 28 per cent of the semi/unskilled class and 45 per cent of those who could not be allocated a social class due to a lack of employment history. The same pattern can be seen in Figure 3.10, which shows a strong gradient in persistent vulnerability by the mother's education.

${ }^{28} \mathrm{CSO}$ data rules for GUI restrict the presentation of cells with fewer than 30 cases. 
FIGURE 3.9: LONGITUDINAL ECONOMIC VULNERABILITY PROFILE BY HOUSEHOLD SOCIAL CLASS W1 ('98 COHORT)

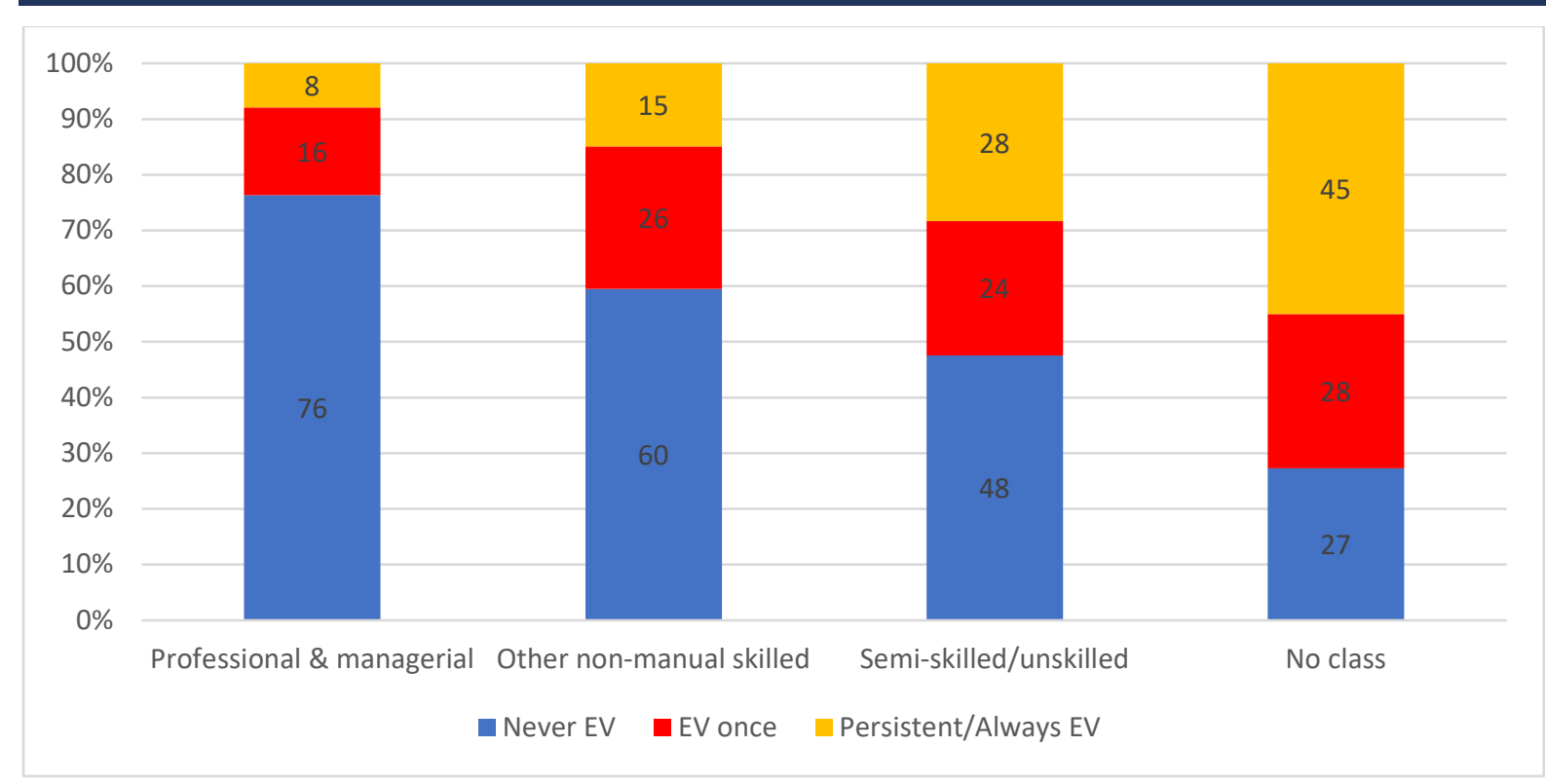

Source: GUI ‘98 cohort, w1, w2, w3 longitudinal sample.

FIGURE 3.10: LONGITUDINAL ECONOMIC VULNERABILITY PROFILE BY MOTHER'S EDUCATION W1 ('98 COHORT)

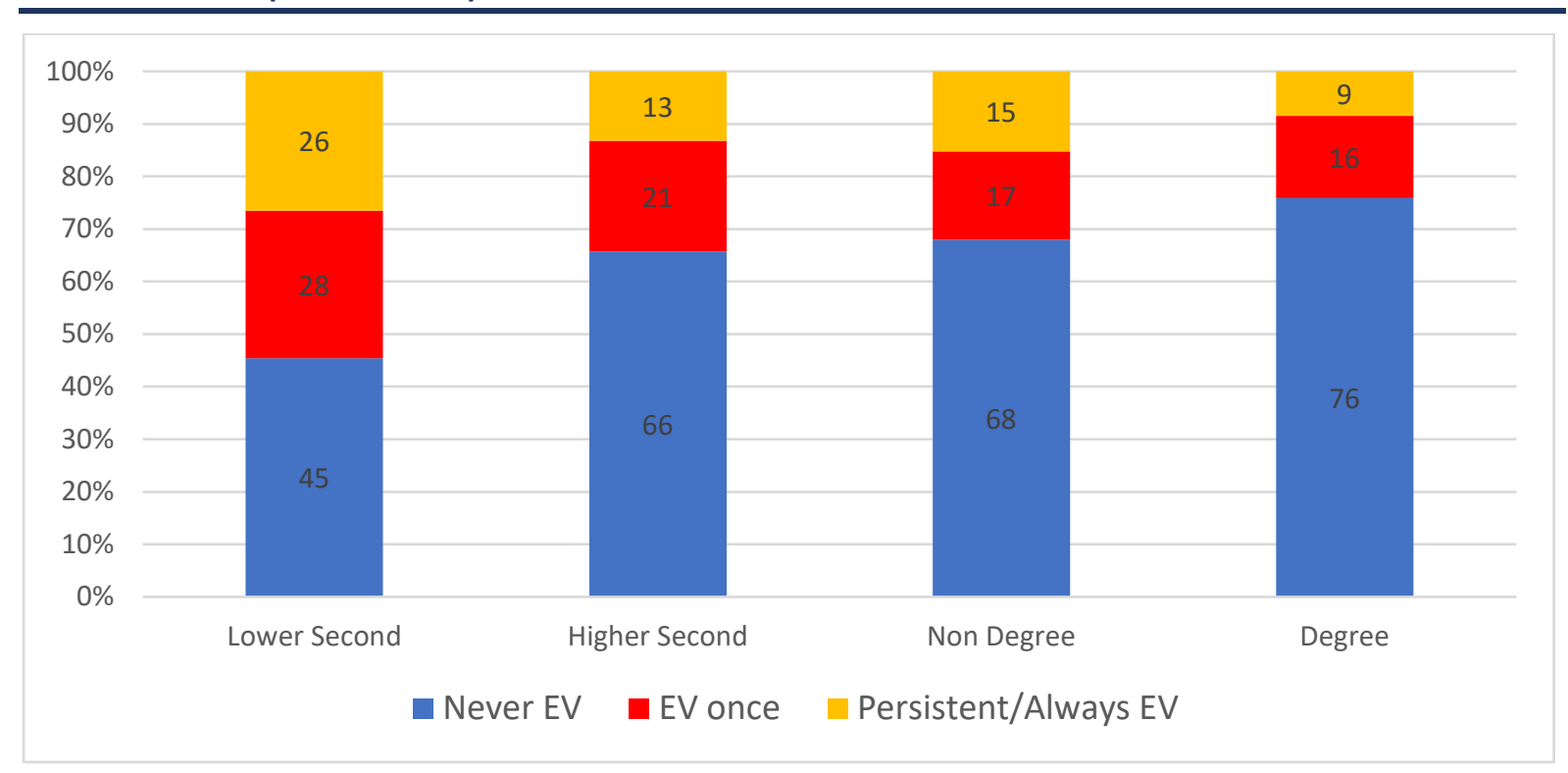

Source: GUI ‘98 cohort, w1, w2, w3 longitudinal sample.

The difference in (the mother's) nationality is somewhat wider than that observed for the younger cohort (Figure 3.11): 16 per cent of Irish nationals are persistently EV compared to 26 per cent of those of another nationality. The difference between the cohorts may reflect the timing of migration or compositional 
differences between families in the two cohorts. There are fewer respondents from ethnic minority backgrounds in the ' 98 cohort, so it is not possible to provide descriptive statistics for separate groups. Among families where the mother is from an ethnic minority, 42 per cent are persistently EV compared to 16 per cent of the majority white group.

FIGURE 3.11: LONGITUDINAL ECONOMIC VULNERABILITY PROFILE BY MOTHER'S NATIONALITY \& ETHNICITY W1 ('98 COHORT)

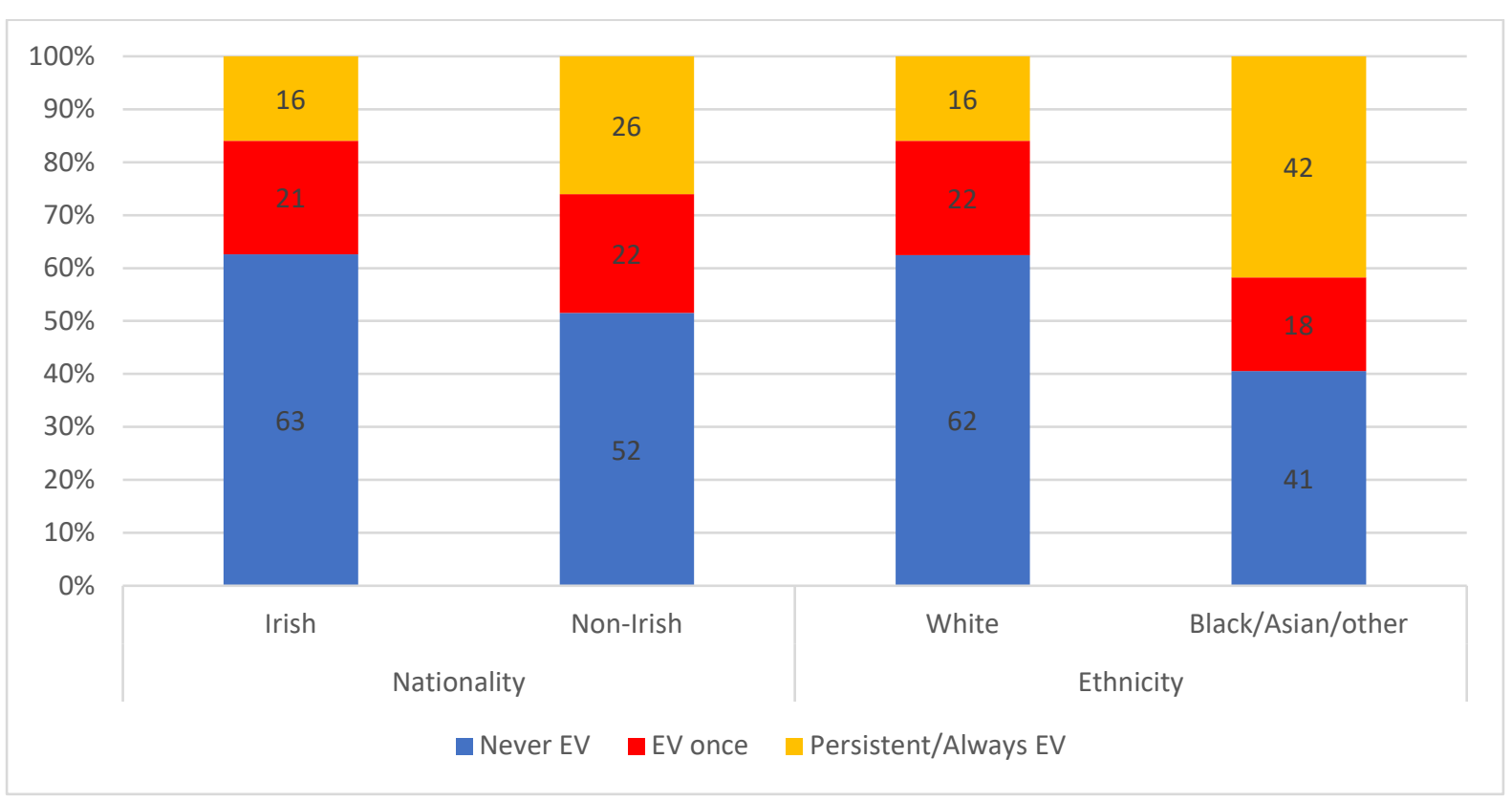

Source: GUI ‘98 cohort, w1, w2, w3 longitudinal sample.

Finally, we consider the labour market situation of families in the first wave of the survey, when the study child was aged 9. Due to small numbers, we cannot present the detailed employment status categories here, so instead we group all nonemployment statuses together (family care, unemployment, unable to work due to illness or disability). More detail is included in the model. More than two-thirds of families where the mother is employed in wave 1 are never vulnerable over the entire period. In families where the mother is not employed, this figure falls to half (Figure 3.12). Households with low work intensity in wave 1 have a very high risk of remaining EV throughout the period; just under half the very low-work intensity group are persistently vulnerable. The mother's employment is part of this story, but in order to understand persistent exclusion, we need to consider both the composition of the household and the employment situation of all adults present. 
FIGURE 3.12: LONGITUDINAL ECONOMIC VULNERABILITY PROFILE BY HOUSEHOLD WORK INTENSITY AND MOTHER'S EMPLOYMENT STATUS W1 ('98 COHORT)

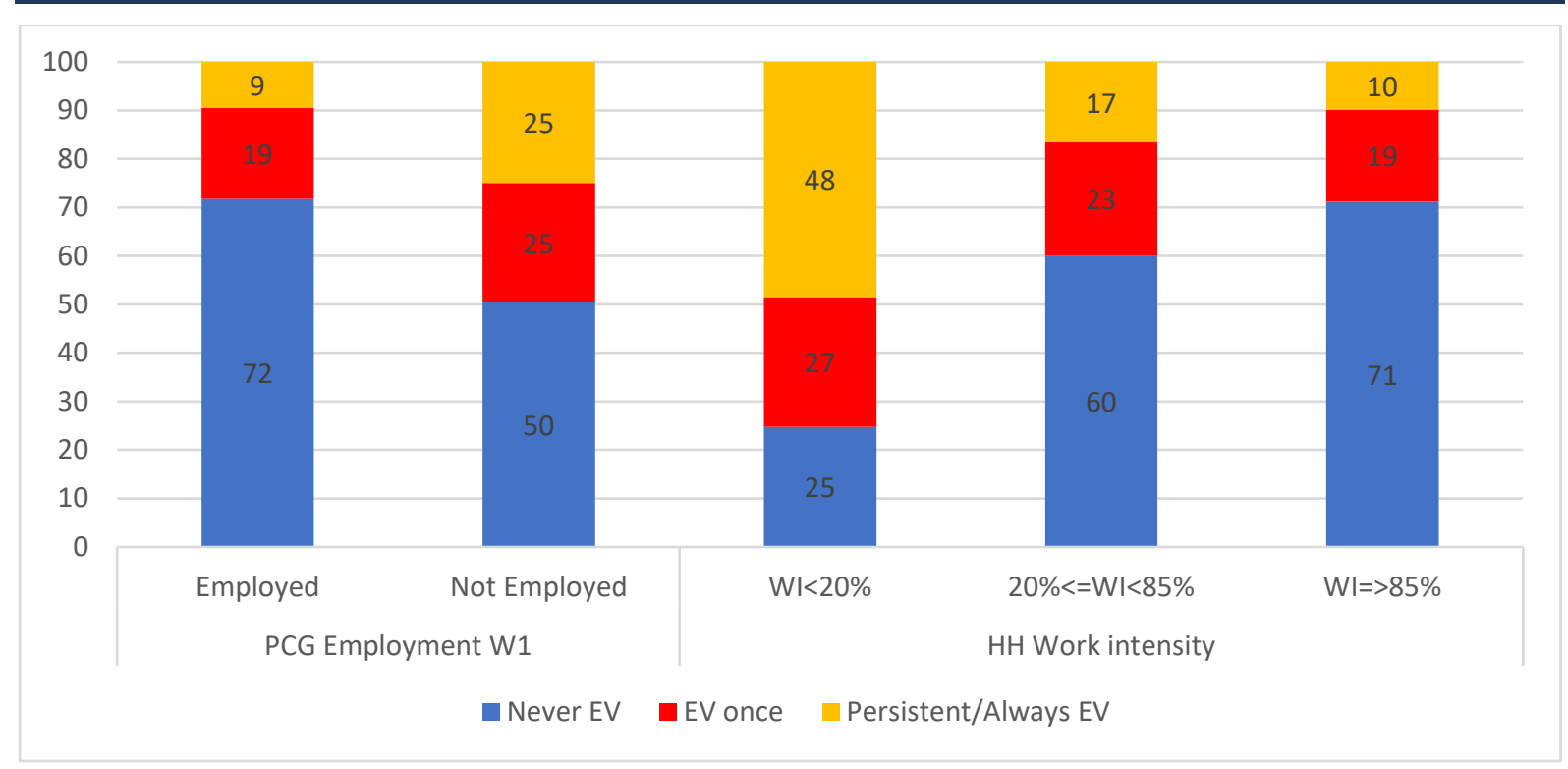

Source: $\quad$ GUI ‘98 cohort, w1, w2, w3 longitudinal sample.

Overall, comparing these patterns of results with those from Watson et al. (2014), there are many similarities. For both cohorts, Watson et al. (2014) also found a strong gradient in the composition of persistent $\mathrm{EV}$ with an over-representation of one-parent families and mothers with low education level, for example.

As with the younger cohort, transitory vulnerability is much more widespread than persistent vulnerability. In many of the graphs, the proportion experiencing a oneoff spell of vulnerability is quite similar across social groups, while persistent vulnerability and avoiding vulnerability throughout the period is much more socially structured. This shows that the risk of poverty is experienced by a relatively wide cross-section of families, but that there is a set of social factors leading to some families being more likely to become trapped in poverty. We explore this question in greater detail in the models of transient and persistent $\mathrm{EV}$ and in the analysis of entry and exit from EV in the next chapter.

\subsubsection{Models of longitudinal EV risk}

The characteristics examined above often intersect within households. Therefore, to get a sense of the relative influence of these factors on the persistence of EV, we estimate multivariate logit models with three economic vulnerable outcomes (never, transient/once, persistent) and we report the risk of falling into each of the last two categories compared to the first one.

The results are presented as odds ratios, that is, the risk of falling into the transient/once or persistent economic vulnerable categories, rather than the 
never EV category for each group. The odds ratios range from 0 to plus infinity, that is, there are no negative values. Values between 0 and 1 mean that the risk of being persistently or transient EV is less than for the reference group, while values over 1 mean indicate an increased relative risk. A value of 1 means that the relative risk is the same as for the reference group. ${ }^{29}$

The first two columns in Table 3.3 present the results for the ' 08 cohort and refer to the period when the study child was aged between 9 months and 9 years.

Family structure is an important predictor of EV, especially persistent EV. The odds ratio of persistent EV are 5.4 times higher for lone-parent families than two-parent families. Large families also bear a greater risk of EV, especially persistent EV. The risks of transient poverty increase for families with three or more children. There is a more linear increase in the risk of persistent EV with family size. Among large families with four or more children the odds ratio is three times higher for persistent poverty relative to families with only one child.

29 The odds ratio summarises the inequality of exposure to an outcome between two groups, one being a reference group. It is the ratio of two odds. Taking persistent vulnerability as an example and partnership as a variable, in Table 3.3 we present the odds ratio for being persistently vulnerable rather than being non-persistently vulnerable for those having no partner rather than having a partner. 
TABLE 3.3: MULTINOMIAL REGRESSION MODEL OF FACTORS ASSOCIATED WITH TRANSIENT AND PERSISTENT ECONOMIC VULNERABILITY (ODDS RATIOS)

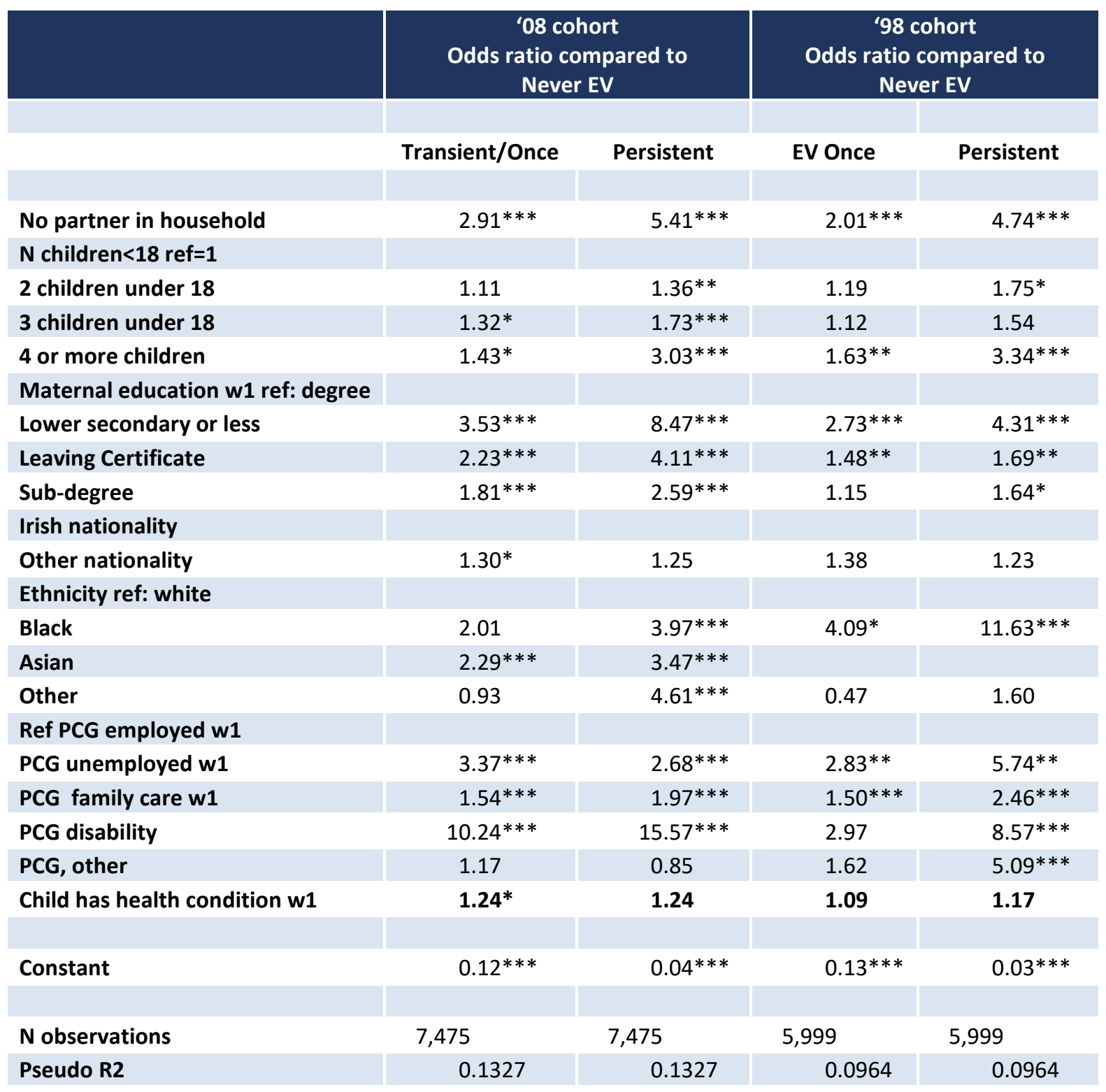

Source: GUI '08 cohort, w1 w2 w3 w5; '98 cohort, w1, w2, w3.

Notes: $\quad *<.05 * *<.01 * * *<.001$.; In the '98 cohort, 'Other ethnicity' includes Asian. For the '08 cohort, persistent poverty = always EV or EV in at least 2 consecutive waves. For the '98 cohort, persistent poverty = always EV or EV 2 of 3 waves.

Social origin as indicated by the mother's educational level is strongly associated with the risks of both transient and persistent EV, even when the mother's employment is held constant, though persistent poverty is more socially stratified than transient poverty. Low educational level of the mother is the second strongest predictor of persistent EV for this age group, leading to an 8.5-times increase in the odds ratio. It should be noted that this is the direct effect of social background, which will also have an indirect influence through family structure, employment and child health. 
Non-Irish nationality is associated with an increase in transient but not persistent EV. Ethnicity is a significant predictor of both transient and persistent EV among the younger cohort. Those of Asian ethnicity have a higher risk of transient EV, while the black and other ethnic groups have a higher odds ratio of persistent poverty.

The mother's employment status in wave 1 , when the child was 9 months old, is a highly significant predictor of both transient and persistent EV. The model allows us to differentiate between different types of non-employment and reveals that the mother's inability to work due to illness or disability is the strongest predictor of both transient and persistent EV. While this is a small group (circa 1 per cent of families in wave 1), their very high risk of poverty is of policy concern. Involuntary unemployment among mothers at wave 1 is more strongly associated with transient and persistent EV than family care, but the latter is nevertheless associated with a heightened risk.

We also add a variable to test the effect of a disability or chronic illness of the child on household EV, as disability can lead to additional household costs. We find a somewhat higher rate of transient EV among these families but there is no significant relationship with persistent $\mathrm{EV}$.

As with the descriptive graphs, the analysis shows that risk of being persistently EV is more highly stratified than the risk of transient $\mathrm{EV}$, as the odds ratios for different groups are substantially larger.

The same analysis is repeated for the older ' 98 cohort and these results are presented in columns 3 and 4 of Table 3.3. By and large, the patterns found for the younger cohort are replicated. The strongest predictors of persistent EV are the mother's disability or unemployment at wave 1 (in this case at 9 years), minority ethnic status, lone parenthood, low maternal education and large family size (4 or more children).

However, there are a number of differences worth noting. Firstly, the relationship between family size and EV appears to be less linear among the older cohort of children, though the odds ratio for those with four or more children is very similar for both cohorts. We find that the proportion of those in bigger families is much larger in the ' 98 cohort, as this is more likely to capture the final family size than wave 1 of the ' 08 cohort. ${ }^{30}$ Overall, 22 per cent of families in the ' 98 cohort have 4 or more children under 18 compared to 7 per cent in the ' 08 cohort, which means that in terms of size, the vulnerable group is much bigger in middle childhood to early adulthood. Given that family size changes over time, we look explicitly at the effect of new births in the analysis of poverty transitions in the next chapter.

\footnotetext{
${ }^{30}$ As the number of children is defined as the number under 18 , this measure does not fully capture larger families with adult children living at home.
} 
Secondly, persistent vulnerability is less strongly linked to the mother's education for the ' 98 cohort compared to the ' 08 cohort. This is possibly an earnings effect. There is a very strong relationship between earnings and maternal employment in early childhood, due in part to high childcare costs (Russell et al., 207), and it is likely that this is weaker for mothers with older children. Thirdly, membership of the black ethnic group is more strongly related to the odds ratio of transient and persistent EV in middle childhood to early adulthood. For the older cohort, the Asian group is too small a group to examine separately, so it is included with other ethnic minority groups; this group does not have any higher risk of transient or persistent EV.

\section{Summary}

This chapter has profiled the experience of EV among families from infancy to middle childhood and from middle childhood to late childhood. Over the 8-9 years covered by the two cohorts, the experience of EV was relatively common, with 44 per cent of the younger cohort and 38 of the older cohort experiencing EV over the period. This high level of exposure to EV reflects the period of extreme economic disruption of the Great Recession through which both cohorts lived. While the analysis shows that many of the same factors are associated with the risk of transitory and persistent poverty, the strength of the relationships differs, meaning that persistent poverty is much more socially structured.

As has been found in previous research, for a significant portion of the group the experience of vulnerability was transient in nature. The mother's unemployment, inability to work due to disability, lone parenthood, large family size, minority ethnic status and low maternal education are the strongest predictors of persistent $\mathrm{EV}$ in both cohorts. The commonality of these factors across two different cohorts suggests that in general the same processes operate in these two adjacent lifecourse periods. The apparent stronger influence of the mother's education for persistent poverty of the younger cohort is further explored in the following chapter. 



\section{CHAPTER 4}

\section{Transitions into and out of poverty in childhood}

In Chapter 3, we examined the characteristics of families with different exposures to economic vulnerability or being economically vulnerable (EV) over time. In this chapter, we examine the factors that result in movements into or out of EV. This allows us to get a better insight into the causal pathways and to indicate where policy interventions may be directed. As we saw in the previous chapters, some families are at greater risk of remaining in EV throughout the period, whereas others find the experience more transitory. This chapter looks at whether certain life and labour market events triggering poverty movements are more common for some families.

\subsection{FLOWS INTO AND OUT OF ECONOMIC VULNERABILITY (EV)}

In Table 4.1, we report the flows into and out of EV for the cohort of children born in 2008. We see that the rise of the numbers in poverty in 2011 is due to a large inflow of families into EV. These entrants account for 58 per cent of those who are EV in wave 2, while stayers account for the remaining 42 per cent. There is also a relatively low outflow of those who were EV in wave 1 (466 of 1,260, which amounts to 37 per cent).

Between wave 2 and wave 3 (2011 to 2013), there was a further increase in the number of EV households. The figures show that this was due predominantly to the rise of those stuck in poverty, the stayers, who accounted for two-thirds (67 per cent) of EV households in 2011, while the remaining third were new entrants. The proportion of families exiting poverty between waves dropped to 33 per cent (628 of 1,884).

Between wave 3 and wave 5 (2013 to 2017), there was a significant fall in the number of families experiencing EV. The flow figures show that this was caused both by an increased outflow from EV and a reduced inflow: 58 per cent of families that were vulnerable in 2013 were no longer vulnerable in 2017. 
TABLE 4.1: FLOWS INTO AND OUT OF ECONOMIC VULNERABILITY, 2008-2017 ('08 COHORT)

\begin{tabular}{|c|c|c|c|c|}
\hline \multirow[t]{2}{*}{ Year } & EV & \multicolumn{3}{|c|}{ Of whom: } \\
\hline & & Stayers & Inflow & Outflow \\
\hline wave 1, 2008 & 1,260 & & & \\
\hline wave 2,2011 & 1,884 & 794 & 1,090 & 466 \\
\hline wave 3, 2013 & 2,227 & 1,256 & 971 & 628 \\
\hline wave 5,2017 & 1,360 & 965 & 395 & 1,263 \\
\hline Weighte & imple & & & \\
\hline $\begin{array}{l}\text { Stayers }= \\
\text { in year } t .\end{array}$ & I EV in ye & $t E V$ in $t-1$ ar & tfflow $=\mathrm{EV}$ & not EV \\
\hline
\end{tabular}

We undertake the same analysis for the '98 cohort. In wave 1, 558 families were EV. This jumped to 1,719 families in wave 2 . Table 4.2 shows that this rise was driven by a large inflow of families into vulnerability $(1,331)$ during the economic recession. This newly vulnerable group accounted for 77 per cent of the EV in wave 2. Despite the recession, 169 families managed to exit vulnerability between wave 1 and wave 2, which amounts to 11 per cent of those vulnerable in wave 1 (169 of 1,558).

As with the younger cohort, the situation of families began to improve in the most recent survey. In wave 3, 1,305 families were EV. This fall in vulnerability was driven by a sharp fall in the inflow to vulnerability and an increased outflow, with 50 per cent of those vulnerable in wave 2 managing to exit.

TABLE 4.2: FLOWS INTO AND OUT OF ECONOMIC VULNERABILITY, 2007-2016 ('98 COHORT)

\begin{tabular}{|c|c|c|c|c|}
\hline \multirow[t]{2}{*}{ Year } & EV & \multicolumn{3}{|c|}{ Of whom: } \\
\hline & & Stayers & Inflow & Outflow \\
\hline wave 1, 2007 & 1,558 & & & \\
\hline wave $2,2011-2012$ & 1,719 & 388 & 1,331 & 169 \\
\hline wave $3,2015-2016$ & 1,305 & 853 & 452 & 866 \\
\hline
\end{tabular}

\subsection{FACTORS INFLUENCING FLOWS INTO AND OUT OF EV}

We can build on these figures on flows to show what particular factors are associated with moves into and out of EV. Our analysis examines how life events occurring between time $t$ and time $t+1$ are linked to entry or exit to EV status in time $t+1$. We consider both labour market events and family events, such as partnership breakdown and the arrival of new children. We pool the data to examine transitions in each pair of panel waves (in the case of the ' 08 cohort wave 1 to wave 2 ; wave 2 to wave 3 ; wave 3 to wave 5 ). This strategy provides larger cell sizes and therefore more robust estimates (Dewilde, 2006; Sandefur and Tuma, 
1987). As the observations are linked, that is, families appear in each pair of waves, we use robust standard errors.

We present, in Table 4.3, the results from two nested models: one model for EV entry and one model for EV exit. The models predicting the EV entry rates are limited to the relevant population 'at risk': only the respondents who are classified as 'not $E V^{\prime}$ ' in wave(t) are at risk of an entry into poverty between wave(t) and wave $(\mathrm{t}+1)$. Similarly, only respondents in $\mathrm{EV}$ at wave $(\mathrm{t})$ are a risk of exits from $\mathrm{EV}$ between wave $(t)$ and wave $(t+1)$.

Table 4.3 shows the factors associated with entry and exit to EV, as expressed in terms of odds ratios. The time variable confirms the pattern seen above. The odds of entering EV between 2008 and 2011 and between 2011 and 2013 do not differ significantly, but there is a substantial fall in the odds of entering EV between 2013 and 2017. This is likely to reflect the improved economic situation over the period, as the country was recovering from the Great Recession; it may also partially reflect the greater time gap between observations. ${ }^{31}$ The exit model shows that there was a fall in the odds of exiting EV between 2011 and 2013 compared to the earlier period, leaving more families stuck in EV, and only in 2013-2017 is there an increase in the odds of exit.

In the following tables, we report several socio-demographic variables of the primary caregiver (PCG), which is the mother in 99 per cent of cases for both cohorts. We include a set of fixed effect control variables, which are variables that we do not allow to vary over time. These include number of children in wave 1 , the mother's education level and disability status in the first year of the survey. The odds ratio of entering EV are 4.5 times higher for families where the mother has the lowest level of education compared to those where the mother has a degree. Conversely, mothers with lower education have lower odds of exiting EV than those with higher education. Where a mother has a disability in wave 1 , the family has 1.5 times greater odds of entering EV and only two-thirds the odds of exiting EV compared to other families. Larger family size also increases the odd ratio of entering EV and reduces the odds of exiting EV.

Turning to the role of family dynamics, we find that the birth of a baby between waves does not significantly alter entry to or exit from EV. In contrast, partnership breakdown leads to a very substantial increase in the odds ratio for entering EV and a significant reduction in the chances of leaving EV. Where a partner moves out of the household, the odds ratio of entering EV is 3.6 times greater than when partnership status remains unchanged. Partnership dissolution also significantly reduces the odds of the family exiting EV. Re-partnering does not lead to an improvement in EV for children and their families; rather, it is associated with a 
significant increase in the odds ratio of entering EV. This may be due to additional household needs related to living costs by having a new person in the household. Equivalised income adjusts household income for the number of adults and children in the household. However, our measure of EV is broader than income alone, suggesting there may be more substantive risks to household financial circumstances that are associated with re-partnering. Re-partnering can involve changing job or moving to a new house, location and school, which can be a stressful experience for household members, particularly children.

TABLE 4.3: ECONOMIC VULNERABILITY ENTRY AND EXIT LOGISTIC MODEL: POOLED DATA ('08 COHORT)

\begin{tabular}{|c|c|c|c|c|}
\hline & (1) & (2) & (3) & (4) \\
\hline & Enter EV & Enter EV & Exit EV & Exit EV \\
\hline \multicolumn{5}{|l|}{ Ref: 2008-11 (9mon-3yr) } \\
\hline 2011-13 (3-5years) & 0.95 & 0.97 & $0.80 *$ & $0.79 *$ \\
\hline 2013-17( 5-9years) & $0.42 * * *$ & $0.43^{* * *}$ & $2.02 * * *$ & $1.82 * * *$ \\
\hline \multicolumn{5}{|l|}{ PCG education (ref Degree) } \\
\hline PCG lower secondary or less & $4.58 * * *$ & $4.20 * * *$ & $0.49 * * *$ & $0.54 * * *$ \\
\hline PCG Leaving Certificate & $2.80 * * *$ & $2.55^{* * *}$ & $0.60 * * *$ & $0.64 * *$ \\
\hline PCG sub-degree & $2.02 * * *$ & $1.91 * * *$ & 0.85 & 0.85 \\
\hline PCG disability & $1.55^{* * *}$ & $1.53 * * *$ & $0.62 * * *$ & $0.63 * * *$ \\
\hline N children w1 & $1.14^{* * *}$ & $1.12^{* * *}$ & $0.87 * * *$ & $0.87^{* * *}$ \\
\hline New baby between waves & 0.96 & 0.92 & 0.84 & 0.85 \\
\hline \multicolumn{5}{|l|}{ No change in partnership (ref) } \\
\hline Partner moved in & $2.40 * * *$ & $2.59 * * *$ & 0.88 & 0.94 \\
\hline Partner moved out & $3.19 * * *$ & $3.55^{* * *}$ & $0.53^{* *}$ & $0.60 *$ \\
\hline \multicolumn{5}{|l|}{ PCG no change (ref) } \\
\hline PCG unemp/Inactive to full-time work & & $0.51 * * *$ & & $2.31 * * *$ \\
\hline PCG unemp/inactive part-time work & & 0.95 & & 1.29 \\
\hline PCG exit employment & & $1.68 * * *$ & & 0.86 \\
\hline PCG full-time to part-time & & 0.76 & & 1.06 \\
\hline PCG part-time to full-time & & $0.64^{* *}$ & & $1.43^{*}$ \\
\hline \multicolumn{5}{|c|}{ SCG no change principal economic status (PES) (ref) } \\
\hline SGC unemp/inactive to full-time emp & & $0.72 *$ & & $2.51 * * *$ \\
\hline SGC unemp/inactive part-time emp & & $1.85^{*}$ & & 1.24 \\
\hline SCG exit employment & & $1.99 * * *$ & & 1.22 \\
\hline SCG full-time to part-time emp & & $2.12 * * *$ & & 1.22 \\
\hline SCG part-time to full-time emp & & 0.82 & & $2.01 *$ \\
\hline Constant & $0.07 * * *$ & $0.07^{* * *}$ & $1.46^{*}$ & 1.24 \\
\hline Observations (pairs of years) & 18,064 & 18,064 & 4,413 & 4,413 \\
\hline
\end{tabular}


Changes in employment status have a less dramatic effect on EV entry than relationship breakdown. The exit of both the mother and the father from employment significantly increases the family's chance of becoming EV compared to those where the mother's employment status is unchanged. The effect of paternal job loss is stronger than maternal job loss. This is likely to reflect the fact that maternal employment hours, especially at this stage of family formation, tends to be much lower than paternal employment, so that the loss of income is likely to be lower and the reference group consists of more families where the mother is not employed in both waves (see Appendix Table A4.1, for the figures on employment transitions between waves).

The mother's entry into employment has a similar positive effect on the odds ratio of leaving EV as the father entering employment, but in both cases the effect is only observed for entry into full-time employment. These results have important implications for the relief of child poverty. The greater impact of partnership breakdown on entry and exit from EV in early childhood may reflect that changes in employment status are better cushioned by the social welfare system than risks associated with changes to family status. The findings also indicate that entry into part-time employment is not sufficient for exiting vulnerability.

The effects of the mother's education level do not change dramatically when employment transitions are included in the model and remain strongly significant. The social gradient in poverty transition risks is not accounted for by labour market transitions during the observation period (though it may well be influenced by labour-market history prior to the birth of the study child). This indicates that tackling longer-term social inequality remains important.

\subsection{EV ENTRY AND EXIT AT AGES 9 TO 17}

We repeat these models to examine whether the same factors trigger entry and exit to EV in middle and late childhood. For this analysis, we have only two pairs of transitions to pool: those occurring between age 9 and age 13, and between 13 and 17 years. The models show that the odds ratio of entering EV is much smaller in the later period, while the odds ratio of moving out of EV is double.

The control factors show that the mother's level of education and disability status at the beginning of the period exert a significant influence on transitions into and out of EV. The size of the odds ratios for the mother's education is considerably smaller than those observed in the younger cohort, suggesting that social background has a larger effect on poverty dynamics in the early years (although this has not been tested formally). ${ }^{32}$ We know that the mother's education has a

\footnotetext{
32 This pattern may also reflect differences in the educational composition of mothers in the two cohorts, with mothers of cohort ' 08 being twice as likely to have degree-level qualifications as mothers of cohort ' 98 .
} 
very strong influence on employment in the early years post childbirth (Russell et al., 2018) and this may weaken as children reach late childhood. The number of children in the household at wave 1 is also significantly associated with a higher odds ratio of entering EV and lower odds ratio of leaving EV, suggesting that poverty continues to be a higher risk for larger families.

TABLE 4.4: $\quad$ ECONOMIC VULNERABILITY ENTRY AND EXIT LOGISTIC MODEL: POOLED DATA ('98 COHORT)

\begin{tabular}{|c|c|c|}
\hline & Enter EV & Exit EV \\
\hline & Odds ratio & Odds ratio \\
\hline \multicolumn{3}{|l|}{ Period (ref 9-13 years, 2008-12) } \\
\hline $13-17$ years (2012-2015/2016) & $0.36 * * *$ & $2.04 * * *$ \\
\hline \multicolumn{3}{|l|}{ PCG education (ref Degree) } \\
\hline PCG Lower Secondary or less & $2.78 * * *$ & $0.61 *$ \\
\hline PCG Leaving Certificate & $1.49 * * *$ & 0.71 \\
\hline PCG Sub-degree & $1.51 * * *$ & 0.66 \\
\hline PCG Disability & $1.66 * * *$ & $0.64 * *$ \\
\hline Number of children in w1 & $1.20 * * *$ & $0.85 * *$ \\
\hline New-born since previous wave & 1.16 & 1.11 \\
\hline \multicolumn{3}{|l|}{ No change in partnership } \\
\hline Partner moved in & $1.94 *$ & 1.24 \\
\hline Partner moved out & $2.46 * * *$ & 0.59 \\
\hline \multicolumn{3}{|l|}{ PCG LFS status (ref no change) } \\
\hline PCG Enter full-time & 0.75 & $3.71 * * *$ \\
\hline PCG Enter part-time & 1.23 & 1.38 \\
\hline PCG Exit employment & $1.93 * * *$ & 0.87 \\
\hline PCG Full-time to part-time & 1.17 & $2.34 *$ \\
\hline PCG Part-time to full-time & 0.77 & $1.91^{* *}$ \\
\hline \multicolumn{3}{|l|}{ SCG LFS status (ref no change) } \\
\hline SCG Enter full-time & 1.10 & $4.05 * * *$ \\
\hline SCG Enter part-time & 1.98 & 0.48 \\
\hline SCG Exit employment & $1.83 * * *$ & 1.26 \\
\hline SCG Full-time to part-time & 1.40 & 0.72 \\
\hline SCG Part-time to full-time & 0.88 & 0.81 \\
\hline Constant & $0.08 * * *$ & 0.98 \\
\hline Observations & 10,337 & 1,690 \\
\hline $\begin{array}{ll}\text { ource: } & \text { GUI ‘08 cohort, w1, w2, w3, w5. } \\
\text { ote: } & * * * p<0.001, * * p<0.01, * p<0.05 .\end{array}$ & & \\
\hline
\end{tabular}

We examine two types of family change: the birth of a child between survey waves and partnership dissolution. While the number of children in wave 1 was 
associated with increased risk of EV entry and a lower likelihood of exit, the birth of a child does not have an additional effect. This result may hide differing effects for socially advantaged and disadvantaged groups (see Vandecasteele, 2011).

Where a partner moves out of the household, the odds ratio of entering EV is 2.5 times higher compared to those where there is no change in partnership status. We again find that, rather than improving the situation of families, re-partnering is linked to a higher odds ratio of entering EV.

Turning to labour market factors, we see that changes in employment status and hours are significantly associated with poverty dynamics. The job loss of a mother or a father is associated with an increase in the odds ratios of EV entry of a similar magnitude. Changes between full- and part-time work by either parent do not influence entry to EV.

The model for exits from EV reveal important effects for maternal and paternal employment. If the mother enters full-time employment, the odds ratio of exiting $\mathrm{EV}$ are more than 3.7 times higher than where there is no change in maternal employment. Furthermore, an increase in maternal work hours, from part- to fulltime, is associated with a significant increase in the odds of leaving EV. This effect is not observed for fathers. Reductions in maternal employment hours also have an unexpected positive impact; this may reflect women reducing hours in response to improved economic circumstances in the household (for example, an increase in a partner's earnings).

A father's entry to full time employment is significantly related to the odds of exiting EV, with an odds ratio somewhat higher (4.1) than in the case of a mother entering full-time employment (3.7). A father's exit from employment between waves is not related to EV exit. However, relatively few families are EV where the secondary caregiver (SCG) is employed (see Chapter 3 ), so few are in the eligible group for this analysis.

\subsection{SUMMARY AND CONCLUSION}

Analysis of transition into and out of EV allows us to explore the triggers associated with the dynamics of child poverty. The impact of the economic recession in the 2009-2013 period is evident in the proportions of children and families stuck in EV. Improving economic circumstances in the later waves of both the younger and older child cohorts is associated with increasing exits from poverty and fewer entries. While these large-scale macro conditions exert an influence on children's exposure to poverty, the effects of family characteristics, family dynamics and paternal and maternal labour market dynamics are also strongly associated with the chances of entering or exiting poverty.

Partnership dissolution is found to be a particularly strong influence on entry to EV in both early and later childhood. This suggests the need for further supports, both 
income and services, for families in this position. This is especially important given the finding in the previous chapter of the high risk of poverty persistence for loneparent families. The unexpected negative effect of re-partnering on entry to EV could arise if a new partner means the loss of welfare entitlements, or if the increase in income that the partner brings does not compensate for the higher needs of a larger family unit. This is a social risk that requires further investigation.

The job loss of mothers and fathers has a similar effect on entry to EV. Maternal entry to employment also plays a significant role in moving families out of vulnerability throughout childhood, though the analysis shows that taking up parttime work is not enough to exit EV. This is an important distinction, since full-time employment, especially in early and middle childhood, requires additional childcare support and may not be practical or desirable for many families. 


\section{CHAPTER 5}

\section{Poverty dynamics and child outcomes}

The aim of this chapter is to explore the relationship between the timing and length of exposure to economic vulnerability or being economically vulnerable (EV) during childhood and a range of child outcomes. Studies based on the GUI survey have illustrated the association between EV and child socio-emotional outcomes (see, for example, Watson et al., 2014). The results presented here provide the most comprehensive analysis, to date, of the impact of duration of EV for children and young people in Ireland, based on their family situation from 9 months to 9 years in the case of cohort ' 08 and from 9 to 17 years for the older cohort ' 98.

Our objective here is to maximise the breadth of outcomes considered, rather than to provide an in-depth analysis of particular outcomes and the causal processes involved. We will consider outcomes across a diverse set of the domains covered in the GUI study: physical health and health behaviours, psychological wellbeing and self-esteem, educational outcomes, socio-emotional wellbeing, and family relationships. These outcomes were selected for inclusion in the GUI study because they have been identified in the literature as being salient for children and young people, are predictive of longer-term outcomes, and are relevant for policy (McNamara et al., 2020b). Within these domains, where possible, we select measures that are repeated in both cohort ' 98 and cohort '08. The measures include both parent- and self-reported items, as well as physical measurements recorded by the interviewer and standardised cognitive tests administered by the interviewer. These outcomes will be examined for both cohorts, thus allowing for differences in early and later childhood to be explored. The findings are presented in terms of the associations between particular outcomes and the duration of EV. The purpose of this broad-brush approach is to identify patterns that warrant further research, rather than to establish that EV 'causes' specific outcomes. As noted in Chapter 1 , the mechanisms, pathways, protective factors and policy levers differ across domains. Therefore, a common model would be inadequate to test these diverse issues.

\subsection{HEALTH OUTCOMES: OBESITY, SUBJECTIVE HEALTH HAVING A HAMPERING ILLNESS/DISABILITY AND RISKY HEALTH BEHAVIOURS}

The GUI study contains a range of indicators of physical health across childhood and adolescence. Overweight and obesity are associated with increased risk of a wide array of health conditions in the long term, including type 2 diabetes, heart disease and respiratory illnesses, and growing rates of overweight and obesity are a matter of considerable policy concern in Ireland and other countries (see, for example, HSE, 2018). Childhood obesity is not only linked to poor current physical 
health outcomes, but also to poorer mental health, and to longer-term health problems in adulthood (Biro and Wein, 2010; von Mutius et al., 2001; Miller and Downey, 1999; Layte and McCrory, 2011). Longitudinal research suggests that childhood obesity predicts the development of poor self-esteem among young people, rather than low self-esteem leading to the excess weight (Wang et al., 2009).

We find that being overweight or obese at age 9 is significantly associated with exposure to EV over early childhood (Table 5.1). The proportion overweight is higher among those with any exposure to EV than among those with no such exposure, but it is similar among children with transient spells of $E V$ and those with more persistent spells. In contrast, obesity among 9-year-olds rises with the duration of exposure to EV. Children who were EV, in all survey waves were three times more likely to be obese than children who were never EV. This association is stronger than the relative differences in obesity risk by poverty trajectory found in the UK, in the Millennium Cohort Study (MCS) (Lai et al., 2019), which found that children in persistent poverty were twice as likely as those never in poverty to be obese at age 14.

A slightly different pattern emerges in older childhood (Table 5.2). At age 17, while the never EV are less likely to be obese than the other two groups, it is those who experience transient EV who record the highest obesity levels, rather than those who were persistently EV. This suggests that transient EV may have a stronger effect in later childhood, which is a question that can be addressed in further research. ${ }^{33}$

TABLE 5.1: OVERWEIGHT/OBESITY AT AGE 9 BY LONGITUDINAL EV IN EARLY/MIDDLE CHILDHOOD, ('08 COHORT)

\begin{tabular}{|c|c|c|c|c|}
\hline & Never EV & EV once/transient & Persistent EV & Always EV \\
\hline \multicolumn{5}{|l|}{ Weight (\%) } \\
\hline Non-overweight & 81.1 & $74.6 * * *$ & $70.0 * * *$ & $69.3^{* * *}$ \\
\hline Overweight & 15.4 & $19.8 * * *$ & $20.7^{* * *}$ & $19.4^{*}$ \\
\hline Obese & 3.6 & $5.7^{* * *}$ & $9.2 * * *$ & $11.3^{* * *}$ \\
\hline Total & 100.0 & 100.0 & 100.0 & 100.0 \\
\hline
\end{tabular}

${ }^{33}$ Further research could also usefully examine gender differences in the trajectory of weight status by longitudinal EV. 
TABLE 5.2: OVERWEIGHT/OBESITY AT 17 BY LONGITUDINAL EV IN MIDDLE/LATE CHILDHOOD ('98 COHORT)

\begin{tabular}{l|c|c|c}
\hline \multicolumn{1}{|c|}{ Weight (\%) } & Never EV & EV once & $\begin{array}{c}\text { Persistent/ } \\
\text { always EV }\end{array}$ \\
\hline Non-overweight & 74.5 & $68.4^{* * *}$ & $71.0^{*}$ \\
\hline Overweight & 19.8 & 20.6 & 19.5 \\
\hline Obese & 5.7 & $11.0 * * *$ & $9.5^{* * *}$ \\
\hline Total & 100.0 & 100.0 & 100.0 \\
\hline Notes: $\quad$ Transient $=$ more than once but never in consecutive waves; Persistent =at least two consecutive waves; ${ }^{* * *}$ &
\end{tabular}

The prevalence of chronic illness or disability that limits the child's daily activity also diverges strongly between children with different cumulative exposure to poverty. Just over 10 per cent of the never EV have such an illness or disability at age 9, while the proportion doubles to 21 per cent for children who are always EV. If anything, the relationship is even stronger for the older cohort: 9.9 per cent of 17-year-olds who were never vulnerable have a hampering disability or illness compared to 27 per cent among those who were always EV. This result is consistent with research in the UK, which found that exposure to poverty, especially persistent poverty, is linked to higher rates of long-standing illness among children (Lai et al., 2019). The mechanisms linking poverty and ill health in childhood include family stress, poor housing, diet, food costs, exposure to environmental toxins, and parental health behaviours (Brooks-Gunn and Duncan, 1997; Barosh et al., 2014). ${ }^{34}$ Other possible routes include unequal access to health care, though the evidence here is more limited and will vary depending on the policy context. The relationship between child disability/illness and family poverty may also run in the other direction: there is some evidence that children's health status and disability have a negative effect on the labour force participation of mothers (Powers, 2003; Porterfield, 2002) and therefore the amount of income mothers can generate. Moreover, poor physical health during childhood predicts poorer educational outcomes in adolescence (Layte and McCrory, 2013) and has been found to have effects on educational, economic and health outcomes into adulthood (Wickrama et al., 2005), meaning the effects of poverty on childhood health are potentially long term.

\footnotetext{
${ }^{34}$ The influence may also operate in the reverse, with serious illness/disability, prompting parents to withdraw from employment to assume a full-time care role, thus increasing exposure to EV.
} 
TABLE 5.3: CHRONIC ILLNESS OR DISABILITY THAT HAMPERS DAILY ACTIVITY AT AGE 9 YEARS BY EXPOSURE TO EV ('08 COHORT)

\begin{tabular}{l|c|c|c|c} 
& Never EV & EV once/transient & Persistent & Always EV \\
\hline No illness/disability & 89.6 & $86.9 * *$ & $81.9^{* * *}$ & $78.8^{* * *}$ \\
\hline Illness/disability & 10.4 & $13.2^{* *}$ & $18.1^{* * *}$ & $21.2^{* * *}$ \\
\hline Total & 100.00 & 100.00 & 100.00 & 100.00 \\
\hline Notes: & $\begin{array}{l}\text { Significance tests refer to the difference between each group and the never EV group. }{ }^{* * *} \mathrm{p}<0.001,{ }^{* *} \mathrm{p}<0.01,{ }^{*} \\
\mathrm{p}<0.05\end{array}$
\end{tabular}

TABLE 5.4: CHRONIC ILLNESS OR DISABILITY THAT HAMPERS DAILY ACTIVITY AT AGE 17 YEARS BY EXPOSURE TO EV ('98 COHORT)

\begin{tabular}{l|c|c|c|c}
\hline & Never EV & EV once & Persistent & \multicolumn{1}{c}{ Always } \\
\hline No illness/disability & 90.1 & $87.6^{* *}$ & $83.5^{* * *}$ & $73.5^{* * *}$ \\
\hline Illness/disability & 9.9 & $12.4^{* *}$ & $16.5^{* * *}$ & $26.5^{* * *}$ \\
\hline Total & 100.0 & 100.0 & 100.0 & 100.0 \\
\hline Notes: & $\begin{array}{l}\text { Significance tests refer to the difference between each group and the never EV group. }{ }^{* * *} p<0.001,{ }^{* *} p<0.01,{ }^{*} \\
p<0.05\end{array}$
\end{tabular}

Among the older cohort, we can also examine the association between duration of EV and a range of health behaviours at age 17. The figures in Table 5.5 show that young people who lived with persistent EV since the age of 9 are twice as likely to smoke regularly as those who were never EV. However, there was no difference in the rate of problem or harmful drinking across the three groups. 
TABLE 5.5: RISKY HEALTH BEHAVIOURS (SMOKING AND DRINKING) AT 17 YEARS BY LONGITUDINAL EV ('98 COHORT)

\begin{tabular}{l|c|c|c|}
\hline \multicolumn{1}{|c|}{ Smoking (\%) } & Never EV & EV once & Persistent/ always EV \\
\hline Never/tried once or twice & 54.5 & $49.3^{*}$ & $42.7^{* * *}$ \\
\hline Used to smoke but not now & 6.5 & 8.3 & - \\
\hline Smoke occasionally & 26.8 & $22.6^{*}$ & - \\
\hline Smoke daily & 12.1 & $19.9 * * *$ & $26.0^{* * *}$ \\
\hline Total & 100.0 & 100.0 & 100.0 \\
\hline \multicolumn{1}{|c|}{ Drinking (\%) } & Never EV & EV once & Persistent/always EV \\
\hline Problem drinking & 38.9 & $34.2 * *$ & 36.0 \\
\hline Total & 100.0 & 100.0 & 100.0 \\
\hline Notes: $\quad * * * p<0.001, * * p<0.01, * p<0.05 ;$ - cell size too small to report. Where figures are not marked with an asterisk, the
\end{tabular}

\subsubsection{Mental health and socio-emotional wellbeing}

The importance of wellbeing and mental health of children and young people is increasingly recognised in Irish education and social policy, at both primary and secondary level (NCCA, 2009; DES, 2012).

Previous research on the GUI cohorts has demonstrated a strong association between different measures of family financial hardship or low income and children's socio-emotional wellbeing (Watson et al., 2014; Nixon, 2012; Nixon et al, 2019; Russell et al., 2016). Using the first two waves of the '08 and '98 cohorts, Watson et al. (2014) found a strong association between EV and problematic strengths and difficulties questionnaire (SDQ) scores over and above the influence of the mother's education, family structure, the mother's age, family change and child's gender. The authors found that there was no difference between the two cohorts in the strength of the association between EV and high SDQ scores, contrary to expectations that poverty might have a more detrimental effect on the development of younger children.

Extending the analysis to examine exposure to EV across a considerably longer period during childhood, we see a very strong association between duration and socio-emotional wellbeing for both cohorts (Tables 5.6 and 5.7). Among both the younger and older cohorts, the average SDQ total difficulties score (where a higher score indicates greater difficulties) rises for each additional level of exposure to vulnerability and this pattern persists for all of the difficulties sub-scales covering both internalising and externalising difficulties. ${ }^{35}$ As well as looking at average scores, the analyses can examine the proportion with problematic scores as defined by the scale author (Goodman, 1997), that is, those with scores of 17 or more. At 9 years of age, the proportion with problematic scores rises from 5 per

35 The exception is hyperactivity for cohort ' 98 , where the contrast is greater between always EV and once/persistent EV. 
cent among children with no EV to 15 per cent among those who were always vulnerable. ${ }^{36}$ At age 17, the gap is even larger: only 3 per cent of those who were never EV had SDQ scores in the problematic range compared to 17 per cent of those who were always EV.

Watson et al. (2014), using the first two waves of the ' 08 cohort, for example, found a similar pattern of association between the length of exposure to EV and high SDQ score. The authors found that children who had no experience of EV had an almost 4 per cent risk of high SDQ, while it was 8 per cent for those with one spell only and 13 per cent for those in persistent EV.

The progressive increases in social and emotional difficulties with duration of exposure to vulnerability suggest the presence of an accumulation effect. Further research is needed to test the causality and robustness of these results to controls. In contrast to the measures of socio-emotional difficulties, children's pro-social scores at age 9 and age 17 are not associated with duration of exposure to EV.

TABLE 5.6: SDQ SCORES AT AGE 9 BY LONGITUDINAL EV ('08 COHORT)

\begin{tabular}{|c|c|c|c|c|}
\hline SDQ & Never EV & EV once/ transient & Persistent EV & Always EV \\
\hline Emotional subscale & 1.82 & $2.39 * * *$ & $2.50 * * *$ & $2.78^{* * *}$ \\
\hline Conduct subscale & 0.99 & $1.28 * * *$ & $1.45^{* * *}$ & $1.61^{* * *}$ \\
\hline Hyperactivity subscale & 2.93 & $3.39 * * *$ & $3.86 * * *$ & $3.98 * * *$ \\
\hline Peer-problem subscale & 0.91 & $1.29 * * *$ & $1.48^{* * *}$ & $1.82 * * *$ \\
\hline Prosocial subscale & 8.94 & $9.02 *$ & 8.94 & 8.80 \\
\hline Total difficulties & 6.65 & $8.35^{* * *}$ & $9.30 * * *$ & $10.19 * * *$ \\
\hline $\begin{array}{l}\text { \% Problematic SDQ score } \\
\text { (score=>17) }\end{array}$ & 4.9 & $10.9 * * *$ & $12.9 * * *$ & $15.4^{* * *}$ \\
\hline
\end{tabular}

\footnotetext{
${ }^{36}$ The figure of $8 \%$ of the total panel sample score in the problematic range at age 9 and 5 per cent at age 17 . The SDQ measure covers an internalising scale (emotional, prosocial and peer-problem scales) and an externalising scale (hyperactivity and conduct subscale).
} 


\begin{tabular}{|l|c|c|c|c|}
\hline & Never EV & EV once & Persistent EV & Always EV \\
\hline Emotional subscale & 1.69 & $2.30^{* * *}$ & $2.65^{* * *}$ & $3.36^{* * *}$ \\
\hline Conduct subscale & 0.94 & $1.05^{* *}$ & $1.21^{* * *}$ & $1.93^{* * *}$ \\
\hline Hyperactivity subscale & 2.22 & $2.63^{* * *}$ & $2.49^{* *}$ & $3.97^{* * *}$ \\
\hline Peer-problem subscale & 1.29 & $1.53^{* * *}$ & $1.72^{* * *}$ & $2.09 * * *$ \\
\hline Prosocial subscale & 8.69 & 8.76 & 8.62 & 8.54 \\
\hline Total difficulties score & 6.13 & $7.51^{* * *}$ & $8.07^{* * *}$ & $11.34^{* * *}$ \\
\hline $\begin{array}{l}\text { \% Problematic score } \\
\text { (score=>17) }\end{array}$ & & & & $17.2^{* * *}$ \\
\hline
\end{tabular}

Source: $\quad$ GUI '98 cohort, w1, w2, w3, PCG questionnaires.

Notes: $\quad * * * \mathrm{p}<0.001, * * \mathrm{p}<0.01, * \mathrm{p}<0.05$; significance refers to difference from Never EV group. Where figures are not marked with an asterisk, the difference is not significant.

\subsubsection{Self-concept}

For the 9-year-old cohort, psychological wellbeing was measured using the PiersHarris self-concept scale (Piers and Herzberg, 2002) which was self-completed by the child. The scale consists of sub-scales that assess the child's self-concept across six domains: behavioural adjustment, intellectual and school status, physical appearance and attributes, freedom from anxiety, popularity, and happiness and satisfaction.

Longer exposure to $\mathrm{EV}$ is associated with poorer self-concept on all six sub-scales and overall self-concept (Table 5.8). Those who are EV across the whole of early childhood have the most negative self-concept of all the groups on all six subscales, but even one-off, transient vulnerability is associated with significantly lower self-concept scores. The proportion of 9-year-olds with a low or very low self-concept score rises from 14 per cent among those who were never EV to 31 per cent among those who were always vulnerable. These patterns are of concern as low self-esteem is associated with a range of negative outcomes, including later mental health problems (Orth et al., 2008; Sowislo and Orth, 2013). 
TABLE 5.8: SELF-CONCEPT AT AGE 9 BY LONGITUDINAL ECONOMIC VULNERABILITY ('08 COHORT)

\begin{tabular}{|c|c|c|c|c|}
\hline & Never EV & $\begin{array}{l}\text { EV once/ } \\
\text { transient }\end{array}$ & Persistent EV & Always EV \\
\hline Behavioural adjustment & 8.4 & $8.2 * * *$ & $8.2 * * *$ & $7.9 * * *$ \\
\hline Intellectual and school status & 7.1 & $6.9 * * *$ & $6.8 * * *$ & $6.6 * * *$ \\
\hline Physical appearance & 6.2 & $6.0 * * *$ & $5.9 * * *$ & $5.7 * * *$ \\
\hline Freedom from anxiety & 6.8 & $6.4 * * *$ & $6.5^{* * *}$ & $6.1 * * *$ \\
\hline Popularity & 5.2 & $5.0 * * *$ & $4.9 * * *$ & $4.6 * * *$ \\
\hline Happiness and satisfaction & 5.5 & $5.4 * * *$ & $5.3 * * *$ & $5.1 * * *$ \\
\hline Low/very low total score \% & $13.6 \%$ & $20.0 \% * * *$ & $21.8 \% * * *$ & $31.2 \% * * *$ \\
\hline
\end{tabular}

A different measure of psychological wellbeing is included in the GUI at age 17. The Anxiety subscale of the Depression, Anxiety and Stress Scale (DASS21) contains seven items that measure autonomic arousal, skeletal muscle effects, situational anxiety and subjective experience of anxiety (see Murphy et al., 2019). ${ }^{37}$ While there is some correlation between anxiety and EV, the differences in score between those in transient and persistent $\mathrm{EV}$ are small. It may be that other factors influence levels of anxiety or stress at this stage, which obscure the relationship between disadvantage and anxiety. Many of these young people were in their final year of second-level education, with previous Irish research showing high levels of exam-related stress among more middle-class and educationally ambitious students (Banks and Smyth, 2015). The relationship between EV and life satisfaction at age 17 appears considerably stronger and satisfaction decreases with duration.

${ }^{37}$ Autonomic arousal is the disturbance of the nervous system that regulates autonomous functions such as heart rate, respiratory function. 
TABLE 5.9: ANXIETY AND LIFE SATISFACTION AT AGE 17 BY LONGITUDINAL ECONOMIC VULNERABILITY ('98 COHORT)

\begin{tabular}{l|c|c|c|c}
\hline & Never EV & EV once & Persistent EV & Always EV \\
\hline Anxiety mean score (0-21) & 3.0 & $3.4^{* * *}$ & $3.7^{* * *}$ & $3.6^{* *}$ \\
\hline $\begin{array}{l}\text { Satisfaction mean score(1-10) } \\
\text { Unweighted N }\end{array}$ & 7.40 & $7.05^{* * *}$ & $6.82^{* * *}$ & $6.24^{* * *}$ \\
\hline $\begin{array}{l}\text { Notes: } \quad * * * p<0.001, * * \\
\quad \\
\quad \text { from } 0 \text { to } 21,91 \text { per cent of respondents have a score less than } 10 .\end{array}$ & 538 & 153 \\
\hline
\end{tabular}

\subsection{EDUCATIONAL AND COGNITIVE OUTCOMES}

GUI contains a rich array of measure on cognitive and educational outcomes. In a review of the research of poverty on child outcomes, Duncan and Brooks-Gunn (2000) suggest that the effect is greater on cognitive/educational outcomes than in other domains. Strong associations between various dimensions of family socioeconomic status and children's cognitive outcomes have been found in multiple studies of the GUI cohorts at different ages (Williams et al., 2009; Smyth et al., 2010; McGinnity et al., 2015; McMullin et al., 2020). The influence of family socioeconomic status (SES) persists even when a range of other environmental, family and personal characteristics are taken into account.

The results of cognitive tests at age 9 for cohort ' 08 show a strong gradient in both reading and selective attention based on duration of EV, with the highest scores found among those who were never exposed to EV and the lowest among those who were persistently or always EV. On the Drumcondra reading test, a standardised test linked to the national curriculum and used in national assessments, the mean logit scores illustrate that progressively longer exposure to $\mathrm{EV}$ is linked to accumulative reductions in reading scores at age 9.

Selective attention is an important measure of general cognitive capacity and executive function (McNamara et al., 2020a), with the latter being crucial for academic development, as well as more general decision-making in later life (Best et al., 2009). We find that, at age 9 , there is a small difference in the mean scores in selective attention of children who experience at least one spell of EV compared to children never exposed. However, there is no evidence from these raw scores that there is a cumulative effect for longer durations. 
TABLE 5.10: COGNITIVE TESTS AT AGE 9 BY LONGITUDINAL ECONOMIC VULNERABILITY ('08 COHORT)

\begin{tabular}{|c|c|c|c|c|}
\hline Drumcondra Reading Test & Never EV & $\begin{array}{l}\text { EV once/ } \\
\text { transient }\end{array}$ & $\begin{array}{l}\text { Persistent } \\
\text { EV }\end{array}$ & $\begin{array}{c}\text { Always } \\
\text { EV }\end{array}$ \\
\hline Logit score (mean=100) & 102.38 & $98.03 * * *$ & $97.23 * * *$ & $91.80 * * *$ \\
\hline $\begin{array}{l}\text { Selective attention test } \\
\text { (mean score out of } 80 \text { ) }\end{array}$ & 32.27 & $31.64 *$ & $31.06 * * *$ & $31.12 *$ \\
\hline
\end{tabular}

FIGURE 5.1: DRUMCONDRA READING TEST LOGIT SCORES FOR 9-YEAR-OLDS WHO WERE NOT EV AND THOSE WHO WERE ALWAYS EV

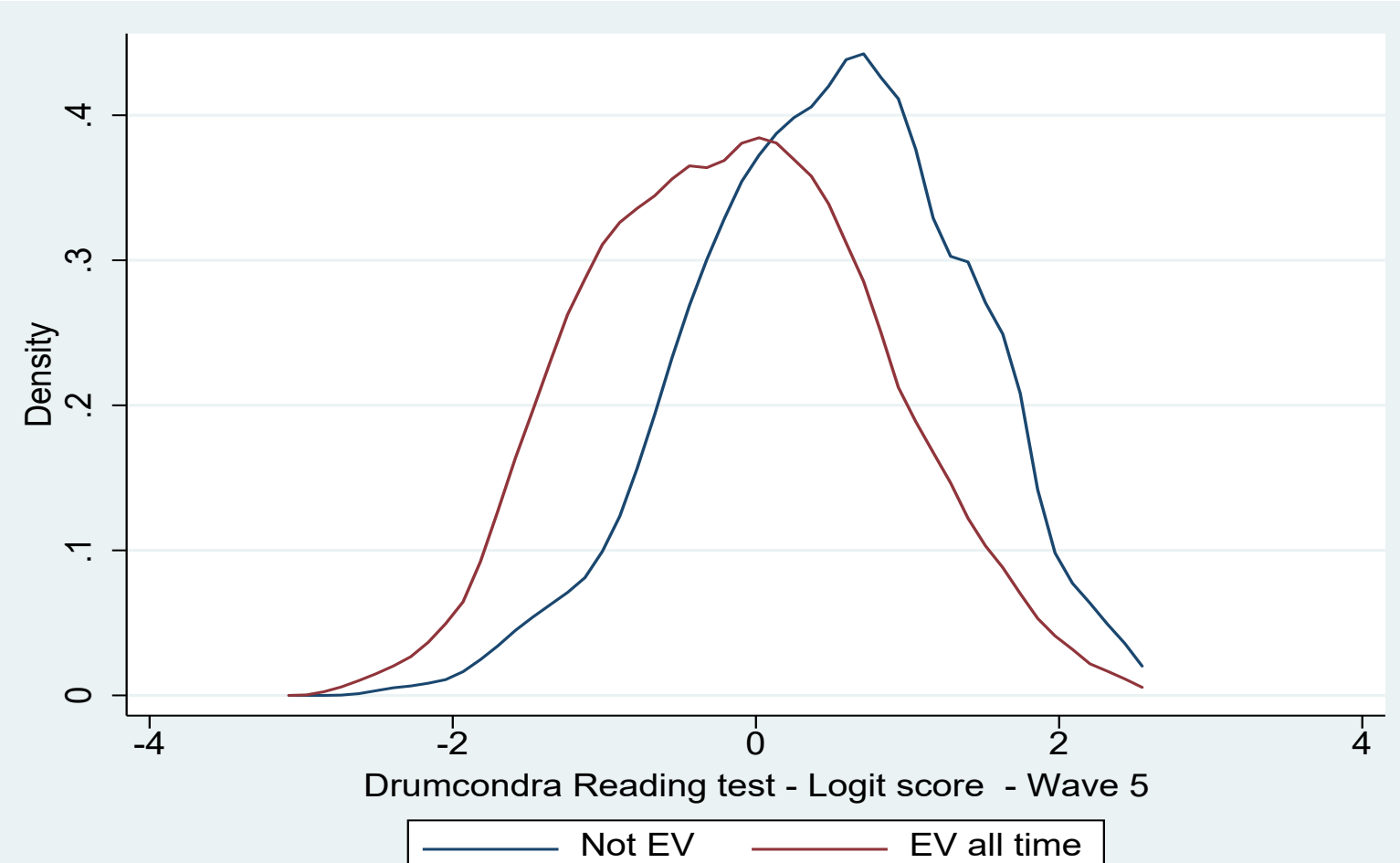

Three cognitive tests were administered to 17 -year-olds: an exercise in which they were asked to name as many animals as possible in one minute; a vocabulary test similar to that used in the UK MCS; and three short questions designed to test financial literacy. In all three tests, those who had any exposure to EV scored significantly lower than those without such exposure (Table 5.11). The lowest test scores were consistently found among those who were EV at all three waves of the study. 
TABLE 5.11: COGNITIVE TESTS AT AGE 17 YEARS BY LONGITUDINAL EV ('98 COHORT)

\begin{tabular}{l|c|c|c|c} 
& Never EV & EV once & Persistent EV & Always EV \\
\hline Animal naming total (mean) & 22.1 & $21.4^{* *}$ & $21.0^{* * *}$ & $18.8^{* * *}$ \\
\hline Maths score (mean) & 2.5 & $2.1^{* * *}$ & $2.1^{* * *}$ & $1.5^{* * *}$ \\
\hline Vocabulary test (mean) & 9.0 & $8.3^{* * *}$ & $8.2^{* * *}$ & $6.9 * * *$ \\
\hline Unweighted N & 4,200 & 1,148 & 538 & 153 \\
\hline Notes: $\quad * * * p<0.001, * * p<0.01, * p<0.05 ;$ significance refers to difference from never EV group. &
\end{tabular}

In addition to test scores, information was collected from the young people on the subjects and subject levels they had taken in the Junior Certificate exam, as well as the grades they received. ${ }^{38}$ While only a small proportion of the cohort now leave school after the Junior Certificate (DES, 2019), grades can influence the subjects and subject levels taken at Leaving Certificate, which in turn influences access to further and higher education and employment. Grades were allocated points ranging from zero for 'fail' grades (E, F and NG) to 10 for a higher-level A grade, and then averaged over the exam subjects taken. Overall, Junior Certificate grades were significantly lower among those exposed to EV and particularly low among those who were always EV (Table 5.12). The gap was sizeable - almost 1.5 grades per subject. Given that young people tended to take 10-12 Junior Certificate subjects, this represents a very significant achievement gap for the EV. A similar pattern was found for Maths, with an even larger gap between those who were never EV and those who were always EV.

TABLE 5.12: JUNIOR CERTIFICATE RESULTS ('98 COHORT)

\begin{tabular}{|c|c|c|c|c|}
\hline & Never EV & EV once & Persistent EV & Always EV \\
\hline Junior Certificate grades (total) & 7.90 & $7.29 * * *$ & $7.14^{* * *}$ & $6.56 * * *$ \\
\hline Junior Certificate Maths grade & 7.47 & $6.58 * * *$ & $6.27 * * *$ & $5.68 * * *$ \\
\hline Unweighted $\mathbf{N}$ & 4,200 & 1,148 & 538 & 153 \\
\hline $\begin{array}{l}* * * p<0.001, * * p<0.01, * p<0.0 \\
10 . \text { These results were collecte } \\
\text { Junior Certificate when they are }\end{array}$ & $\begin{array}{l}\text { ificance refers } \\
\text { ave } 3 \text {, when the }\end{array}$ & $\begin{array}{l}\text { ence from neve } \\
\text { ndents were ag }\end{array}$ & $\begin{array}{l}\text { up. score on a sca } \\
\text { lowever, young pe }\end{array}$ & $\begin{array}{l}\mathrm{m} 0 \text { to } \\
\text { sit the }\end{array}$ \\
\hline
\end{tabular}

38 This measure therefore relies on respondent recall. 
School engagement is one mechanism which may link social disadvantage and educational attainment. We find that, at age 9 , the number of days absent from school increases significantly with each level of EV. More than a quarter of the children in the always vulnerable group missed more than 10 days of school in the previous 12 months compared to 19 per cent of those in persistent EV, 18 per cent of those who experienced transient EV and 10 per cent of those who were never $\mathrm{EV}$. It is likely that this pattern may, at least partly, be linked to the higher levels of chronic illness/disability among those experiencing longer-term EV, though further research would be needed to establish this.

TABLE 5.13: NUMBER OF DAYS ABSENT FROM SCHOOL IN THE PREVIOUS YEAR, AGE 9 ('08 COHORT)

\begin{tabular}{|c|c|c|c|c|}
\hline & Never EV & $\begin{array}{l}\text { EV Once/ } \\
\text { Transient }\end{array}$ & Persistent EV & Always EV \\
\hline 3 days or fewer & 48.5 & $40.2 * * *$ & $36.6 * * *$ & $31.0 * * *$ \\
\hline 4-6 days & 25.3 & 24.3 & 23.3 & $17.2 * * *$ \\
\hline 7-10 days & 16.0 & 17.5 & $21.2^{* * *}$ & $26.2 * * *$ \\
\hline More than 10 days & 10.2 & $18.1 * * *$ & $19.0 * * *$ & $25.6 * * *$ \\
\hline Total & 100 & 100 & 100 & 100 \\
\hline Unweighted $\mathbf{N}$ & 4,633 & 1,479 & 1,100 & 279 \\
\hline
\end{tabular}

Among the 17-year-olds, we use self-reported dislike of school as a measure of school engagement. Dislike of school increased with each level of exposure to EV, which again suggests an accumulation of disadvantage. A third of those who are always vulnerable dislike school compared to one fifth of those who are never EV. Dislike of school is associated with poorer educational outcomes and with poorer self-image (Smyth et al., 2011) and has been found to be associated with more risky health behaviours (Nolan and Smyth, 2020), as well as poorer mental health and wellbeing (Nolan and Smyth, forthcoming). 
TABLE 5.14: DISLIKE SCHOOL BY LONGITUDINAL ECONOMIC VULNERABILITY, AGE 17 ('98 COHORT)

\begin{tabular}{l|c|c|c|c|}
\hline \multicolumn{1}{|c|}{ I dislike(d) school } & Never EV & EV once & Persistent EV & Always EV \\
\hline Strongly agree and agree & 20.4 & $28.6 * * *$ & $31.9 * * *$ & $34.0^{* * *}$ \\
\hline Disagree & 49.2 & $43.8^{* * *}$ & 47.3 & 46.3 \\
\hline Strongly disagree & 30.5 & $27.6^{*}$ & $20.8^{* * *}$ & $19.7 * * *$ \\
\hline Total & 100.0 & 100.0 & 100.0 & 100.0 \\
\hline Notes: $\quad * * * p<0.001, * * p<0.01, * p<0.05 ;$ significance refers to difference from never EV group. Where figures are not \\
$\quad$ marked with an asterisk, the difference is not significant.
\end{tabular}

\subsection{RELATIONSHIPS}

Social and familial supports are extremely important for children and young people's wellbeing. Peer supports are particularly crucial during adolescence (Brown and Larson, 2009). The family stress model suggests that poverty can undermine family relationships because of the stress it places on parents, leading to poorer parenting behaviour (Conger et al., 1992). Poverty may also restrict young people's ability to participate in social life, either through a lack of resources or stigma and exclusion.

We begin by assessing the quality of the relationship with parents. This information is collected from both the primary caregiver (PCG) (mostly mothers) and the secondary caregiver (SCG) (mostly fathers, where present). The scores are based on the Pianta scale, which has two sub-dimensions: closeness and conflict. We find that closeness with parents among 9-year olds is not significantly related to EV. However, conflict with the PCG (mothers) is significantly higher among those with experience of EV compared to those who are never EV (Table 5.15). In the case of conflict with fathers, only those who are persistently or always vulnerable are significantly different from those who are never vulnerable.

A similar pattern is noted for the older cohort at 17 years. Closeness to parents does not vary by exposure to EV, but both transient and persistent EV are associated with greater conflict with the PCG. 
TABLE 5.15: CLOSENESS AND CONFLICT WITH PRIMARY AND SECONDARY CAREGIVERS AT 9 YEARS ('08 COHORT) BY LONGITUDINAL EV STATUS

\begin{tabular}{l|c|c|c|c|} 
& Never Ev & EV Once & Persistent EV & Always EV \\
\hline High closeness with PCG & 75.2 & 75.9 & 75.0 & 73.5 \\
\hline High closeness with SCG & 56.7 & 58.8 & 59.4 & 59.1 \\
\hline High conflict with PCG & 22.2 & $27.2^{* * *}$ & $31.3^{* * *}$ & $33.4^{* * *}$ \\
\hline High conflict with SCG & 21.6 & 23.3 & $26.8^{* *}$ & $32.3^{* *}$ \\
\hline Notes: $\quad * * *$ p<0.001, ** p<0.01, * p<0.001, ; significance refers to difference from never EV group. High conflict = in top \\
$\quad$ quartile for conflict levels. High closeness = top quartile for closeness, High conflict = top quartile for conflict
\end{tabular}

TABLE 5.16: CLOSENESS AND CONFLICT WITH PRIMARY AND SECONDARY CAREGIVERS AT 17 YEARS ('98 COHORT) BY LONGITUDINAL EV STATUS

\begin{tabular}{l|c|c|c|}
\hline & Never Ev & EV Once & $\begin{array}{c}\text { Persistent and Always } \\
\text { EV }\end{array}$ \\
\hline High closeness with PCG & 77.6 & 77.5 & 80.5 \\
\hline High closeness with SCG & 75.8 & 75.2 & 78.7 \\
\hline High conflict with PCG & 22.0 & $28.9^{* * *}$ & $29.8^{* * *}$ \\
\hline High conflict with SCG & 23.7 & 26.4 & 26.2 \\
\hline
\end{tabular}

Notes: $\quad * * * p<0.001, * * p<0.01, * p<0.05$. significance refers to difference from never EV group. High conflict $=$ in top quartile for conflict levels. High closeness $=$ top quartile for closeness.

The measure of self-image discussed above shows that 9-year-old children exposed to longer durations of EV felt less popular among their peers. The Piers-Harris selfconcept scale was not administered at age 17, as it was not age-appropriate. Instead, we rely on the young person's self-report of the size of their friendship network. We find that, at 17, having fewer than two friends was more common among those who experienced one spell of EV and was higher again among those who were persistently or always vulnerable (Table 5.17).

TABLE 5.17: N N NMBER OF FRIENDS AT AGE 17 BY LONGITUDINAL EV STATUS ('98 COHORT)

\begin{tabular}{l|c|c|c|} 
& Never EV & EV once & Persistent/Always EV \\
\hline $\mathbf{0 - 2}$ & 7.5 & $10.8^{* * *}$ & $18.6^{* * *}$ \\
\hline $\mathbf{3 - 5}$ & 45.4 & 46.5 & $49.5^{*}$ \\
\hline $\mathbf{6 - 1 0}$ & 39.1 & $34.8^{* *}$ & $26.7^{* * *}$ \\
\hline $\mathbf{1 0 +}$ & 8.0 & 7.9 & 5.2 \\
\hline Total & 100.0 & 100.0 & 100.0 \\
\hline \multicolumn{2}{|l}{} \\
\hline
\end{tabular}




\subsection{CONCLUSION}

The results presented in this chapter show a strong association between exposure to $\mathrm{EV}$ and important outcomes across all domains examined: health outcomes and behaviour, socio-emotional outcomes, cognitive outcomes, educational attainment and relationships. The association appears to be weaker in the case of relationships with parents, which is reflective of a high level of positive relationships with parents and suggests that this is a resource that may be drawn on by young people experiencing poverty. The analyses are descriptive so do not test causality; nor do they control for other potential confounding factors or test potential differential effects for different groups, for example, boys and girls. These descriptive analyses provide the first step in the identification of key domains/relationships for future research on causal pathways and protective factors. Nevertheless, the associations found across such a broad range of outcomes are consistent with a large body of literature which shows that poverty has profound implications for children and young people's current wellbeing, and that these immediate consequences, including those on health and education, are likely to have implications for longer-term health, wellbeing and labour market outcomes.

In most cases, the pattern of results suggests a cumulative process, whereby persistent EV is associated with worse outcomes than one-off or transient vulnerability. However, this has not been formally tested.

Different outcome measures are appropriate for younger children at 9 years and young adults at 17 years, which means that we cannot formally test differences between the cohorts. Nevertheless, the pattern of results is very similar for exposure to poverty in early and middle childhood and adolescence/early adulthood. In no case do we find a relationship between longitudinal EV and an outcome that is significant for only one of the cohorts. This does not mean that the strength of the effects is identical, nor even that the mechanisms at work are the same during different phases of childhood. However, it does suggest that to prevent poor outcomes, we need to tackle child poverty at all ages. Investment in children in early childhood may well reap higher rewards for specific outcomes (Heckman, 2011) but these results also suggest that the prevention of poverty, and especially persistent poverty in middle and late childhood, is likely to yield very positive results for young people's emotional, physical and educational wellbeing. In future research, it would also be possible to examine the timing of poverty spells. For example, does exposure to EV at 9 months have a different effect on cognitive development than exposure at 9 years? 



\section{CHAPTER 6}

\section{Conclusions}

\subsection{BACKGROUND TO THE STUDY}

Childhood poverty casts a long shadow, limiting opportunities, stifling cognitive and educational potential, causing stress, anxiety and poor mental health, and leading to poor health outcomes in the medium and long term (Cooper and Stewart, 2013; Cooper and Stewart, 2020; Conger and Donnellan, 2007; Duncan and Brooks-Gunn, 1997; Elder, 1999; Schoon et al., 2012). Poverty may also damage social and emotional development and affect children and young people's sense of self and relationships with others (Twenge and Campbell, 2002; Russell et al., 2015; Watson et al., 2014). This study sets out to explore childhood exposure to poverty in Ireland and its impact on selected child outcomes, using the most comprehensive data available to date. The two cohorts of the Growing up in Ireland (GUI) survey now provide evidence of the economic circumstances and living conditions of children from infancy to 9 years and from 9 years to 17 years. This provides the opportunity to study the antecedents and consequences of child poverty in a way that has not been possible before. As the cohort ages and new waves of data become available, it will be possible to assess the longer-term implications of exposure to poverty at different stages of childhood across the life course for an even wider array of outcomes, including labour market experiences and mental and physical health in adulthood.

Theoretical and empirical research has highlighted that understanding poverty requires a multidimensional approach and that cross-sectional measures of low income are insufficient to identify poverty (Nolan and Whelan, 2007; Whelan et al 2019). We therefore build on previous research that adopts multiple indicators of standard of living and uses methods of latent class analysis (LCA) to identify underlying vulnerabilities (Watson et al., 2014; Whelan, Nolan and Maître, 2006). The analysis uses three indicators: low income, material deprivation and financial stress (great difficulty/difficulty in making ends meet). Using LCA, we identify two groups in each wave of data - those that are economically vulnerable (EV), and those that are not vulnerable. The proportion of children, young people and their families that we identify as being EV varies from 9.2 per cent among the older cohort at age 9 (2007-2008) to a high of 29 per cent for the younger cohort at age 3 (2011-2012).

Previous research has highlighted that the temporal dimension of poverty is crucial, especially in the case of child poverty (see Cooper and Stewart, 2020). Therefore, we construct a longitudinal profile of exposure to EV over an approximately 9-year period for both cohorts, covering the years 2007 to 2017. 
A key finding of the research is that exposure to $\mathrm{EV}$ on at least one occasion was a common experience among families with young children (44 per cent) and older children (38 per cent) during this time period, and that even such transitory experience of vulnerability are associated with poorer child outcomes. The impact of the Great Recession is clearly visible for both cohorts, with EV peaking in 20112012. These young people and their families went through a period of severe economic turmoil. The effects on EV in families persisted for longer than the macroeconomic indicators would suggest (such as a change in GDP), as resources became depleted. This may also reflect the lagged effect of the recession on some elements of public spending (for example, public healthcare expenditure). The recession not only led to large inflows into $\mathrm{EV}$, but it also led to a reduction in exits, meaning that more and more families became trapped. For the younger cohort, the odds ratio of leaving EV fell by a fifth between 2011 and 2013 compared to the period 2008-2011 (which was already a difficult period). For the older cohort, the odds ratio of exit was significantly lower in the period 2008 to 2011-2012 than in 2012 to 2015-2016. These period effects are measured after changes in employment status of parents have already been taken into account so represent conservative estimates of the exposure of families to EV.

While the experience of $\mathrm{EV}$ is relatively common, consistent with previous research, we find that for a proportion of this group the experience is transitory, that is, they are no longer vulnerable in the next survey wave. This applies to about half of those who are EV in both cohorts ( 56 per cent in the ' 98 cohort and 49 per cent in the ' 08 cohort). In the ' 08 cohort, 22.8 per cent are persistently (in at least two consecutive waves) or always vulnerable (in every wave); in the '98 cohort, 16.6 per cent are persistently or always vulnerable. These results suggest that EV and persistent vulnerability are more common among families with younger children.

\subsection{WHAT ARE THE FACTORS ASSOCIATED WITH PERSISTENT POVERTY?}

A range of factors, familiar from previous poverty research across all households in Ireland (Watson et al., 2016, 2017, 2018), are associated with the risk of persistent EV in childhood. The findings indicate that lone parenthood, low household work intensity, lower maternal education, disability or unemployment of the primary caregiver (PCG), and larger family size are all strongly associated with the risk of persistent EV. The strong role of the status of the PCG is an important finding, as previous research has often focused on the employment status of the father alone. The GUI study also allows us to examine the relationship between ethnicity and child poverty in Ireland in a way that has not been previously possible. We find that those of black ethnic background have a significantly higher relative risk of persistent EV. 
Two important points emerge from a comparison of risk factors for transient poverty and the comparison across cohorts. Firstly, while all of the same risk factors play a role in transient vulnerability, the experience of persistent vulnerability is much more socially structured, with wider differences between the groups. Secondly, we see that by and large the same factors increase the risk of persistent poverty in early and later childhood. However, family size, maternal employment status and maternal education all appear to have a stronger influence among the younger cohort. This may reflect particularly strong barriers to employment when children are very young and/or particular needs for these groups that are not currently met. In contrast, membership of a minority ethnic group is a stronger predictor of persistent vulnerability for the older cohort, though it is unclear what the explanation is for this pattern.

\subsection{THE DYNAMICS OF CHILD POVERTY - WHAT INFLUENCES INFLOW TO AND OUTFLOW FROM ECONOMIC VULNERABILITY (EV)?}

The longitudinal profile of families demonstrates that poverty is not a static experience. As a complement to the analysis of the factors associated with persistent forms of poverty, we undertook a dynamic analysis of the changes in family structure and labour market transitions that influence movements into and out of EV.

As mentioned above, the broader economic and labour market climate played a significant role in shaping poverty transitions. In terms of family processes, we found that relationship breakdown was highly relevant for moves into EV at this stage of the life course. Controlling for other factors, in the ' 98 cohort, the odds ratios of entering EV were 2.5 times greater where a partner had left the household than for families where there was no partnership change. In the '08 cohort, the odds ratios were 3.5 times higher in the case of relationship dissolution compared to no change. This finding echoes results from international research (Fouarge and Layte, 2005; Vandecasteele, 2011). There is an unexpected association between re-partnering and an increased odds ratio of entering EV in both cohorts, suggesting a risk factor that is not currently on the policy radar. This may arise due to the loss of welfare benefits or because the new partner's income is not sufficient to offset the additional needs of the family. As the measure of EV is much broader than income, it is unlikely that this is an artefact of equivalence scales.

The birth of a new child between waves was not significantly associated with entries to EV for either cohorts, though larger families (at wave 1 ) were less likely to exit from vulnerability and more likely to enter EV for both cohorts. It is possible that the birth of a child has a differential impact depending on the social class of the family, which has been found by Vandecasteele (2011), although this has not been explored in the current research. 
The analysis also sheds new light on the influence of the labour market transitions of mothers and fathers on child poverty. Maternal entry to, and exit from, employment is found to be a significant trigger for movement into and out of EV. Maternal job loss is as important as paternal job loss in EV entry in mid to later childhood and is almost as important in early childhood (odds ratio of 1.6 versus 2.0 for paternal job loss). Similarly, a mother's transition into full-time work has a positive influence on the likelihood of exiting vulnerability - one almost as strong as a father's transition into full-time employment. An increase from part-time employment to full-time employment by either a mother or a father also has a positive effect on the odds ratio of exiting vulnerability. Significantly, transition into part-time employment is not associated with exits from EV, which has implications for labour market and social policies, and to which we return below.

\subsection{OUTCOMES FOR CHILDREN AND YOUNG PEOPLE}

Chapter 5 of the report presents results from a descriptive analysis on the relationship between longitudinal exposure to EV and a range of key outcomes, chosen to represent the main domains in children's lives. It was beyond the scope of the current report to explore the distinct mechanisms, protective factors and confounding influences for each set of outcomes. The purpose instead is to provide a broad-brush picture of how this newly developed indicator of longitudinal vulnerability over a prolonged period is associated with outcomes at age 9 and age 17. While the analysis cannot identify causal processes, it highlights the myriad of ways in which poverty may be influencing children's lives and provides the basis for a broader research agenda that explores the temporal dimension of child poverty and outcomes at different stages of development.

There are a number of important lessons that can be drawn from this initial analysis of outcomes.

Firstly, EV during childhood is associated with poorer outcomes across a range of dimensions that are important from current wellbeing, developmental and policy perspectives. This includes cognitive and educational attainment (including Junior Certificate grades), school engagement, socio-emotional development, life satisfaction, self-concept, chronic illness/disability, ${ }^{39}$ obesity, health behaviours, conflict with mother, and number of friends. Only closeness of relationships with parents and pro-social behaviour were not significantly related to EV exposure.

Secondly, in the majority of cases there appears to be a cumulative effect of exposure, in that outcomes are poorer in the case of persistent or constant exposure, though this requires further modelling and research.

\footnotetext{
${ }^{39}$ As noted above child disability/chronic illness and EV may contribute to EV, via reduced labour-market participation of the PCG.
} 
Thirdly, an important finding is that even transitory spells of EV are associated with worse outcomes compared to never experiencing EV. This pattern is evident for almost all the outcomes that were observed and is confirmed by the significance tests contrasting those who were once EV versus never EV. This is significant because it suggests that widespread exposure to at least one spell of EV because of the economic recession is likely to have negative consequences for children and young people's outcomes some years later, when they are aged 9 and 17 respectively. This potential scarring effect of the recession warrants further research using causal models and is relevant in planning the policy response to the economic shock caused by the Covid-19 pandemic.

Fourthly, the strength and pattern of relationships between EV and child outcomes is found to be very similar in the ' 08 cohort and the ' 98 cohort. This has potentially important implications for the timing of policy interventions, in that it suggests effective interventions can be made throughout early, middle childhood and adolescence. Future analysis of specific outcomes can formally test whether multidimensional poverty experienced at different time points has a differential impact.

\subsection{LIMITATIONS OF THE RESEARCH}

While the accumulated waves of the GUl study provides an unprecedented opportunity to study poverty dynamics and persistence in Ireland, there are a number of limitations to the current research that should be noted. Firstly, while the data now allow us to observe the economic situation of families over a 9-year period, the information is censored at both ends. For families that are EV in the first wave of the survey, we do not know how long they have been in that position. In the '08 cohort, we know the child's situation since infancy. However, the '98 cohort may have been exposed to different levels of poverty in the first nine years of their life, which we do not observe, and which may influence outcomes. ${ }^{40}$

Secondly, while we have information on families' circumstances at each wave, we lack information on the situation between waves. This is likely to mean that we under-estimate the incidence of transient poverty as families may experience difficulties between waves. As the measure of poverty that we use is designed to pick up underlying vulnerability, this may help to mitigate against this gap in data. The absence of between-wave data also affects the observations of key transitions, such as changes in employment. For example, short spells of employment or unemployment between survey years will not be captured. The effects of

\footnotetext{
${ }^{40}$ In the analysis of EV transitions, we address this left censoring by including pairs of waves and dropping those who were vulnerable in wave 1
} 
employment transitions may therefore be underestimated as the 'no change' group is imprecisely measured.

Thirdly, the analysis of the relationships between transient and persistent poverty and child outcomes is limited to bivariate analyses and causal relationships are not tested. The aim was to provide a broad overview of these associations and highlight areas for further detailed analyses.

Finally, as a study of families in private households, the GUI is likely to miss some of the families experiencing the most severe poverty, including homeless families.

\subsection{POLICY IMPLICATIONS}

The research highlights the characteristics of families and the types of processes that are likely to trigger movements into and out of poverty and can thus help to inform policies to prevent persistent poverty and to assist families in exiting poverty.

The key role of both maternal and paternal employment in lifting families out of $\mathrm{EV}$ and preventing entries into poverty highlights the central importance of employment supports such as active labour market policies and the current emergency pandemic supports to prevent mass unemployment, including the Pandemic Unemployment Payment and the Employment Wage Subsidy Scheme. These supports are crucial to preventing child poverty and the devastating effects this can have in the short and longer term (see Beirne et al., 2020, and Regan and Maître, 2020, for analyses of these supports in the early part of the pandemic). Access to employment that is sufficient to lift families out of poverty also requires a policy focus on low pay, access to education and skills development, and significant public investment in affordable, high-quality childcare.

The research identifies a number of vulnerable families, including lone parents, ethnic minorities, larger families and families where the PCG has low levels of education, or where they have a disability, that are at a high risk of becoming trapped in poverty and this warrants additional policy intervention to prevent the range of negative outcomes identified in the descriptive analyses.

Lone-parent families are found to be at risk of persistent poverty; furthermore, entry into lone parenthood (partner exits) and re-partnering were both found to be associated with moves into EV. Additional protections and supports for these social risks could prevent longer-term consequences. Parents who are separating are likely to require information and advice around accessing welfare payments, child maintenance rights and obligations, and housing supports (see Mooney et al. 2009).

Given the high reliance of lone parents on benefits, their income is particularly susceptible to changes in welfare benefits. Analysis of the distributional impact of budget 2019 showed that lone parents saw larger-than-average losses as a 
percentage of disposable income relative to a wage-indexed benchmark (Roantree et al., 2018). ${ }^{41}$ Our analysis of EV transitions shows that entry to part-time work by the PCG is not sufficient to move households out of EV; yet, for those raising a family as a lone parent, part-time work may be the only feasible option.

These results, combined with findings that employed lone parents experience high levels of deprivation and income poverty (though it is significantly lower than lone parents who are not employed, ${ }^{42}$ see Regan and Maître, 2020), emphasise that employment alone is not sufficient to move lone parents out of poverty. The value of core welfare supports for lone parents are critical as well as income supports for working families.

Furthermore, the childcare supports needed to facilitate entry to full-time work for the PCG, in both lone and couple households, are significant. While there have been welcome increases in childcare supports in the recent years, the costs are still prohibitive to many (Russell et al., 2018; OECD, 2020).

While the poverty risk of large families is sometimes seen as a problem of the past, the research highlights that this has not gone away. Large families have an increased risk of entering poverty and are less likely to move out of poverty, even holding other factors equal, including changes in employment of the PCG and secondary caregiver (SCG). These findings suggest a need for additional supports for child dependents. A recent analysis of measures to mitigate the costs of the carbon tax for low income families (O'Malley et al., 2020), demonstrated that increases to Qualified Children allowance for welfare recipients was a highly efficient method of targeting households below the poverty line. They estimated that a $€ 4$ per week rise in the qualified children payment would decrease the child poverty rate by half a percentage point even when introduced alongside a $€ 7.50$ increase in the carbon tax. ${ }^{43}$ The additional poverty risks facing large families was previously acknowledged by the higher rate of child benefit for third or higher children but this was removed in 2014. The effect of this change has not been evaluated and there could be justification for its reintroduction.

In general, the results do not provide evidence for targeting supports at families at one particular age. The comparison of the relationship between childhood outcomes and longitudinal EV across the two cohorts points to the importance of anti-poverty interventions across all age groups from early childhood to middle childhood and adolescence. While there has been a strong focus on early childhood

\footnotetext{
${ }^{41}$ Change in the One-Parent Family Payments in 2012-2013 are likely to have impacted the incomes of lone parents in the third wave of the ' 98 cohort analysis by Redmond et al. (2020) suggests that the change was associated with an increase in employment and income.

${ }^{42} \mathrm{~A}$ total of $29.5 \%$ of lone parents in employment were deprived compared to $9.6 \%$ of households with 2 parents $1-3$ children in employment. The respective proportions for AROP (being at risk of poverty) were $18.6 \%$ and $4.9 \%$.

43 The same reduction in child poverty could be achieved by increasing the allowance for children under 12 by $€ 4$, for children over 12 by $€ 2.50$ and increasing the fuel allowance by $€ 1.50$. The cost of these measures was between $€ 50$ and $€ 55$ million, which represents a third of the revenue raised from the carbon tax.
} 
interventions, preventing EV at later stages of childhood and adolescence is likely to have positive effects on key educational, health and social outcomes. There are plenty of opportunities to intervene in later childhood to make a difference to outcomes in both the short and longer term.

Finally, we acknowledge that the range of policies necessary to mitigate the negative effects of poverty on children's outcomes are much broader than those mentioned here, and encompass educational policies, health care policy, sports and recreation policy, housing policy, family supports and many other services. Further research on the precise mechanisms at work for the range of outcomes considered will shed further light on effective policy interventions. The analyses highlight a number of potential areas for further research. Longitudinal models of health and educational/cognitive outcomes would allow us to test specific hypotheses about the accumulation of disadvantage and to formally test differences/similarities in the timing of poverty. Such research could also include wider environmental factors available in the data. To date, the effect of poverty and children and young people's self-esteem and relationships has mainly been explored through qualitative analyses. The GUI provides an opportunity to build on these studies and to explore this question on a nationally representative sample. Our initial analyses show a strong association of poverty with friendship networks at 17 and self-concept at 9 years. These are crucial topics from a social inclusion perspective and are likely to be important for immediate and longer-term wellbeing. Finally, future waves of data collection will allow us to test for even longer-run impacts and will provide the opportunity to examine the effects of childhood poverty on occupational attainment when the '98 cohort enter the job market. 


\section{REFERENCES}

Andriopoulou, E. and Tsakloglou, P. (2011). 'The determinants of poverty transitions in Europe and the role of duration dependence', IZA Discussion Paper No. 5692.

Atkinson, A., Cantillon, B., Marlier, E., and B. Nolan (2002). Social indicators: the EU and social inclusion, Oxford: Oxford University Press.

Bane, M.J. and Ellwood, D.T (1986). 'Slipping into and Out of Poverty: The Dynamics of Spells', Journal of Human Resources, Vol. 21, pp. 1-23.

Banks, J. and Smyth, E. (2015). "'Your whole life depends on it": academic stress and high-stakes testing in Ireland', Journal of Youth Studies, Vol. 18, No. 5, pp. 598-616.

Barcena-Martin, E., Blanco-Arana, M.C. and S. Pérez -Moreno (2017). 'Dynamics of child poverty in the European Countries', ECINEQ Working Paper 2017 - 437.

Bargain, O., Callan, T., Doorley, K., and C. Keane (2015). 'Changes in income distributions and the role of tax-benefit policy during the Great Recession: an international perspective, Fiscal Studies, Vol. 38, No. 4, December 2017, pp. 559-585, https://doi.org/10.1111/1475$\underline{5890.12113}$

Barosh, L., Friel, S., Engelhard, K., and L. Chan (2014). 'The cost of a healthy and sustainable diet who can afford it?', Australia and New Zealand Journal of Public Health, Vol. 38, No. 1, pp. 712

Beirne, K., Doorley, K., Regan, M., Roantree, B., and D. Tuda (2020). 'The potential costs and distributional effect of COVID-19 related unemployment in Ireland', ESRI: Budget Perspectives 2021, Paper 1.

Benzeval, M., Bond, L., Campbell, M., M. Egan, T. Lorenc, M. Petticrew, and F. Popham (2014). How does money influence health? York: Joseph Rowntree Foundation.

Best, J.R., Miller, P.H., and L.L. Jones (2009). 'Executive functions after age 5: changes and correlates', Developmental Review, Vol. 29, No. 3, pp. 180-200.

Biro, F.M. and Wien, M. (2010) 'Childhood obesity and adult morbidities', Am J Clin Nutr. May; Vol. 91, No. 5, pp. 1499S-1505S.

Bradley, R. and Corwyn, R. (2002). 'Socioeconomic status and child development', Annual Review of Psychology, Vol. 53, pp. 371-99.

Bradshaw, J. and Chzhen, Y. (2015). 'The outcomes of the crisis for pensioners and children', Belgian Journal of Social Security/Belgisch Tijdschrift voor Sociale Zekerheid, Vol. 1, pp. 39-50.

Breen, R. and Moisio, P. (2004). 'Poverty dynamics corrected for measurement error', J. Econ. Inequal., Vol. 2, pp. 171-191.

Brooks-Gunn, J. and Duncan, G.J. (1997). 'The effects of poverty on children', The Future of Children, Vol. 7, No. , pp. 55-71. 
Brown, B. and Larson, J. (2009). 'Peer relationships in adolescence', Chapter 3, in Handbook of adolescent psychology, Vol. 2, John Wiley \& Sons. https://doi.org/10.1002/9780470479193.adlpsy002004

Byrne, D. and Treanor, M. (2020). Income, poverty and deprivation among children, Dublin: Department of Children and Youth Affairs.

Central Statistics Office (CSO) (2020). Survey of Income and Living Conditions (SILC) 2019 (Statistical Release). Dublin: Central Statistics Office.

Chambers, R. (1989) 'Vulnerability: how the poor cope: editorial', IDS Bulletin, Vol. 20, No. 2.

Chzhen, Y. (2017). 'Unemployment, social protection spending and child poverty in the European Union during the Great Recession', Journal of European Social Policy, Vol. 27, No. 2, pp. 123137.

Coates, D., Corcoran, D, Cronin, H., and A. Brioscu (2020). The initial impacts of the COVID-19 pandemic on Ireland's labour market, Dublin: Central Bank.

Cole, T.J. and Lobstein, T. (2012). 'Extended international (IOTF) body mass index cut-offs for thinness, overweight and obesity', Pediatric Obesity, Vol. 7, No. 4, pp. 284-294.

Conger, R.D. and Donnellan, M.B. (2007). 'An interactionist perspective on the socioeconomic context of human development', Annual Review of Psychology, Vol. 58, pp. 175-199.

Conger, R.D., Conger, K.J., Elder, G.H.J., Lorenz, F.O., Simons, F.L., and L.B. Whitbeck (1992). 'A family process model of economic hardship and adjustment of early adolescent boys', Child Development, Vol. 63, pp. 526-541.

Cooper, K. and Stewart. K. (2013). Does money affect children's outcomes? A systematic review, York: Joseph Rowntree Foundation.

Cooper, K. and Stewart, K. (2020). 'Does household income affect children's outcomes? A systematic review of the evidence', Child Indicators Research, https://doi.org/10.1007/s12187-020$\underline{09782-0}$

Dahl, E. (2008). 'Poverty dynamics and social exclusion: an analysis of Norwegian panel data', Jnl Soc. Pol., Vol. 37, No. 2, pp. 231-249.

Darmody, M., Smyth, E., H. and Russell (2020). Implications of the COVID-19 pandemic for policy in relation to children and young people: a research review, ESRI Survey and Statistical Report Series Number 94.

Department of Children and Youth Affairs (DCYA) (2014). Better outcomes brighter futures. The national policy framework for children and young people 2014-2020, Dublin: Department of Children and Youth Affairs.

Department of Education and Skills (DES) (2012). A framework for Junior Cycle, Dublin: DES.

Department of Education and Skills (DES) (2015). Wellbeing in Primary schools: guidelines in mental health promotion, Dublin: DES.

Department of Education and Skills (DES) (2019). Retention rates of pupils in second-level schools, Dublin: DES. 
Department of Employment Affairs and Social Protection (DEASP) (2019). Social inclusion monitor 2017, Dublin: Department of Employment Affairs and Social Protection.

Department of Employment Affairs and Social Protection. (2020). Roadmap for social inclusion 20202025, Dublin: Department of Employment Affairs and Social Protection.

Dewilde, C. (2006) 'Becoming poor in Belgium and Britain: the impact of demographic and labour market events', Sociological Research Online, Vol. 11, No. 1, pp 87-103.

DiPrete, T. and Mcmanus, P. (2000). 'Family change, employment transitions and the welfare state: household income dynamics in the United States and Germany', American Sociological Review Vol. 65, pp. 343-370.

aDiPrete T. A. and Eirich G.M. (2006). 'Cumulative advantage as a mechanism for inequality: a review of theoretical and empirical developments', Annual Review of Sociology, Vol. 32, pp. 271-297.

Dickerson, A. and Popli, G.K. (2016). 'Persistent poverty and children's cognitive development: evidence from the UK Millennium Cohort Study', Journal of the Royal Statistical Series A, Vol. 179, Part 2, pp. 535-558

Duncan, G. and Rodgers, W. (1991). 'Has children's poverty become more persistent?', American Sociological Review, Vol. 56, pp. 538-550.

Duncan, G.J. (1984). Years of poverty, years of plenty, Ann Arbor: Institute for Social Research, University of Michigan.

Duncan, G.J. and Brooks-Gunn, J. (2000). 'Family poverty, welfare reform, and child development', Child Development, Vol. 71, No. 1, pp. 188-196.

Duncan, G.J., Brooks-Gunn, J. and P. Klebanov (1994). E'conomic deprivation and early childhood development', Child Development, Vol. 65, No. 2, pp. 296-318.

Duncan, G.J., Kalil, A., and K.M. Ziol-Guest (2018). 'Parental income and children's life course: lessons from the Panel Study of Income Dynamics', The ANNALS of the American Academy of Political and Social Science, Vol. 680, No. 1, pp. 82-96.

Duncan, G.J., Magnuson, K., Kalil, A., and K. Ziol-Guest (2012). 'The importance of early childhood poverty', Social Indicators Research, Vol. 108, pp. 87-98.

Duncan, G.J., Yeung, W.J., Brooks-Gunn, J. and J.R. Smith (1998). 'How much does childhood poverty affect the life chances of children?', American Sociological Review, Vol. 63, Nos 4-6, pp. 406423.

Elder, G. (1999). Children of the great depression, 25th Anniversary Edition, Routledge.

Erola, J., Jalonen, S., and H. Lehti (2016). 'Parental education, class and income over early life course and children's achievement', Research on Social Stratification and Mobility, Vol. 44, pp. 33-43.

Erola, J. (2009). 'Social mobility and education of Finnish cohorts born 1936-75: succeeding while failing in equality of opportunity?', Acta Sociologica, Vol. 52, No. 4, pp. 307-327.

Eurostat (2021). 'People at risk of poverty or social exclusion', European Commission, https://ec.europa.eu/eurostat/web/products-datasets/-/sdg $01 \quad 10$ 
Evans, G.W., Chen, E., Miller, G.E., and T.E. Seeman (2012). 'How poverty gets under the skin: a life course perspective'. In V. Maholmes and R. King (eds), The Oxford handbook of poverty and child development, New York: Oxford University Press.

Fahey, T., Keilthy, P., and E. Polek (2012). Family relationships and family well-being: a study of the families of nine year-olds in Ireland, Dublin: UCD and the Family Support Agency.

Fouarge, D. and Layte, R. (2005). Welfare regimes and poverty dynamics: the duration and recurrence of poverty spells in Europe', Journal of Social Policy, Vol. 34, No. 3, pp. 407-426.

Gambaro, L., Stewart, K., and J. Waldfogel (2014). 'Introduction'. In An equal start? Providing quality early education and care for disadvantaged children, Bristol: Policy Press.

Goodman, R. (1997). 'The Strengths and Difficulties Questionnaire: a research note', Journal of Child Psychology and Psychiatry, Vol. 38, No. 5, pp. 581-586.

Graham, H. and Power, C. (2004). Childhood disadvantage and adult health: a lifecourse framework, NHS Health Development Agency.

Guo, G. (1998). 'The timing of influences of cumulative poverty on children's cognitive ability and achievement', Social Forces, Vol. 77, No. 1, pp. 257-287.

Hagenaars, A., de Vos, K., and M.A. Zaidi (1994). Poverty statistics in the late 1980s: research based on micro-data, Luxembourg: Office for Official Publications of the European Communities.

Heckman, J.J. (2011). 'The economics of inequality: the value of early childhood education', American Educator, Vol. 35, No. 1, pp. 31-35, 47.

HSE (2018). Tackling childhood obesity: a written submission from the health service executive to the joint committee on children and youth affairs, https://data.oireachtas.ie/ie/oireachtas/committee/dail/32/joint committee on children an d youth affairs/submissions/2018/2018-08-22 submission-health-service-executive en.pdf

IMF (2003). Vulnerability indicators: a factsheet, http://www.imf.org/external/np/facts/vul.html.

Jarvis, S. and Jenkins, S.P. (1995). 'Do the poor stay poor? New evidence about income dynamics from the British Household Panel Survey', Occasional Paper No. 95-2, Colchester: ESRC Research Centre on Micro-Social Change, University of Essex.

Jenkins, S.P. and Rigg, J.A. (2001). The dynamics of poverty in Britain, London: Department for Work and Pensions, DWP Research Report No. 157.

Jenkins, S. and van Kerm, J. (2011). 'Patterns of persistent poverty: evidence from EU-SILC' (No. 2011-30). ISER Working Paper Series.

Keane, C., Callan, T., Savage, M., Walsh, J. R, and B. Colgan (2014). 'Distributional impact of tax, welfare and public service pay policies: Budget 2015 and Budgets 2009-2015', Quarterly Economic Commentary, Dublin: The Economic and Social Research Institute.

Lai, E.T., Wickham, S., Law, C., Whitehead, M., Barr, B., and D. Taylor-Robinson (2019). 'Poverty dynamics and health in late childhood in the UK: evidence from the Millennium Cohort Study', Archives of Disease in Childhood, Vol. 104, No. 11, pp. 1049-1055. 
Layte, R., Bennett, A., McCrory, C., and J. Kearney (2013). 'Social class variation in the predictors of rapid growth in infancy and obesity at age 3 years,' International Journal of Obesity, Vol. 38, No. 1, pp. 1-9.

Layte, R. and McCrory, C. (2013). 'Paediatric chronic illness and educational failure: the role of emotional and behavioural problems', Social Psychiatry and Psychiatric Epidemiology, Vol. 48, No. 8, pp. 1307-1316.

Layte, R. and McCrory, C. (2011). Growing up in Ireland - National longitudinal study of children: overweight and obesity among 9-year-olds, Dublin: Stationery Office.

Lazarsfeld, P.F. (1950). 'The logical and mathematical foundation of latent structure analysis'. In S. Stouffer, L. Guttman, E. Suchman, P. Lazarsfeld, S. Star, and. Clausen (eds), Measurement and prediction, Princeton, NJ: Princeton University Press.

Lazarsfeld, P.F. and Henry, N.W. (1968). Latent structure analysis, Boston, MA: Houghton Mifflin.

Manly, T., Anderson, V., Nimmo-Smith, I., Turner, A., Watson, P., and I.H. Robertson (2001).' The differential assessment of children's attention: the Test of Everyday Attention for Children (TEA-Ch), normative sample and ADHD performance', Journal of Child Psychology and Psychiatry, Vol. 42, No. 8, pp. 1065-1081.

Manly, T., Robertson, I.H., Anderson, V., and I. Nimmo-Smith (1999). The Test of Everyday Attention for Children (TEA-CH), Bury St. Edmunds: Thames Valley Test Company.

Marsh, H.W. and Craven, R. (2006). 'Reciprocal effects of self-concept and performance from a multidimensional perspective', Perspectives on Psychological Science, Vol. 1, pp. 95-180.

McGinnity, F., Russell, H., and A. Murray (2015). Growing Up in Ireland, National Longitudinal Study of Children: Non-parental Childcare and Child Cognitive Outcomes at Age 5. Stationery Office.

McMullin, P., McGinnity, F., Murray, A., and H. Russell (2020). 'What you do versus who you are: home-learning activities, social origin and cognitive skills among young children in Ireland', European Sociological Review, Vol, 36, No. 4, pp. 610-625.

McNamara, E., O'Mahony, D., and A. Murray (2020a). Growing up in Ireland: design, instrumentation and procedures for cohort '08 of growing up in Ireland at 9 years old (Wave 5). (Technical Series No. 2020-1), Dublin: ESRI/TCD/DCYA.

McNamara, E., Murphy, D., Murray, A, Smyth, E. and D. Watson (2020b). The lives of 17/18-yearolds, GUI cohort 98, Report 7, Dublin: ESRI/TCD/DCYA.

Merton, R.K. (1968). 'The Matthew effect in science', Science, New Series, Vol. 159, No. 3810, pp. 56-63.

Miller, C.T. and Downey, K.T. (1999). A meta-analysis of heavyweight and self-esteem, Personality and Social Psychology Review, Vol. 3, No. 1, pp. 68-84.

Moisio, P. (2004a). 'Poverty dynamics according to direct, indirect and subjective measures modelling Markovian processes in a discrete time and space with error', PhD Thesis, European University Institute Florence.

Moisio, P. (2004b). 'A latent class application to the multidimensional measurement of poverty', Quantity and Quality-International Journal of Methodology, Vol. 38, pp. 703-717. 
Mooney, A., Oliver, C., and M. Smith (2009). Impact of family breakdown on children's well-being: evidence review, Department for Children Schools and Families, Research Report DCSF-RR13.

Murphy, D., Williams, J., Murray, A., and E. Smyth (2019). Growing up in Ireland: design, instrumentation and procedures for cohort '98 at 17/18 years of age (Technical Series No. 2019-5). Dublin: ESRI/TCD/DCYA.

NCCA (2009). Aistear: the early childhood curriculum framework, Dublin: NCCA.

Nixon, E. (2012). Growing up in Ireland: national longitudinal study of children-how families matter for social and emotional outcomes of 9-year-old children, Dublin: Government Publications.

Nixon, E., Layte, R., and M. Thornton (2019). The effects of economic recession and family stress on the adjustment of 3-year-olds in Ireland: analysis of wave 1 and wave 2 of the '08 (infant) cohort of Growing up in Ireland, Dublin: Stationery Office.

Nolan, A. and Layte, R. (2009). 'Child access to GP services in Ireland: do user fees matter?' In J. Williams, S. Greene, E. Doyle, E. Harris, R. Layte, S. McCoy, M. and Thornton (eds), Growing up in Ireland: the Lives of 9-year-olds. Dublin: The Stationery Office.

Nolan, A. and Smyth, E. (forthcoming). Risk and protective factors for mental health and wellbeing in childhood and adolescence. Dublin: The Economic and Social Research Institute.

Nolan, A. and Smyth, E. (2020). Clusters of health behaviours among young adults in Ireland. Dublin: The Economic and Social Research Institute.

Nolan, B. and Whelan, C. T. (2007). 'On the multidimensionality of poverty and social exclusion'. In J. Micklewright and S. Jenkins (eds), Poverty and inequality: new directions. Oxford: Oxford University Press.

O'Malley, S. Roantree, B., and J. Curtis (2020). Carbon taxes, poverty and compensation options, ESRI Survey and Statistical Report Series, Dublin: The Economic and Social Research Institute.

Orth, U., Robins, R.W., and B.W. Roberts (2008). 'Low self-esteem prospectively predicts depression in adolescence and young adulthood', Journal of Personality and Social Psychology, Vol. 95, No. 3, p. 695.

Piers, E. V. and Herzberg, D.S. (2002). 'Piers-Harris 2: Piers-Harris children's self-concept scale (2nd ed.), Los Angeles, CA: Western Psychological Services.

Porterfield, S.L. (2002). 'Work choices of mothers in families with disabilities', Journal of Marriage and Family, Vol. 64, pp. 972-981.

Power, C., Hertzman, C., Mathews, S., and O. Manor O (1997). 'Social differences in health: 'Life cycle effects between ages 23 and 33 in the 1958 British birth cohort', Am J Public Health, Vol. 87, pp. 1499-503.

Powers, E.T. (2003). 'Children's health and maternal work activity: estimates under alternative disability definitions', Journal of Human Resources, Vol. 38, No.3, pp. 522-556.

Quail, A., O'Reilly, C., Watson, D., McNamara, E., O'Mahony, D., and A. Murray (2019). Growing up in Ireland a summary guide to cohort '08 at 9 years (wave 5 of the infant cohort at 9 years, Dublin: ESRI/TCD/DCYA. 
Redmond, P., McGuinness, S., and C. Keane (2020). 'The impact of one parent family payment reforms on the labour market outcomes of lone parents', IZA DP No. 13109, https://www.iza.org/publications/dp/13109/the-impact-of-one-parent-family-paymentreforms-on-the-labour-market-outcomes-of-lone-parents

Reagan, M. and Maître, B. (2020). Child poverty in Ireland and the pandemic recession, Papers BP2021/4, Dublin: The Economic and Social Research Institute.

Ridge, T. (2011). 'The everyday costs of poverty in childhood: a review of qualitative research exploring the lives and experiences of low-income children in the UK, Children \& Society Vol. 25, pp. 73-84.

Roantree, B., Bercholz, M., Doorley, K., Keane, C., Regan, M., and J. Walsh (2018). 'Budget 2019: tax and welfare changes,' Quarterly Economic Commentary: Special Articles, The Economic and Social Research Institute.

Russell, H., Kenny, O., and F. McGinnity (2016). Childcare, early education and socio-emotional outcomes at age 5: evidence from the growing up in Ireland Study. Dublin: The Economic and Social Research Institute.

Russell, H., McGinnity, F., Fahey, É., and K. Oona (2018). Maternal employment and the cost of childcare in Ireland, Research Series, The Economic and Social Research Institute, No. RS73.

Sandefur, G.D. and Tuma, N.B. (1987). 'How data type affects conclusions about individual mobility', Social Science Research, Vol. 16, pp. 301-28.

Savage. M, Callan, M., Nolan, T., and B. Colgan (2015). The Great Recession, Austerity and Inequality: Evidence from Ireland, The Economic and Social Research Institute, I WP499.

Schoon, I., Cheng, H., and E. Jones (2010). 'Resilience in children's development'. In H. Hansen, H. Joshi, and S. Dex (eds), Children of the 21st century: the first five years, Ch. 14, Bristol: Policy Press.

Schoon, I., Jones, E., Cheng, H., and B. Maughan (2012). 'Family hardship, family instability and children's cognitive development', J. Epidem. Community Health, Vol. 66, pp. 716-722.

Sen, A. (1979). 'Equality of what? In S.M. McMurrin (ed.), Tanner lectures on human values, Cambridge: Cambridge University Press, pp. 197-220.

Smyth, E. (2016a). Arts and cultural participation among children and young people, Dublin: Arts Council/ESRI.

Smyth, E. (2016b) 'Inequalities from the start? Children's integration into primary school'. In J. Williams, E. Nixon, E. Smyth, D.S. Watson (eds), Cherishing all the children equally? Ireland 100 years on from the Easter Rising, Ch. 7, pp. 132-152

Smyth, E., Banks, J., and E. Calvert(2011). From Leaving Certificate to leaving school: a longitudinal study of sixth year students. Dublin: The Economic and Social Research Institute.

Smyth, E., Whelan, C.T., McCoy, S., Quail, A., and E. Doyle (2010). 'Understanding parental influence on educational outcomes among 9-year olds in Ireland: the mediating role of resources, attitudes and children's own perspectives', Child Indicators Research, Vol. 3, No. 1, pp. 85-104. 
Sowislo, J.F. and Orth, U. (2013). 'Does low self-esteem predict depression and anxiety? A metaanalysis of longitudinal studies', Psychological Bulletin, Vol. 139, No. 1, pp. 213-240.

Tomlinson, M. and Walker, R. (2009). Coping with complexity: child and adult poverty, London: Child Poverty Action Group.

Twenge, J.M., and Campbell, W.K. (2002). 'Self-esteem and socioeconomic status: a meta-analytic review', Pers. Soc. Psychol. Rev., Vol. 6, pp. 59-71.

United Nations (2003). Report on the world social situation: social vulnerability: sources and challenges, New York: United Nations Department of Economic and Social Affairs.

Vaalavuo, M. (2015). 'Poverty dynamics in Europe: from what to why', Working paper 03/2015, Brussels: European Commission.

Vandecasteele, L. (2010). 'Poverty trajectories after risky life events in different European welfare regimes, European Societies, Vol. 12, No. 2, pp. 257-278.

Vandecasteele, L. (2011). 'Life course risks or cumulative disadvantage? The structuring effect of social stratification determinants and life course events on poverty transitions in Europe', European Sociological Review, Vol. 27, No. 2, pp. 246-263 246, DOI:10.1093/esr/icq005

Von Mutius E., Schwartz J., Neas L.M., Dockery, D., and S.T. Weiss (2001). 'Relation of body mass index to asthma and atopy in children: the National Health and Nutrition Examination Study III', Thorax, Vol. 56, pp. 835-838.

Waldfogel, J. (2013). 'Socio-economic inequality in childhood and beyond: an overview of challenges and findings from comparative analyses of cohort studies,' Longitudinal and Life Course Studies, Vol. 4, No. 3, pp. 268-275.

Waldfogel, J. (2015). 'The role of preschool in reducing inequality: preschool improves child outcomes, especially for disadvantaged children,' IZA World of Labor, doi: $\underline{10.15185 / \text { izawol.219 }}$

Wang, F., Wild, T.C., Kipp, W., Kuhle, S., and P.J. Veugelers (2009). 'The influence of childhood obesity on the development of self-esteem,' Statistics Canada, Health Reports, Vol. 20, No. 2, pp. 21-27.

Watson, D., Maitre, B., Whelan, C.T., and J. Williams (2014). Dynamics of child economic vulnerability and socio-emotional development: an analysis of the first two waves of the growing up in Ireland study. Dublin: Office of the Minister for Children.

Watson, D., Maître, B., and C.T. Whelan (2012). Understanding childhood deprivation in Ireland. Dublin: Department of Social Protection and The Economic and Social Research Institute.

Watson, D., Maître, B., Whelan, C.T., and H. Russell. (2016). Social risk and social class patterns in poverty and quality of life in Ireland: an analysis of the CSO Survey on Income and Living Conditions, 2004 to 2013, Dublin: The Economic and Social Research Institute and Department of Social Protection. 
Watson, D.B., Maître, C. T. Whelan and H. Russell. (2017) Poverty, economic stress and quality of life: lessons from the Irish case International Review of Economics, Vol. 64, Issue 2, June 2017, pp.125-143

Watson, D., B. Maître, Grotti, R. and C. T. Whelan. (2018). Poverty dynamics of social risk groups in the EU: an analysis of the EU Statistics on Income and Living Conditions, 2005 to 2014. Dublin: The Economic and Social Research Institute and Department of Employment Affairs and Social Protection.

Whelan, C.T., Nolan, B., and Maitre, B. (2007) Multiple Deprivation and Multiple Disadvantage in Ireland: An Analysis of EU-SILC. Policy Research Series Paper No. 61, Dublin: The Economic and Social Research Institute.

Whelan, C.T., Layte, R., Maitre, B., and B. Nolan(2000). 'Poverty dynamics: an analysis of the 1994 and 1995 waves of the European Community Household Panel', European Societies, Vol. 2, No. 4, pp. 505-531.

Whelan, C.T. and Maître, B. ( 2005). 'Vulnerability and multiple deprivation perspectives on economic exclusion in Europe: a latent class analysis', European Societies, Vol. 7, No. 3, pp. 423-450.

Whelan, C.T. and Maître, B. (2010). 'Protecting the vulnerable: poverty and social exclusion in Ireland as the crisis emerged', Economic and Social Review, Vol. 41, No. 4, pp. 501-525.

Whelan, C.T., Watson, D., and B. Maître, B. (2019). 'From income poverty to multidimensional quality of life,' Economic and Social Review, Vol. 50, No. 4, pp. 683-705.

Wickrama K., Conger R.D., and W. Abraham (2005). 'Early adversity and later health: the intergenerational transmission of adversity through mental disorder and physical illness, Journal of Gerontology, Vol. 60, pp.125-129.

Williams, J., Greene, S., Doyle, E., Harris, E., Layte, R., McCoy, S., McCrory, C., Murray, A., Nixon, E., O'Dowd, T., O'Moore, M., Quail, A., Smyth, E., Swords, L., and M. Thornton (2009). Growing up in Ireland: the lives of nine-year-olds. Dublin: The Stationery Office.

World Bank (2000). World development report 2000-01: attacking poverty, New York: Oxford University Press.

YouthInMind (2020). https://www.sdqinfo.org/py/sdqinfo/b3.py?language=Englishqz(UK) 



\section{LATENT CLASS ANALYSIS: GOODNESS OF FIT}

We ran statistical tests in order to assess the model fit for latent class models with one class, two classes and three classes (the model cannot be estimated for four classes and more). The Bayesian Information Criterion (BIC) and the Akaike's Information Criterion assess the overall fit of a model. The lower the criteria, the better the fit. For both cohorts, the model with three classes produces the best fit, though it is only marginally better than the two-class model. Moreover, it is also important to consider the size of the classes identified, so that their interpretation is meaningful. For example, if we look at the results for the ' 08 cohort, the model with three classes produces respective class size of $80.4 \%, 14.8 \%$ and $4.8 \%$. As the third class is small and the analysis of transitions between three categories would result in an overly complex matrix of moves without improving understanding, we therefore adopt the latent class model with two classes.

TABLE A2.1: LATENT CLASS MODEL FIT FOR INFANT AND CHILD COHORT CROSS-SECTIONAL SAMPLE WAVE 1

\begin{tabular}{|l|c|c|c|c|}
\hline \multicolumn{1}{|c|}{ Model } & Observation & $\begin{array}{c}\text { Degrees of } \\
\text { freedom }\end{array}$ & AIC & BIC \\
\hline 9 months & 11,131 & 4 & 36729 & 36758.27 \\
\hline One class & 11,131 & 8 & 33642.44 & 33700.98 \\
\hline Two classes & 11,131 & 12 & 33546.17 & 33633.98 \\
\hline Three classes & & & & \\
\hline 9 years & 8,563 & 4 & 17458.89 & 17487.12 \\
\hline One class & 8,563 & 8 & 16210.34 & 16266.78 \\
\hline Two classes & 8,563 & 12 & 16194.07 & 16278.74 \\
\hline Three classes & & & & \\
\hline
\end{tabular}


TABLE A2.2: 'ALTERNATIVE CONSISTENT POVERTY’ RATES FOR COHORTS ’08 AND ‘98

\begin{tabular}{|l|c|c|}
\hline & '08 Cohort & '98 Cohort \\
\hline $\mathbf{9}$ months & 5.0 & \\
\hline $\mathbf{3}$ years & 6.5 & \\
\hline $\mathbf{5}$ years & 7.7 & \\
\hline $\mathbf{9}$ years & 5.9 & 2.2 \\
\hline $\mathbf{9}$ years & & 5.7 \\
\hline $\mathbf{1 3}$ years & & 6.8 \\
\hline $\mathbf{1 7 / 1 8}$ years & & \\
\hline
\end{tabular}

Note: Alternative consistent poverty= in the bottom income quintile and lacking 2 or more items of 11 material deprivation items. Cross-sectional samples.

TABLE A2.3: $\quad$ LATENT CLASS PROFILE OF NON-EV ('98 COHORT), LONGITUDINAL SAMPLE

\begin{tabular}{|c|c|c|c|}
\hline & 9 years & 13 years & 17 years \\
\hline $\begin{array}{l}\text { Size of Not economically } \\
\text { vulnerable group }\end{array}$ & 90.8 & 71.5 & 78.4 \\
\hline \multicolumn{4}{|l|}{$\begin{array}{l}\text { Characteristics of Not economically } \\
\text { vulnerable group }\end{array}$} \\
\hline Economic stress & 1.4 & 0.0 & 5.3 \\
\hline Bottom income quintile & 12.9 & 12.2 & 9.3 \\
\hline $\begin{array}{l}\text { Material deprivation } \\
\text { (mean deprivation on } 11 \text { items) }\end{array}$ & 0.1 & 0.1 & 0.1 \\
\hline N Not EV unweighted & 5,711 & 4,662 & 5,061 \\
\hline Total unweighted & 6,039 & 6,039 & 6,039 \\
\hline
\end{tabular}

Note: $\quad$ Sample of children present in all waves. Longitudinal weight applied.

TABLE A2.4: $\quad$ LATENT CLASS PROFILE OF NON-EV INFANT COHORT ('08 COHORT), LONGITUDINAL SAMPLE

\begin{tabular}{|c|c|c|c|c|}
\hline & 9 months & 3 years old & 5 years old & 9 years old \\
\hline $\begin{array}{l}\text { Size of Not economically } \\
\text { vulnerable group }\end{array}$ & 83.2 & 74.9 & 70.3 & 81.9 \\
\hline \multicolumn{5}{|c|}{$\begin{array}{l}\text { Composition of Not economically } \\
\text { vulnerable group }\end{array}$} \\
\hline Economic stress & 3.1 & 5.8 & 7.7 & 2.4 \\
\hline Bottom income quintile & 11.7 & 9.5 & 9.2 & 10.7 \\
\hline $\begin{array}{l}\text { Material deprivation (mean } \\
\text { deprivation on } 11 \text { items) }\end{array}$ & 0.1 & 0.1 & 0.1 & 0.1 \\
\hline N Not EV unweighted & 6,511 & 5,955 & 5,635 & 6,402 \\
\hline Total N unweighted & 7,505 & 7,505 & 7,505 & 7,505 \\
\hline
\end{tabular}


TABLE A2.5: SOCIO-DEMOGRAPHIC PROFILE OF ECONOMIC VULNERABILITY OF '08 AND ‘98 COHORT AT WAVE 1

\begin{tabular}{|c|c|c|c|c|c|c|}
\hline & \multicolumn{3}{|c|}{ '08 cohort } & \multicolumn{3}{|c|}{ ‘98 cohort } \\
\hline & Not EV & $E V$ & Total & Not EV & $E V$ & Total \\
\hline No partner in household w1 & 10.8 & 41.7 & 16.0 & 14.1 & 49.3 & 17.3 \\
\hline Partner in household w1 & 89.2 & 58.4 & 84.0 & 85.9 & 50.7 & 82.7 \\
\hline Total & 100.0 & 100.0 & 100.0 & 100.0 & 100.0 & 100.0 \\
\hline 1-2 children under 18 w1 & 76.9 & 65.0 & 74.9 & 46.3 & 39.1 & 45.7 \\
\hline 3 children under 18 w1 & 17.1 & 22.2 & 17.9 & 32.7 & 28.9 & 32.3 \\
\hline 4 or more children w1 & 6.0 & 12.8 & 7.2 & 21.0 & 32.0 & 22.0 \\
\hline Total & 100.0 & 100.0 & 100.0 & 100.0 & 100.0 & 100.0 \\
\hline PCG lower secondary or less w1 & 15.0 & 43.4 & 19.8 & 26.9 & 51.4 & 29.2 \\
\hline PCG Leaving Certificate w1 & 23.9 & 29.3 & 24.8 & 38.0 & 27.7 & 37.1 \\
\hline PCG sub-degree w1 & 30.1 & 19.4 & 28.3 & 16.9 & 12.2 & 16.5 \\
\hline PCG degree or third level w1 & 31.0 & 7.9 & 27.1 & 18.2 & 8.8 & 17.3 \\
\hline Total & 100.0 & 100.0 & 100.0 & 100.0 & 100.0 & 100.0 \\
\hline PCG Irish nationality w1 & 88.6 & 81.6 & 87.4 & 94.6 & 88.6 & 94.0 \\
\hline PCG other nationality w1 & 11.4 & 18.4 & 12.6 & 5.4 & 11.4 & 6.0 \\
\hline Total & 100.0 & 100.0 & 100.0 & 100.0 & 100.0 & 100.0 \\
\hline PCG employed w1 & 61.6 & 27.3 & 55.8 & 56.7 & 27.0 & 54.0 \\
\hline PCG unemployed/disability/other & 6.9 & 15.4 & 8.3 & 6.2 & 17.8 & 7.2 \\
\hline PCG home duties w1 & 31.6 & 57.3 & 35.9 & 37.1 & 55.2 & 38.8 \\
\hline Total & 100.0 & 100.0 & 100.0 & 100.0 & 100.0 & 100.0 \\
\hline N observations & 6,511 & 996 & & 5,711 & 328 & 6,039 \\
\hline
\end{tabular}


TABLE A3.1: SOCIO-DEMOGRAPHIC CHARACTERISTICS OF CHILDREN, '08 COHORT PANEL DATA

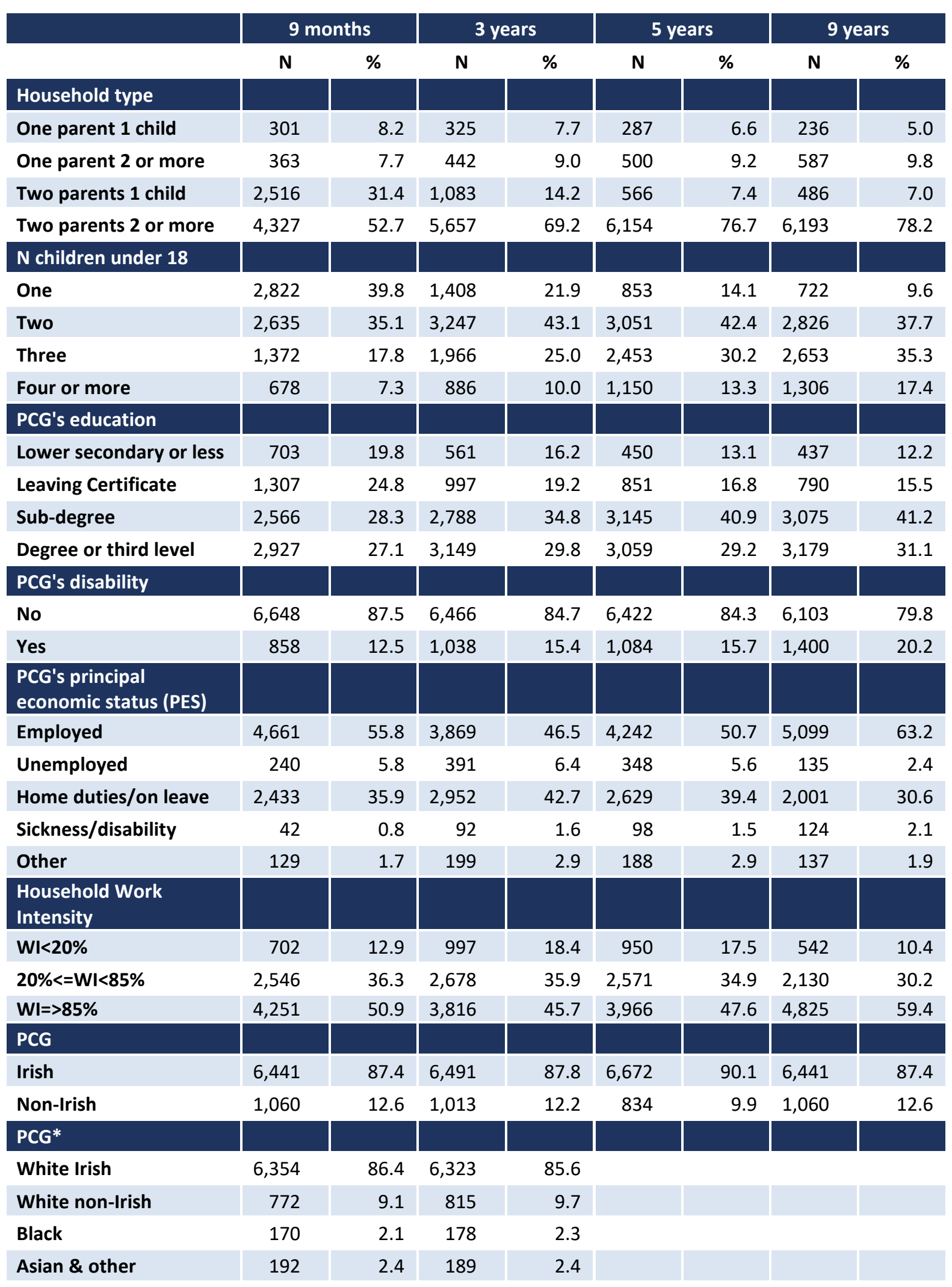

Note: $\quad *$ Ethnicity info available only in waves 1 \& 2; N unweighted, \% Weighted, Longitudinal sample. 
TABLE A3.2: SOCIO DEMOGRAPHIC CHARACTERISTICS OF CHILDREN '98 COHORT PANEL DATA

\begin{tabular}{|c|c|c|c|c|c|c|}
\hline & \multicolumn{2}{|c|}{9 years } & \multicolumn{2}{|c|}{13 years } & \multicolumn{2}{|c|}{$17 / 18$ years } \\
\hline & $\mathbf{N}$ & $\%$ & $\mathbf{N}$ & $\%$ & $\mathbf{N}$ & $\%$ \\
\hline \multicolumn{7}{|l|}{ Household type } \\
\hline One parent 1 or 2 children & 402 & 10.7 & 496 & 12.4 & 707 & 16.3 \\
\hline One parent $\mathbf{2}$ or more & 187 & 6.6 & 227 & 6.1 & 174 & 4.1 \\
\hline Two parents 1 or 2 children & $\begin{array}{r}2,227 \\
6\end{array}$ & 34.9 & 2,755 & 43.0 & 3,497 & 54.5 \\
\hline Two parents 2 or more & 3,174 & 47.8 & 2,561 & 38.5 . & 1,615 & 25.1 \\
\hline \multicolumn{7}{|l|}{ N Children Under 18} \\
\hline Zero & & & & & 464 & 8.2 \\
\hline One & 577 & 12.0 & 949 & 17.9 & 2,163 & 37.2 \\
\hline Two & 2,103 & 33.7 & 2,302 & 37.5 & 1,921 & 30.5 \\
\hline Three & 2,118 & 32.3 & 1,807 & 27.7 & 1,036 & 16.2 \\
\hline Four or More & 1,241 & 22.0 & 981 & 16.9 & 455 & 7.9 \\
\hline \multicolumn{7}{|l|}{ PCG's education } \\
\hline Lower Secondary or less & 886 & 29.2 & 629 & 20.5 & 652 & 20.3 \\
\hline Leaving Certificate & 1,865 & 37.1 & 1,866 & 39.6 & 2,219 & 43.3 \\
\hline Sub-degree & 1,543 & 16.5 & 1,553 & 18.9 & 1,235 & 15.5 \\
\hline Degree or Third Level & 1,745 & 17.3 & 1,991 & 21.0 & 1,883 & 20.9 \\
\hline \multicolumn{7}{|c|}{$\begin{array}{l}\text { PCG's Chronic physical/mental health } \\
\text { problems }\end{array}$} \\
\hline No & 5,271 & 86.9 & 4,996 & 81.8 & 4,963 & 81.6 \\
\hline Yes & 766 & 13.1 & 1,043 & 18.2 & 1,029 & 18.4 \\
\hline \multicolumn{7}{|l|}{ PCG's PES } \\
\hline Employed & 3,562 & 54.0 & 3,830 & 58.0 & 4,135 & 64.3 \\
\hline Unemployed & 82 & 2.58 & 191 & 3.9 & 157 & 4.1 \\
\hline Home duties/on leave & 2,248 & 38.8 & 1,767 & 33.7 & 1,300 & 24.8 \\
\hline Sickness/disability & 39 & 0.2 & 104 & 1.7 & 166 & 3.1 \\
\hline Other & 103 & 4.5 & 147 & 2.8 & 234 & 3.8 \\
\hline \multicolumn{7}{|l|}{ Household Work Intensity } \\
\hline$W \mid<20 \%$ & 319 & 10.9 & 509 & 13.7 & 415 & 10.1 \\
\hline $20 \%<=W \mid<85 \%$ & 2,334 & 37.7 & 2,099 & 36.1 & 1,773 & 31.9 \\
\hline$W I=>85 \%$ & 3,386 & 51.4 & 3,428 & 50.2 & 3,768 & 58.0 \\
\hline \multicolumn{7}{|l|}{ PCG } \\
\hline Irish & 5,665 & 94.0 & 5,699 & 95.3 & 5,761 & 96.1 \\
\hline Non-Irish & 366 & 6.0 & 275 & 4.7 & 231 & 3.9 \\
\hline \multicolumn{7}{|l|}{ PCG* } \\
\hline White Irish & 6,354 & 86.4 & 6,323 & 85.6 & & \\
\hline White non-Irish & 772 & 9.1 & 815 & 9.7 & & \\
\hline Black & 170 & 2.1 & 178 & 2.3 & & \\
\hline Asian and other & 192 & 2.4 & 189 & 2.4 & & \\
\hline
\end{tabular}


TABLE A4.1: PRINCIPAL AND SECONDARY CARE GIVER EMPLOYMENT TRANSITIONS BY PAIR OF WAVES, 2007-2016 ‘98 COHORT (\%)

\begin{tabular}{|l|c|c|c|c|c|c|c|}
\hline & No change & $\begin{array}{c}\text { Enter } \\
\text { full-time }\end{array}$ & $\begin{array}{c}\text { Enter part- } \\
\text { time }\end{array}$ & $\begin{array}{c}\text { Exit } \\
\text { work }\end{array}$ & $\begin{array}{c}\text { Full-time } \\
\text { to part- } \\
\text { time }\end{array}$ & $\begin{array}{c}\text { Part-time to } \\
\text { full-time }\end{array}$ & Total \\
\hline PCG & & & & & & \\
\hline $\mathbf{9 - 1 3}$ years old & 66.8 & 2.6 & 8.8 & 10.3 & 4.1 & 7.4 & 100 \\
\hline $\mathbf{1 3 - 1 7}$ years old & 67.0 & 5.1 & 7.5 & 7.1 & 3.4 & 9.9 & 100 \\
\hline SCG & & & & & & & \\
\hline $\mathbf{9 - 1 3}$ years old & 78.1 & 2.3 & 1.0 & 14.2 & 3.7 & 0.7 & 100 \\
\hline $\mathbf{1 3 - 1 7}$ years old & 75.1 & 6.0 & 1.6 & 14.0 & 1.2 & 2.1 & 100 \\
\hline
\end{tabular}

TABLE A4.2: PRINCIPAL AND SECONDARY CARE GIVER EMPLOYMENT TRANSITIONS BY PAIR OF WAVES, 2007-2016 ‘08 COHORT (\%)

\begin{tabular}{|c|c|c|c|c|c|c|c|}
\hline & $\begin{array}{c}\text { No } \\
\text { change }\end{array}$ & $\begin{array}{c}\text { Enter } \\
\text { full-time }\end{array}$ & $\begin{array}{c}\text { Enter } \\
\text { part-time }\end{array}$ & Exit work & $\begin{array}{c}\text { Full to } \\
\text { part-time }\end{array}$ & $\begin{array}{c}\text { Part to } \\
\text { full-time }\end{array}$ & Total \\
\hline 9 months-3 years & 68.3 & 6.8 & 9.8 & 8.0 & 3.5 & 3.7 & 100 \\
\hline $3-5$ years & 75.3 & 2.4 & 6.2 & 7.0 & 4.5 & 4.6 & 100 \\
\hline $5-9$ years & 65.4 & 5.9 & 9.1 & 6.5 & 4.4 & 8.8 & 100 \\
\hline \multicolumn{8}{|l|}{ SCG } \\
\hline 9 months -3 years & 80.3 & 4.4 & 0.9 & 10.7 & 2.5 & 1.2 & 100 \\
\hline $3-5$ years & 81.8 & 5.7 & 1.6 & 7.6 & 1.5 & 1.9 & 100 \\
\hline $5-9$ years & 76.7 & 8.3 & 1.4 & 10.6 & 0.8 & 2.3 & 100 \\
\hline
\end{tabular}


Whitaker Square,

Sir John Rogerson's Quay,

Dublin 2

Telephone +35318632000

Email admin@esri.ie

Web www.esri.ie

Twitter @ESRIDublin 